\title{
Investigation of the applicability of neural-fuzzy logic modeling for culvert hydrodynamics
}

Jonathan M. Lester

West Virginia University

Follow this and additional works at: https://researchrepository.wvu.edu/etd

\section{Recommended Citation}

Lester, Jonathan M., "Investigation of the applicability of neural-fuzzy logic modeling for culvert hydrodynamics" (2003). Graduate Theses, Dissertations, and Problem Reports. 2510.

https://researchrepository.wvu.edu/etd/2510

This Dissertation is protected by copyright and/or related rights. It has been brought to you by the The Research Repository @ WVU with permission from the rights-holder(s). You are free to use this Dissertation in any way that is permitted by the copyright and related rights legislation that applies to your use. For other uses you must obtain permission from the rights-holder(s) directly, unless additional rights are indicated by a Creative Commons license in the record and/ or on the work itself. This Dissertation has been accepted for inclusion in WVU Graduate Theses, Dissertations, and Problem Reports collection by an authorized administrator of The Research Repository @ WVU.

For more information, please contact researchrepository@mail.wvu.edu. 
Investigation of the Applicability of Neural-Fuzzy Logic Modeling for Culvert Hydrodynamics

\author{
Jonathan M. Lester \\ Dissertation submitted to the \\ College of Engineering and Mineral Resources \\ at West Virginia University \\ in partial fulfillment of the requirements \\ for the degree of
}

\author{
Doctor of Philosophy \\ in \\ Civil Engineering \\ Robert N. Eli, Ph.D., P.E., Chair \\ Ronald W. Eck, Ph.D., P.E. \\ Donald D. Gray, Ph.D., P.E. \\ John M. Kuhlman, Ph.D., P.E. \\ Donald K. Jamison, Ph.D., P.E.
}

Morgantown, West Virginia

2003

Keywords: Culvert, Hydraulics, Hydrodynamics, Neural-Fuzzy logic 


\section{ABSTRACT \\ Investigation of the Applicability of Neural-Fuzzy Logic Modeling for Culvert Hydrodynamics}

\section{Jonathan M. Lester}

As a result of an earlier WV DOH study, the idea came to the forefront of using a completely new approach to analyzing the complex subject of culvert hydrodynamics. The literature indicates that there have been no reports of artificial intelligence, to include neural networks, fuzzy logic, or combined neural-fuzzy logic, used to investigate and predict culvert hydrodynamics.

The scope of this dissertation is to investigate the applicability of using neuralfuzzy logic to predict culvert diameters. To analyze these flows, commercial culvert software was employed to account for all types of flow conditions. This included different slopes, lengths, flow-rates, pipe sizes, and headwater and tail water conditions. For all of the variables included in the analysis of culvert flow, some are complex in nature and require selection of different parameters. A large data set was created, from which to draw out different flow types for analysis. The use of fuzzy logic enables the user to enter variables and the developed code then interprets the data and solves for diameter. These trained data sets have a compliment checking data which is derived from similar calculations, with one variable slightly larger. These data sets were trained in a neural-fuzzy model and the result was a predicted culvert diameter data set. The predicted diameters were then compared to the actual diameters to determine the accuracy of the model. For all data sets evaluated, the root mean square error was less than 12 inches. The overall weighted root mean squared error for the training data sets was 1.989 inches and 2.658 inches for the checking data sets. 


\section{ACKNOWLEDGEMENTS}

I cannot begin to come close to thanking all of the people who have helped me get through these several years. I will however, make an attempt. Thanks to Dr. Robert N. Eli, for taking me under his wing and all of his guidance over the years. Thanks also to Dr. Donald D. Gray for his expert teaching and guidance during my coursework. To Dr. Darrell R. Dean, Jr., who helped me through my Master's and taught me how to be a surveyor. Thanks to Dr. Ron Eck for all of his help along the way and his excellent teaching during the years I was here. To all of the other professors who have taught me in the many courses I have undertaken here at WVU. To all of the roommates (Ben, Dom, Travis, Brad, Taggart, Bubby, Ford, Helms, Neil, Michelle, and finally Conrad) with whom I have shared an apartment or house with over the years, I thank you for your patience and hope you enjoy the Lester stories. To the 9 landlords who have rented to me, some of which did not even know about me, thank you for teaching me the reason to purchase a house when I got to Lexington. To all the undergraduate students that I have taught, I appreciate your patience while I learned the art of instructing engineering. I think I learned more from teaching you all than I did in my 9 years of course work! Thank you to the Faculty and staff here at the Civil Engineering department; I appreciate everything each of you has done for me over the years. Especially Crystal May for all of her help, advice, and friendship. Thanks to Mike Blankenship, as well for his help, advice and friendship. Additionally, thanks for accommodating my defense date scheduling problem at the last minute. To my part-time employer, Parsons Brinckerhoff, with whom I have learned an enormous amount about the practical aspects of Civil Engineering, I thank you for employing me. Thanks to the many friendships that I have formed while here in Morgantown, I have met some truly great friends, some that will remain a lifetime. Thanks to the night-time janitorial staff for their friendships over the years. Thanks to the Faculty, staff and corps of cadets at Virginia Military Institute. To my friends at Coca-Cola, U.S. Tobacco Corporation, and Metallica, thank you for keeping me awake! Thanks to my family and friends, for having the patience to put up with me during these several trying years, I know I have been difficult. Thanks to Jen Peterson Trimble for showing me that Bill Gates was not as evil as I had once surmised. Thanks to Keith Bryant for running around getting signatures and putting this thing to rest in my absence during the final weeks prior to graduating. Finally, thanks to Col. Donald K. Jamison for believing in me from the start, all the way to the culmination. 


\section{TABLE OF CONTENTS}

ABSTRACT

ACKNOWLEDGEMENTS

$\underline{\text { PAGE }}$

TABLE OF CONTENTS

ii

LIST OF FIGURES

LIST OF TABLES

iii

iv

V

ix

CHAPTER 1 - INTRODUCTION

1

CHAPTER 2 - CULVERTS

2

2.1 Culvert Hydraulics

2

2.2 Flow Control

6

2.3 Design Considerations 25

2.4 Design Methods 28

CHAPTER 3 - FUZZY LOGIC 34

3.1 Defined 34

3.2 Beginnings 35

3.3 Overview 36

3.4 Neural Networks 37

3.5 Neuro-Adaptive Learning Techniques 38

3.6 Example 38

CHAPTER 4 - PROCEDURE 41

4.1 Membership Functions 41

4.2 Number of Membership Functions 41

4.3 Number of Training Epochs Used 42

4.4 Data Generation Method 45

4.5 Classification of Culvert Types 47

4.6 Training on Diameter, D -vs- Training on Flow Rate, Q 50

CHAPTER 5 - RESULTS COMPARISON 53

5.1 Formula Generated Data Sets 55

5.2 Data Sets Generated From Method of Steps 59

5.3 USGS Culvert Type Data Sets 68

5.4 Quantifying the Results 80

CHAPTER 6 - CONCLUSIONS AND RECOMMENDATIONS 88

6.1 Conclusions 88

6.2 Recommendations 89

REFERENCES $\quad 90$

APPENDIX A: $\quad 95$

APPENDIX B: $\quad 96$

VITA 110 


\section{LIST OF FIGURES}

Figure

2.2.1 Typical Inlet Control Flow Conditions

page

2.2.2 Types of Inlet Control 9

2.2.3 Inlet Control curves for different flow conditions 10

2.2.4 Typical Outlet Control Flow Conditions 14

2.2.5 Types of Outlet Control 16

2.2.6 Full Flow Energy and Hydraulic Grade Lines 20

2.2.7 Performance Curves for (a) Weirs (b) Orifices 23

2.2.8 Culvert Performance Curve $\quad 24$

$\begin{array}{lll}2.3 & \text { Form DR }-4 & 31\end{array}$

3.1. Example of how the MatLab Neural-Fuzzy logic editor processes data and derives at an output. $\quad 39$

3.2. Screen capture of results from two input variables and one output variable from the ANFIS editor for example of Figure 3.1.

4.1 Screen capture of ANFIS editor showing the increase in checking error after minimum error was achieved

4.2 Plot of data with a sixth order trend line 44

4.3 Plot of data with a second order trend line 44

4.4 Six Different Culvert Types and Their Description $\quad 48$

$\begin{array}{lll}4.5 & \text { ANFIS Model Flow Chart } & 49\end{array}$

4.6 Screen capture from MatLab after training on flow rate of Type 4 data 50

4.7 Screen capture from MatLab after training on flow rate of Type 5 data 51

4.8 Screen capture from MatLab after training on diameter of Type 4 data 51

4.9 Screen capture from MatLab after training on diameter of Type 5 data 52

5.1 Training Data Set of Formula Generated Type 4 Data 56 
5.2 Checking Data Set of Formula Generated Type 4 Data 56

5.3 Training Data Set of Formula Generated Type 5 Data 58

5.4 Checking Data Set of Formula Generated Type 5 Data 58

$\begin{array}{lll}5.5 & \text { Training data set for Step } 1 \text { data } & 60\end{array}$

5.6 Checking data set for Step 1 data 60

$\begin{array}{lll}5.7 & \text { Training data set for Step } 2 \text { data } & 61\end{array}$

5.8 Checking data set for Step 2 data $\quad 61$

$5.9 \quad$ Training data set for Step 3 data 62

$\begin{array}{ll}\text { 5.10 Checking data set for Step } 3 \text { data } & 62\end{array}$

5.11 Training data set with two variables, for Step 4 data 63

5.12 Checking data set with two variables, for Step 4 data 63

5.13 Training data set with three variables, for Step 4 data 64

5.14 Checking data set with three variables, for Step 4 data 64

5.15 Training data set with four variables, for Step 4 data 65

5.16 Checking data set with four variables, for Step 4 data 65

5.17 Training data set with five variables, for Step 4 data 66

5.18 Checking data set with five variables, for Step 4 data 66

5.19 Training data set with six variables, for Step 4 data 67

5.20 Checking data set with six variables, for Step 4 data 67

$\begin{array}{lll}5.21 & \text { Training data set of Type } 1 \text { data } & 69\end{array}$

$\begin{array}{lll}5.22 & \text { Checking data set of Type } 1 \text { data } & 69\end{array}$

$\begin{array}{lll}5.23 & \text { Training data set of Type } 2 \text { data } & 71\end{array}$

$\begin{array}{lll}5.24 & \text { Checking data set of Type } 2 \text { data } & 71\end{array}$ 
5.25 Training data set of Type 3 data 73

$\begin{array}{lll}5.26 & \text { Checking data set of Type } 3 \text { data } & 73\end{array}$

$\begin{array}{lll}5.27 & \text { Training data set of Type } 4 \text { data } & 75\end{array}$

$\begin{array}{lll}5.28 & \text { Checking data set of Type } 4 \text { data } & 75\end{array}$

$\begin{array}{lll}5.29 & \text { Training data set of Type } 5 \text { data } & 77\end{array}$

$\begin{array}{lll}5.30 & \text { Checking data set of Type } 5 \text { data } & 77\end{array}$

$\begin{array}{lll}5.31 & \text { Training data set of Type } 6 \text { data } & 79\end{array}$

$\begin{array}{lll}5.32 & \text { Checking data set of Type } 6 \text { data } & 79\end{array}$

5.33 Plot of Training data with brackets above and below the expected result 80

5.34 Type 1 training data with error bounds above and below the expected result 82

5.35 Type 1 checking data with error bounds above and below the expected result 82

5.36 Type 2 training data with error bounds above and below the expected result 83

5.37 Type 2 checking data with error bounds above and below the expected result 83

5.38 Type 3 training data with error bounds above and below the expected result 84

5.39 Type 3 checking data with error bounds above and below the expected result 84

5.40 Type 4 training data with error bounds above and below the expected result 85

5.41 Type 4 checking data with error bounds above and below the expected result 85

5.42 Type 5 training data with error bounds above and below the expected result 86

5.43 Type 5 checking data with error bounds above and below the expected result 86

5.44 Type 6 training data with error bounds above and below the expected result 87

5.45 Type 6 checking data with error bounds above and below the expected result 87

B.1 Triangular membership function - trimf 96 
B.2 Trapezoidal membership function - trapmf 96

B.3 Generalized bell membership function - gbellmf 96

$\begin{array}{lll}\text { B.4 Gaussian membership function - gaussmf } & 97\end{array}$

B.5 Two-sided composite of two different Gaussian curves - gauss2mf 97

$\begin{array}{lll}\text { B.6 } & P i \text { membership function }- \text { pimf } & 97\end{array}$

B.7 The difference between two sigmodial functions - dsigmf 97

B.8 The product of two sigmodial functions - psigmf 98

B.9 Type 4 culvert, training on Diameter. Triangular membership function - trimf

B.10 Type 4 culvert, training on Diameter. Trapezoidal membership function - trapmf

B.11 Type 4 culvert, training on Diameter. Generalized bell membership function - gbellmf

B.12 Type 4 culvert, training on Diameter. Gaussian membership function - gaussmf

B.13 Type 4 culvert, training on Diameter. Two-sided composite of two different Gaussian curves - gauss2mf

B.14 Type 4 culvert, training on Diameter. Pi membership function - pimf

B.15 Type 4 culvert, training on Diameter. Difference between two sigmodial functions - dsigmf

B.16 Type 4 culvert, training on Diameter. Product of two sigmodial functions - psigmf

B.17 Type 4 culvert, training on flow rate. Triangular membership function - trimf

B.18 Type 4 culvert, training on flow rate. Trapezoidal membership function - trapmf

B.19 Type 4 culvert, training on flow rate. Generalized bell membership function - gbellmf 
B.20 Type 4 culvert, training on flow rate. Gaussian

membership function - gaussmf

B.21 Type 4 culvert, training on flow rate. Two-sided composite

of two different Gaussian curves - gauss2mf

102

B.22 Type 4 culvert, training on flow rate. Pi membership function - pimf

102

B.23 Type 4 culvert, training on flow rate. Difference

between two sigmodial functions - dsigmf

B.24 Type 4 culvert, training on flow rate. Product of

two sigmodial functions - psigmf

103

B.25 Type 5 culvert, training on Diameter. Triangular

membership function - trimf

B.26 Type 5 culvert, training on Diameter. Trapezoidal membership

function - trapmf

B.27 Type 5 culvert, training on Diameter. Generalized bell

membership function - gbellmf

B.28 Type 5 culvert, training on Diameter. Gaussian

membership function - gaussmf

B.29 Type 5 culvert, training on Diameter. Two-sided composite

of two different Gaussian curves - gauss2mf

105

B.30 Type 5 culvert, training on Diameter. Pi membership function - pimf

105

B.31 Type 5 culvert, training on Diameter. Difference between

two sigmodial functions - dsigmf

106

B.32 Type 5 culvert, training on Diameter. Product of two

sigmodial functions - psigmf

106

B.33 Type 5 culvert, training on flow rate. Triangular

membership function - trimf

B.34 Type 5 culvert, training on flow rate. Trapezoidal

membership function - trapmf

B.35 Type 5 culvert, training on flow rate. Generalized

bell membership function - gbellmf 
B.36 Type 5 culvert, training on flow rate. Gaussian membership function - gaussmf.

B.37 Type 5 culvert, training on flow rate. Two-sided composite of two different Gaussian curves - gauss2mf

B.38 Type 5 culvert, training on flow rate. Pi membership function - pimf.

B.39 Type 5 culvert, training on flow rate. Difference between two sigmodial functions - dsigmf

B.40 Type 5 culvert, training on flow rate. Product of two sigmodial functions - psigmf 


\section{LIST OF TABLES}

$\underline{\text { Table }}$

2.1 Flow conditions based on Froude number

page

2.2 Factors influencing Culvert Performance

2.3 Coefficients for Inlet Control Design Equations

2.4 Data Requirements for Culvert Design

28

4.1 Range of Input Variables for Compilation of Culvert Data

4.2 Progression of variable complexity with corresponding row and column size for different data sets

4.3 Combination of Variables for Step Four Data Sets

4.4 Culvert types and their description with headwater and tail water conditions

5.1 Results of Neural Fuzzy Logic Epoch and Checking Error and Root Mean Squared Error for all six types of culverts

5.2 Results of percent of data points falling outside of error bounds, six inches above and below actual diameter for step data sets

5.3 Percent of data points falling outside error bounds for six culvert types 


\section{CHAPTER 1 - INTRODUCTION}

Culvert Capacity Charts were developed by the Portland Cement Association (PCA) as early as 1962. Since their inception, many charts, nomographs, graphical solutions, and computer algorithms, have presented approximate predictions of the flow regime in a circular pipe. The Federal Highway Administration (FHWA) presented a working document in 1985, using charts and nomographs, to accommodate an analysis of flow capacity in culverts. Still more researchers have presented computer models to predict flow behavior in culverts. These works were a direct result of the complex nature of the flow through a culvert. The West Virginia Department of Highways convened a study to determine the methods to evaluate culverts that are greater that five-hundred feet in length, which is the maximum length supported in their drainage manual. As a result of that study, the idea came to the forefront of using a completely new approach to analyzing this complex subject. The literature indicates that there have been no reports of artificial intelligence, to include neural networks, fuzzy logic, or combined neural-fuzzy logic, used to investigate and predict culvert hydrodynamics.

The purpose of the present work is to investigate the feasibility of using a neural-fuzzy logic modeling for predicting culvert diameters. This investigation is to determine if the neuralfuzzy logic model can be used to determine culvert size based on other input parameters. 


\section{CHAPTER - 2 CULVERTS}

A culvert is a conduit placed under a fill, such as a highway embankment, that conveys stream flow through the fill or past some other flow obstruction. Culverts should be designed to pass the design discharge without overtopping the fill and without erosion of the fill at either the upstream or downstream end of the culvert. The objective of culvert design is to determine the most economic dimensions that can provide the passage of a designed discharge without exceeding the allowable headwater elevation. Culverts may be constructed from a variety of materials and are available in many different shapes and configurations. The three most common materials are concrete (reinforced and non-reinforced), corrugated steel, and corrugated aluminum lined with other materials to inhibit corrosion and abrasion, or to reduce hydraulic resistance. Typical culvert shapes include circular, pipe arch, box, elliptical and arch. The shape used is based on the construction cost, the limitations on the upstream water surface elevation, the roadway embankment height, and the hydraulic performance.

Several different inlet configurations exist. These include projecting the culvert barrels, cast-in-place concrete headwalls, pre-cast or prefabricated end sections, wing-walls, and culvert ends mitered to conform to the fill slope. Structural stability, aesthetics, erosion control, and fill retention are considerations in the selection of various inlet and outlet configurations. The hydraulic capacity of a culvert may be improved by an appropriate inlet configuration selection (Normann, et al., 1985). This selection may provide a gradual flow transition that minimizes energy losses and creates a hydraulically efficient inlet condition.

\subsection{Culvert Hydraulics}

Obtaining an accurate solution of culvert hydraulics represents a formidable computational task. Culverts often act as a significant constriction to flow and are subject to a range of flow types including both rapidly varied and gradually varied flow. Flow conditions vary for different culverts. Additionally, they also vary over time, for any given culvert installation (Chaudhry, 1993). The culvert barrels may flow full or partly full depending on the upstream and downstream conditions, barrel characteristics, and inlet geometry. The characteristics of the flow are very complicated because the flow is affected by multiple variables. If the culvert is flowing partly full, the culvert acts as an open channel. When the culvert is flowing full, however, the flow is pressure or pipe flow. 
An exact theoretical analysis of culvert flow is extremely complex because the flow is usually non-uniform with regions of gradually varying and rapidly varying flow (Chow, 1959). To perform an exact analysis, backwater and drawdown calculations, energy and momentum balances, and the results of hydraulic model studies must be applied.

\subsubsection{Flow Conditions}

A culvert will flow full when the outlet is submerged or when the outlet is not submerged but the headwater is high and the barrel is long (Chow, 1959). Full flow in a culvert barrel is rare. Usually, at least part of the barrel will flow partly full. The only way to accurately determine exactly how much of the barrel is flowing full is to perform water surface profile calculations.

Several factors determine whether a culvert runs full or not: diameter, length, roughness of culvert, as well as the headwater and tail water depths. Length is one of the most important of these factors, if the culvert entry is of conventional type. A culvert is often called, "Hydraulically long," if it runs full (Henderson, 1966).

A culvert does not flow full even if the entrance is submerged if head, $\mathrm{H}$ at inlet is less than $1.5 \mathrm{D}$, where $\mathrm{D}$ is the height of the culvert at the entrance and $\mathrm{H}$ is the head-pond water level - the culvert invert level. Similarly, a culvert having a square-edged entrance may not flow full even if the headwater is higher than the top of the culvert because of the flow contraction at the top (Chaudhry, 1993).

Laboratory investigations indicate that a culvert, usually with a square edge at the top of the entrance, will not flow full even if the entrance is below headwater level when the outlet is not submerged. The flow entering the culvert, under these conditions, will contract to a depth less than the height of the culvert in a manner very similar to the contraction of flow in the form of a jet under a sluice gate. This high - velocity will continue through the culvert length, becoming reduced slowly as head is gradually lost by friction. If the culvert is not sufficiently long to allow the expanding depth of flow below the contraction to rise and fill the barrel, the culvert will never flow full (Chow, 1959).

\subsubsection{Pipe Flow}

The hydraulic condition in a culvert flowing full is called pressure or pipe flow. A condition that can create pipe flow in a culvert is the back-pressure caused by a high downstream water surface elevation. A high upstream water surface elevation may produce full flow also. The capacity of a culvert operating under pressure flow is affected by the hydraulic characteristics of the culvert and the up and downstream conditions. 


\subsubsection{Free Surface Flow}

There are three categories of free surface flow: subcritical, supercritical or critical. A dimensionless relationship, the Froude number, Fr, is used as a basis for this categorization, and is given by Equation 2-1. Table 2.1 shows the relations used to categorize flow.

$$
F_{r}=\frac{V}{\sqrt{g y_{h}}}
$$

where: $\quad \mathrm{V} \quad=$ average velocity in $\mathrm{ft} / \mathrm{s}(\mathrm{m} / \mathrm{s})$.

g = acceleration due to gravity in $\mathrm{ft} / \mathrm{s} 2(\mathrm{~m} / \mathrm{s} 2)$.

$\mathrm{y}_{\mathrm{h}} \quad=$ hydraulic depth of the free surface flow in $\mathrm{ft}(\mathrm{m})$.

\begin{tabular}{|l|l|}
\hline \multicolumn{2}{|l|}{ Table 2.1. Flow conditions based on Froude number } \\
\hline Froude Number & Flow Condition \\
\hline Less than 1.0 & Subcritical \\
\hline Equal to 1.0 & Critical \\
\hline Greater than 1.0 & Supercritical \\
\hline
\end{tabular}

To analyze free surface flow conditions, a point of known depth and flow must first be identified. This point is defined as the control section. The identification of subcritical or supercritical flow is required to continue the analysis of the free surface flow conditions. Subcritical flow characteristics, like depth and velocity, can be affected by downstream disturbances or restrictions; while supercritical flow characteristics are not affected by downstream disturbances. For example, in a steep culvert flowing partially full, the critical depth would occur at the culvert inlet, subcritical flow could exist in the upstream channel, and supercritical flow would exist in the culvert barrel.

\subsubsection{Headwater}

Energy is needed to force flow through a culvert system. This energy is in the form of an increased water surface elevation on the upstream end of the culvert. The depth of the upstream water surface is measured from the invert at the culvert entrance and is called the headwater depth.

\subsubsection{Tail water}

Tail water is defined as the depth of water downstream of the culvert measured from the outlet invert. It is an important factor in determining the hydraulic capacity of a culvert under 
outlet control conditions. Tail water depth can be influenced by the barrel roughness or by a flow obstruction in the downstream channel. 


\subsection{Flow Control}

There are two basic kinds of flow control: inlet and outlet control. In order to analyze culvert flow, the flows are categorized and analyzed on the basis of the control section, which is a location where there is a unique relationship between the flow rate and the upstream water surface elevation. Inlet control occurs when the culvert barrel can convey more flow than the inlet will accept. The control section for a culvert operating under inlet control is located just inside the entrance. At this point, critical depth occurs and the flow type immediately downstream is supercritical. Outlet control flow occurs when the culvert barrel is not capable of conveying as much flow as the inlet opening will accept. The control section for outlet control flow in a culvert is located at the barrel exit or further downstream. The characterization of pressure, sub critical, and supercritical flow types plays an important role in determining the location of the control section and thus the form of control. The hydraulic capacity of a culvert depends on a different combination of factors for each type of flow control. In this way, flow is either governed by inlet control or outlet control. A culvert that is flowing partially full can operate under inlet or outlet control. The major flow controls for both inlet and outlet control are summarized in Table 2.2.

Table 2.2. Factors Influencing Culvert Performance

\begin{tabular}{|c|c|c|c|c|c|c|c|c|c|c|}
\hline 总 & 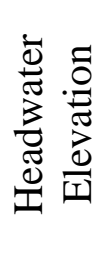 & 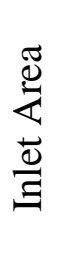 & 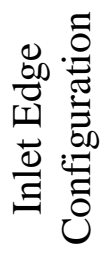 & 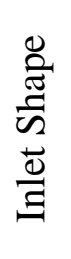 & 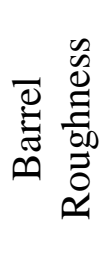 & 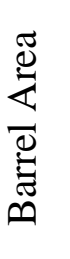 & 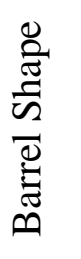 & 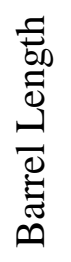 & 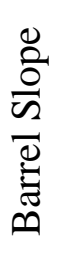 & 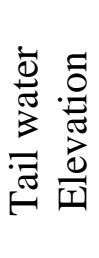 \\
\hline $\begin{array}{l}\text { Inlet } \\
\text { Control }\end{array}$ & $\mathrm{X}$ & $X$ & $X$ & $X$ & & & & & $*$ & \\
\hline $\begin{array}{l}\text { Outlet } \\
\text { Control }\end{array}$ & $X$ & X & $X$ & $X$ & $X$ & $X$ & $X$ & $X$ & X & $X$ \\
\hline
\end{tabular}

* The barrel slope affects the inlet control performance to a small degree, but may be neglected. Source: (Normann, et al., 1985). 


\subsubsection{Inlet Control}

Under inlet control conditions, the flow rate is independent of the length, the slope, or the roughness of the culvert. Discharge depends only on headwater elevation above the invert at the entrance, the culvert dimensions, and entrance geometry. The culvert will always flow partially full under inlet control conditions (Portland Cement Association, 1964).

\section{Factors Influencing Inlet Control}

The hydraulic characteristics downstream of the inlet control section do not affect the culvert capacity. Headwater depth is measured from the invert of the inlet control section to the surface of the upstream pool. The inlet geometry includes the inlet area, the inlet edge configuration, and the inlet shape. The inlet area is the cross-sectional area of the face of the culvert. The inlet edge configuration describes the entrance type; while the inlet shape is usually the same as the shape of the culvert barrel. Another factor that influences inlet control performances is the barrel slope. This is only a small effect and may be neglected in inlet control calculations. Figure 2.2.1 shows the conditions for typical inlet control.

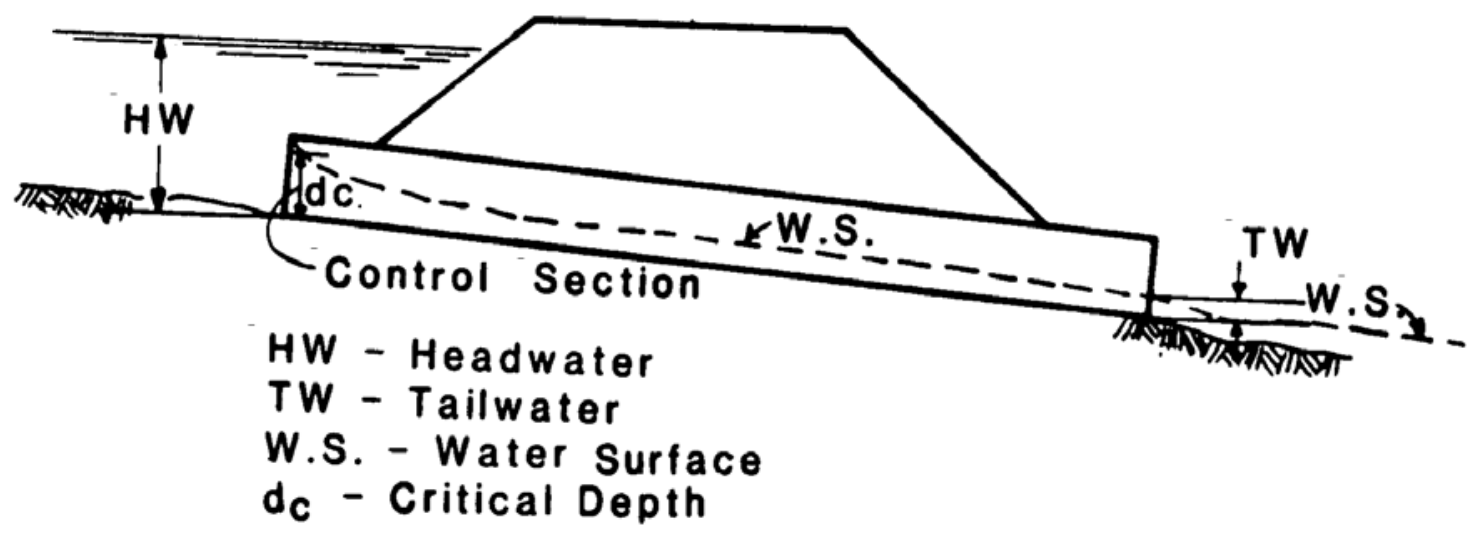

Figure 2.2.1. Typical Inlet Control Flow Conditions. Source: (Normann, et al., 1985). 


\section{Examples of Inlet Control:}

Inlet control flow is characterized by shallow, high velocity flow known as supercritical flow. For supercritical flow, the control section is at the inlet. The type of inlet control flow depends on whether or not the inlet and outlet of the culvert are submerged. Chow, (1959), Henderson, (1966), and Normann, et al., (1985), describe four types of inlet control in the literature. These four types are illustrated in Figure 2.2.2.

\section{The Hydraulics of Inlet Control}

Inlet control performance is defined by three regions of flow; submerged, transition, and unsubmerged. For low headwater depths, the entrance of the culvert operates as a weir. For high headwater depths, the entrance of the culvert operates as an orifice.

A weir is an un-submerged flow control section where the upstream water surface elevation is a single - valued function of flow rate. The relationship between the flow rate and the water surface elevation is determined by running model tests of the weir geometry. These measurements are then used to develop equations for an un-submerged inlet control flow. These equations have two forms:

$$
\begin{array}{ll}
\text { Form 1: } & \frac{H W_{i}}{D}=\frac{H_{c}}{D}+K\left[\frac{Q}{A D^{\frac{1}{2}}}\right]^{M}-\frac{1}{2} S_{o}^{2} \\
\text { Form 2: } & \frac{H W_{i}}{D}=K\left[\frac{Q}{A D^{\frac{1}{2}}}\right]^{M}
\end{array}
$$

where: $\quad H W_{i} \quad=$ headwater depth above the inlet control section invert in $\mathrm{ft}(\mathrm{m})$.

$D \quad=$ interior height of the culvert barrel in $\mathrm{ft}(\mathrm{m})$.

$H_{c} \quad=$ specific head at critical depth in $\mathrm{ft}(\mathrm{m}) . H_{c}=\left(d_{c}+V_{c}^{2} / 2 g\right)$.

$Q=$ flow-rate $\left(\mathrm{ft}^{3} / \mathrm{s}\right.$ or $\left.\mathrm{m}^{3} / \mathrm{s}\right)$.

$A=$ cross sectional area in $\mathrm{ft}^{2}\left(\mathrm{~m}^{2}\right)$.

$S_{o} \quad=$ culvert barrel slope in $\mathrm{ft} / \mathrm{ft}(\mathrm{m} / \mathrm{m})$.

$K, M=$ constants, found in most culvert references, and Table 2.3 

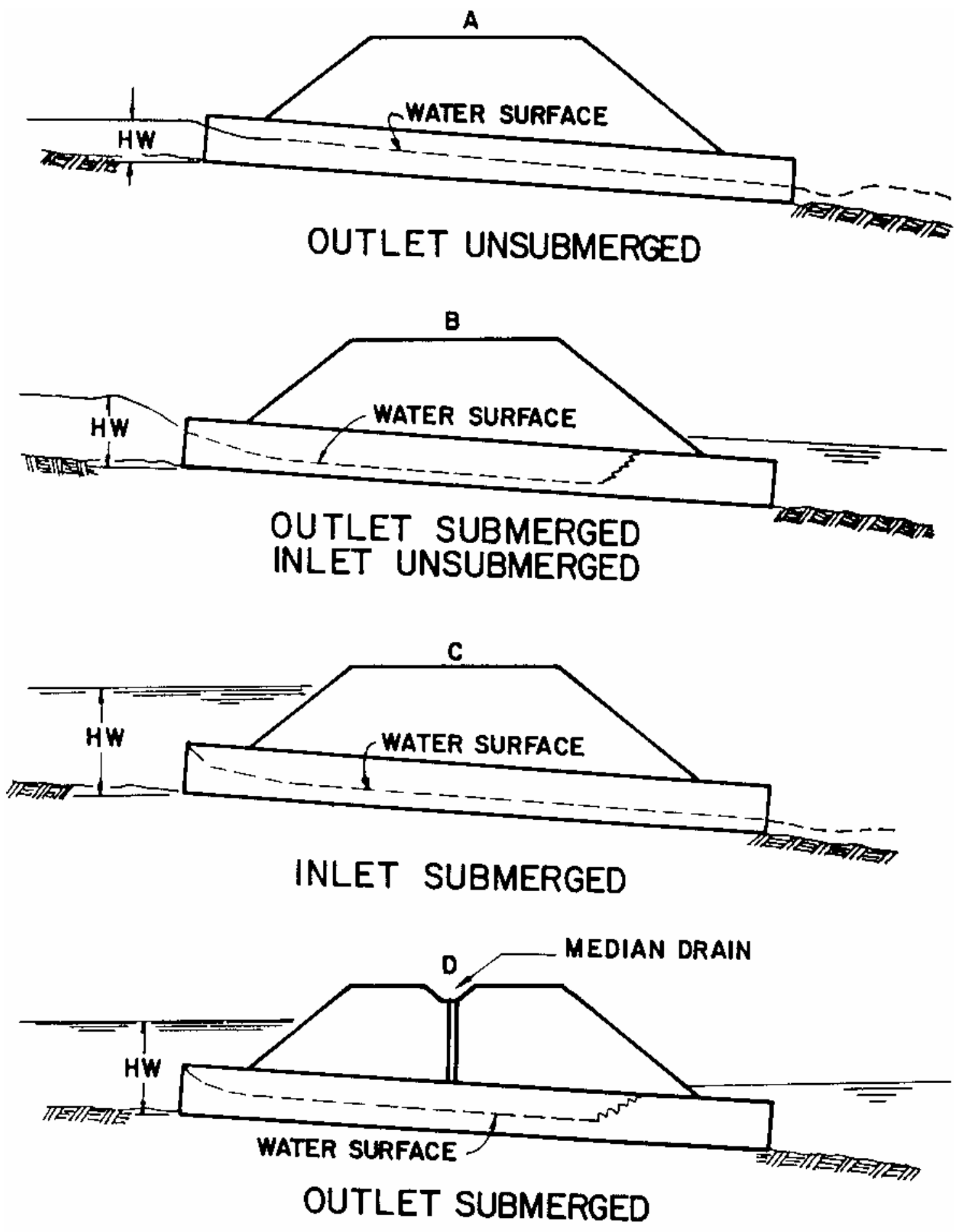

Figure 2.2.2. Types of Inlet Control. (A.) Inlet \& Outlet Un-submerged, (B.) Inlet Unsubmerged \& Outlet Submerged, (C.) Inlet Submerged \& Outlet Un-submerged, and (D) Inlet and Outlet submerged. Source: (Normann, et al., 1985). 
Table 2.3 provides a summary of coefficients for inlet control. Generally, equations 2-2 and 2-3 are applied when $Q / A D^{1 / 2}<3.5$. As the culvert entrance becomes submerged under headwaters, it acts as an orifice. An orifice is an opening submerged on the upstream end and flowing freely on the downstream end that functions as a control section. The relationship between the flow rate and the headwater can be defined based on results from model tests. The results may then be used to develop an equation defining that relationship which is of the following form:

$$
\frac{H W}{D}=c\left[\frac{Q}{A D^{1 / 2}}\right]^{2}+¥-0.5 S_{o}
$$

The constants, c and $¥$ may be found in most culvert references as well, and Table 2.3. Equation 2-4 applies when $Q / A D^{1 / 2}>4$.0. When using equations 2-3 and 2-4 with mitered inlets, a slope correction factor of $+0.75 S_{o}$ should be used, instead of $-0.5 S_{o}$.

The flow transition zone between low headwater (weir control) and high headwater (orifice control) is poorly defined. This zone may be approximated, by plotting the unsubmerged and submerged flow equations, and connecting them with a line tangent to both curves. An example of this is shown in Figure 2.2.3.

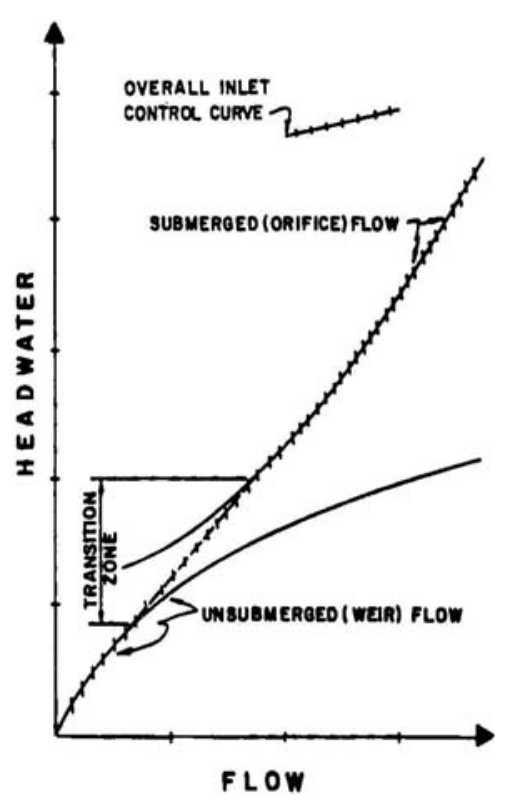

Figure 2.2.3. Inlet Control curves for different flow conditions. Source: (Normann, et al., 1985). 
Table 2.3. Coefficients for Inlet Control Design Equations.

\begin{tabular}{|c|c|c|c|c|c|c|}
\hline \multirow{2}{*}{$\begin{array}{l}\text { Shape and } \\
\text { Material }\end{array}$} & \multirow{2}{*}{$\begin{array}{l}\text { Inlet edge } \\
\text { Description }\end{array}$} & \multicolumn{3}{|c|}{ Unsubmerged } & \multicolumn{2}{|c|}{ Submerged } \\
\hline & & form & $\mathbf{K}$ & $\mathbf{M}$ & c & $\mathbf{Y}$ \\
\hline \multirow{3}{*}{$\begin{array}{l}\text { Circular } \\
\text { Concrete }\end{array}$} & Square edge w/ headwall & \multirow{3}{*}{1} & 0.0098 & 2.0 & 0.0398 & 0.67 \\
\hline & Groove end w/ headwall & & .0078 & 2.0 & .0292 & .74 \\
\hline & Groove end projecting & & .0045 & 2.0 & .0317 & .69 \\
\hline \multirow{3}{*}{$\begin{array}{l}\text { Circular } \\
\text { CMP }\end{array}$} & Headwall & \multirow{3}{*}{1} & .0078 & 2.0 & .0379 & .69 \\
\hline & Mitered to slope & & .0210 & 1.33 & .0463 & .75 \\
\hline & Projecting & & .0340 & 1.5 & .0553 & .54 \\
\hline \multirow{2}{*}{ Circular } & Beveled ring, $45^{\circ}$ bevels & \multirow[t]{2}{*}{1} & .0018 & 2.5 & .0300 & .74 \\
\hline & Beveled ring, $33.7^{\circ}$ bevels & & .0018 & 2.5 & .0243 & .83 \\
\hline \multirow{3}{*}{$\begin{array}{l}\text { Rectangular } \\
\text { Box }\end{array}$} & $30^{\circ}$ to $75^{\circ}$ wingwall flares & \multirow{3}{*}{1} & .026 & 1.0 & .0385 & .81 \\
\hline & $90^{\circ}$ and $15^{\circ}$ wingwall flares & & .061 & 0.75 & .0400 & .80 \\
\hline & $0^{\circ}$ wingwall flares & & .061 & 0.75 & .0423 & .82 \\
\hline \multirow{2}{*}{$\begin{array}{l}\text { Rectangular } \\
\text { Box }\end{array}$} & $45^{\circ}$ wingwall flare $\mathrm{d}=.0430$ & \multirow[t]{2}{*}{2} & .510 & .667 & .0309 & .80 \\
\hline & $18^{\circ}$ to $33.7^{\circ}$ wingwall flares $\mathrm{d}=.0830$ & & .486 & .667 & .0249 & .83 \\
\hline \multirow{3}{*}{$\begin{array}{l}\text { Rectangular } \\
\text { Box }\end{array}$} & $90^{\circ}$ headwall w/ 3/4" chamfers & \multirow{3}{*}{2} & .515 & .667 & .0375 & .79 \\
\hline & $90^{\circ}$ headwall w/ $45^{\circ}$ bevels & & .495 & .667 & .0314 & .82 \\
\hline & $90^{\circ}$ headwall w/ $33.7^{\circ}$ bevels & & .486 & .667 & .0252 & .865 \\
\hline \multirow{4}{*}{$\begin{array}{l}\text { Rectangular } \\
\text { Box }\end{array}$} & 3/4" chamfers; $45^{\circ}$ skewed headwall & \multirow{4}{*}{2} & .522 & .667 & .0402 & .73 \\
\hline & 3/4" chamfers; $30^{\circ}$ skewed headwall & & .533 & .667 & .0425 & .705 \\
\hline & 3/4" chamfers; $15^{\circ}$ skewed headwall & & .545 & .667 & .04505 & .68 \\
\hline & $45^{\circ}$ bevels; $10^{\circ}-45^{\circ}$ skewed headwall & & .498 & .667 & .0327 & .75 \\
\hline
\end{tabular}


Table 2.3 Continued

\begin{tabular}{|c|c|c|c|c|c|c|}
\hline \multirow{3}{*}{$\begin{array}{l}\text { Rectangular } \\
\text { Box, 3/4" } \\
\text { chamfers }\end{array}$} & $45^{\circ}$ non-offset wingwall flares & \multirow{3}{*}{2} & .497 & .667 & .0339 & .803 \\
\hline & $18.4^{\circ}$ non-offset wingwall flares & & .493 & .667 & .0361 & .806 \\
\hline & $\begin{array}{l}18.4^{\circ} \text { non-offset wingwall flares, } \\
30^{\circ} \text { skewed barrels }\end{array}$ & & .495 & .667 & .0386 & .71 \\
\hline \multirow{3}{*}{$\begin{array}{l}\text { Rectangular } \\
\text { Box } \\
\text { Top Bevels }\end{array}$} & $45^{\circ}$ wingwall flares - offset & \multirow{3}{*}{2} & .497 & .667 & .0302 & .835 \\
\hline & $33.7^{\circ}$ wingwall flares - offset & & .495 & .667 & .0252 & .881 \\
\hline & $18.4^{\circ}$ wingwall flares - offset & & .493 & .667 & .0227 & .887 \\
\hline \multirow{3}{*}{ C M Boxes } & $90^{\circ}$ headwall & \multirow{3}{*}{1} & .0083 & 2.0 & .0379 & .69 \\
\hline & Thick wall projecting & & .0145 & 1.75 & .0419 & .64 \\
\hline & Thin wall projecting & & .0340 & 1.5 & .0496 & .57 \\
\hline \multirow{3}{*}{$\begin{array}{l}\text { Horizontal } \\
\text { Ellipse } \\
\text { Concrete }\end{array}$} & Square edge with headwall & \multirow{3}{*}{1} & .01 & 2.0 & .0398 & .67 \\
\hline & Groove end with headwall & & .0018 & 2.5 & .0292 & .74 \\
\hline & Groove end projecting & & .0045 & 2.0 & .0317 & .69 \\
\hline \multirow{3}{*}{$\begin{array}{l}\text { Vertical } \\
\text { Ellipse } \\
\text { Concrete }\end{array}$} & Square edge with headwall & \multirow{3}{*}{1} & .01 & 2.0 & .0398 & .67 \\
\hline & Groove end with headwall & & .0018 & 2.5 & .0292 & .74 \\
\hline & Groove end projecting & & .0095 & 2.0 & .0317 & .69 \\
\hline \multirow{3}{*}{$\begin{array}{l}\text { Pipe Arch } \\
\text { 18" Corner } \\
\text { Radius CM }\end{array}$} & $90^{\circ}$ headwall & \multirow{3}{*}{1} & .0083 & 2.0 & .0379 & .69 \\
\hline & Mitered to slope & & .03 & 1.0 & .0463 & .75 \\
\hline & Projecting & & .034 & 1.5 & .0496 & .57 \\
\hline \multirow{3}{*}{$\begin{array}{l}\text { Pipe Arch } \\
\text { 18" Corner } \\
\text { Radius CM }\end{array}$} & Projecting & \multirow{3}{*}{1} & .0296 & 1.5 & .0487 & .55 \\
\hline & No Bevels & & .0087 & 2.0 & .0361 & .66 \\
\hline & $33.7^{\circ}$ Bevels & & .003 & 2.0 & .0264 & .75 \\
\hline \multirow{3}{*}{$\begin{array}{l}\text { Pipe Arch } \\
\text { 31" Corner } \\
\text { Radius CM }\end{array}$} & Projecting & \multirow{3}{*}{1} & .0296 & 1.5 & .0487 & .55 \\
\hline & No Bevels & & .0087 & 2.0 & .0361 & .66 \\
\hline & $33.7^{\circ}$ Bevels & & .003 & 2.0 & .0264 & .75 \\
\hline
\end{tabular}


Table 2.3 Continued

\begin{tabular}{|c|c|c|c|c|c|c|}
\hline \multirow{3}{*}{ Arch CM } & $90^{\circ}$ headwall & \multirow{3}{*}{1} & .0083 & 2.0 & .0379 & .69 \\
\hline & Mitered to slope & & .03 & 1.0 & .0463 & .75 \\
\hline & Thin wall Projecting & & .034 & 1.5 & .0496 & .57 \\
\hline \multirow[b]{2}{*}{ Circular } & Smooth tapered inlet throat & \multirow[t]{2}{*}{2} & .534 & .555 & .0196 & .89 \\
\hline & Rough tapered inlet throat & & .519 & .64 & .0289 & .90 \\
\hline \multirow{3}{*}{$\begin{array}{l}\text { Elliptical } \\
\text { Inlet Face }\end{array}$} & Tapered inlet - beveled edges & \multirow[t]{3}{*}{2} & .536 & .622 & .0368 & .83 \\
\hline & Tapered inlet - square edges & & .5035 & .719 & .0478 & .80 \\
\hline & Tapered inlet - thin edge projecting & & .547 & .80 & .0598 & .75 \\
\hline Rectangular & Tapered inlet throat & 2 & .475 & .667 & .0179 & .97 \\
\hline \multirow{2}{*}{$\begin{array}{l}\text { Rectangular } \\
\text { Concrete }\end{array}$} & Side tapered - less favorable edges & \multirow[t]{2}{*}{2} & .56 & .667 & .0466 & .85 \\
\hline & Side tapered - more favorable edges & & .56 & .667 & .0378 & .87 \\
\hline \multirow{2}{*}{$\begin{array}{l}\text { Rectangular } \\
\text { Concrete }\end{array}$} & Slope tapered - less favorable edges & \multirow[t]{2}{*}{2} & .50 & .667 & .0466 & .65 \\
\hline & Slope tapered - more favorable edges & & .50 & .667 & .0378 & .71 \\
\hline
\end{tabular}

Source: Haestad, 1995. 


\subsubsection{Outlet Control}

Under outlet control conditions, the total discharge is dependent on all hydraulic factors upstream of the culvert outlet. These factors include: headwater elevation, entrance geometry, culvert geometry, roughness, length, and slope; see Table 2.2. When a culvert is flowing full, it must operate under outlet control. The control section for outlet control flow in a culvert is located at the barrel exit or farther downstream. Typical outlet control flow conditions are demonstrated in Figure 2.2.4. Either sub critical or pressure flow exists in the barrel under these conditions.

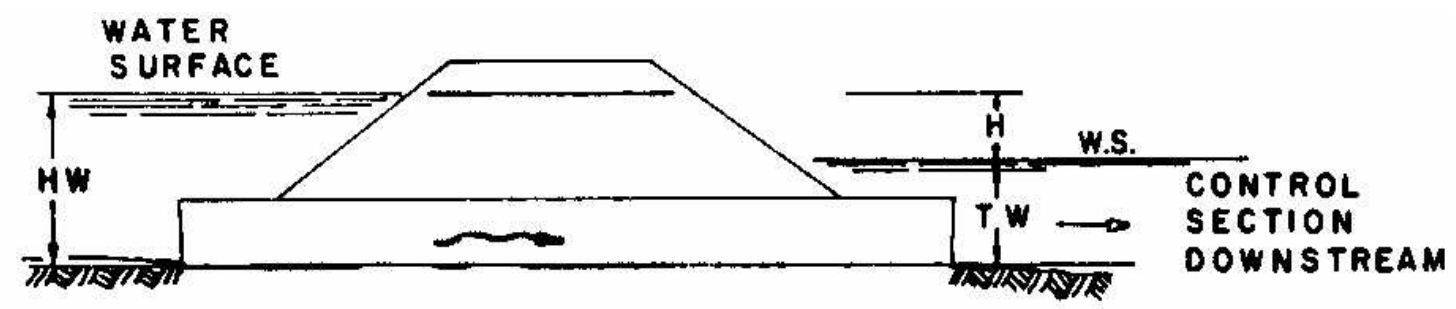

A. SUBMERGED
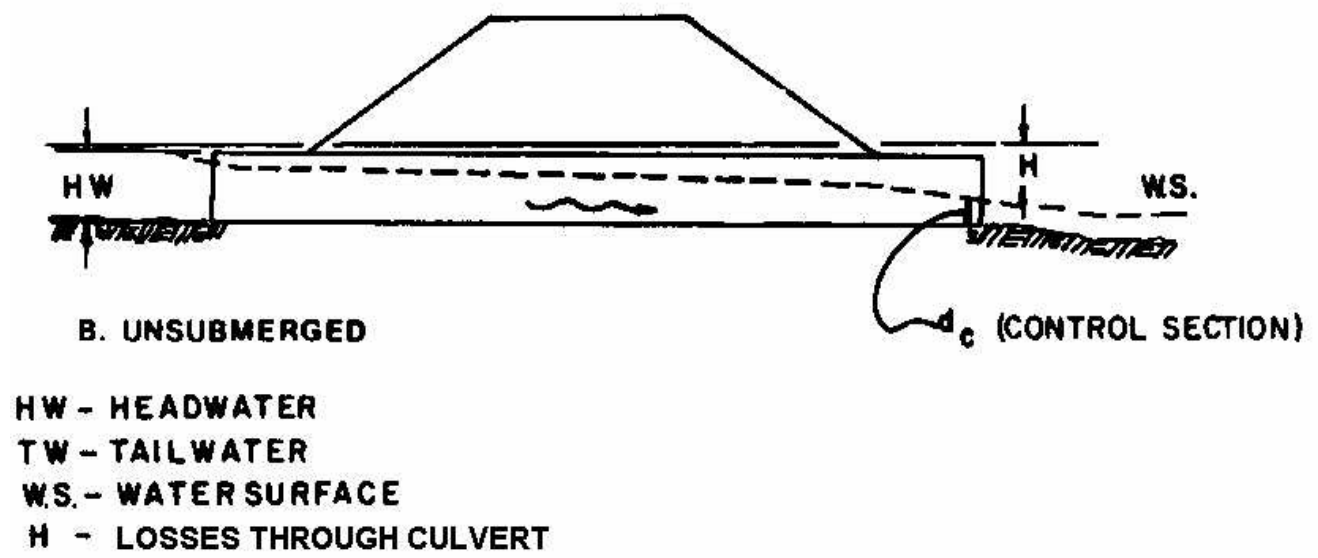

Figure 2.2.4. Typical Outlet Control Flow Conditions. (A.) Submerged and (B.) Unsubmerged. Source: (Normann, et al., 1985). 


\section{Factors Influencing Outlet Control}

All of the hydraulic and geometric characteristics of the culvert play a role in determining its hydraulic capacity. These characteristics include the inlet geometry, upstream water surface elevation, the water surface elevation at the outlet, the slope, and the length and hydraulic roughness of the culvert barrel. A summary of these characteristics was presented earlier in Table 2.2. The barrel roughness is a function of the material used to make the barrel. The roughness is represented by a hydraulic resistance coefficient such as the Manning $\mathrm{n}$ value. The barrel area is self-explanatory. The barrel length is the total culvert length from the entrance to the exit of the culvert. The barrel slope is the actual slope of the culvert barrel. Tail water elevation is based on the downstream water elevation. Backwater calculations from a downstream control, a normal depth approximation or field observations must be used to define the tail water elevation.

\section{Examples of Outlet Control}

A culvert flowing in outlet control will typically have a relatively deep, low velocity flow. For sub critical flow, the control is at the outlet. Tail water depth is either the critical depth at the culvert outlet or the downstream channel depth, whichever is greater. The type of outlet control flow depends on whether or not the inlet and outlet of the culvert are submerged. Five typical outlet control scenarios, as illustrated in Figure 2.2.5, are discussed in the literature by Chow, (1959), Henderson, (1966), and Normann, et al., (1985). 

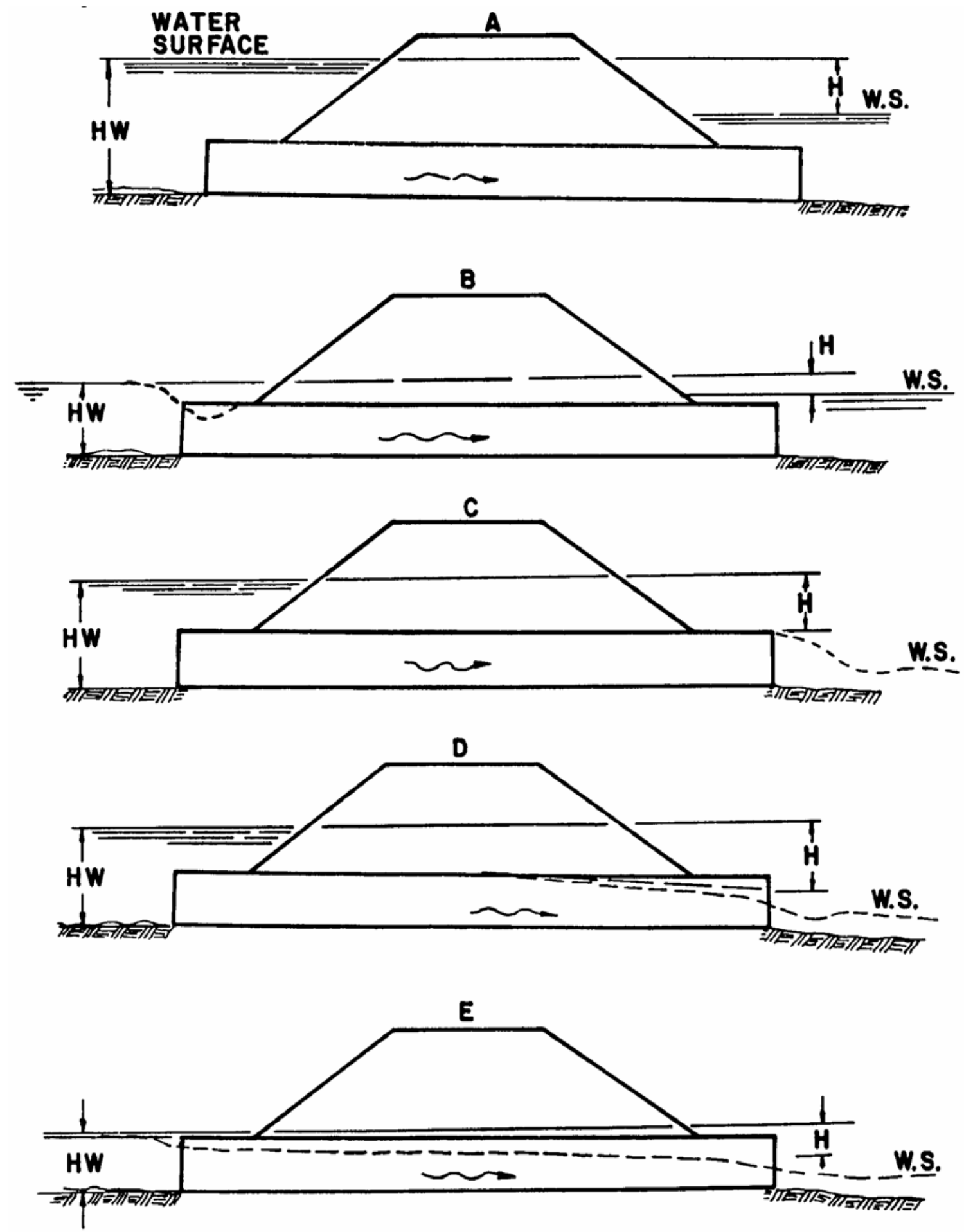

Figure 2.2.5. Types of Outlet Control: (A) Inlet \& outlet submerged, (B) Inlet un-submerged \& outlet submerged, (C) Inlet submerged \& outlet un-submerged, (D) Inlet \& outlet flowing freely, and (E) Inlet \& outlet un-submerged. Source: (Normann, et al., 1985). 
In Figure 2.2.5 A, both the inlet and the outlet are submerged. The barrel is in pressure flow throughout its entire length. This condition is often assumed when performing outlet control calculations, but seldom exists.

In Figure 2.2.5 B, the outlet is submerged and the inlet is un-submerged. The headwater is not very deep thus; the inlet top is exposed as the flow contracts into the culvert.

In Figure 2.2.5 C, the inlet is submerged to such an extent that the culvert flows full throughout its entire length while the exit is un-submerged. This scenario rarely happens according to Normann, et al., 1985.

In 2.2.5 D, the inlet is submerged and the outlet flows freely with a low tail water. The barrel flows partly full over at least part of its length and flow passes through critical depth just upstream of the outlet.

In Figure 2.2.5 E, neither the inlet nor the outlet is submerged. The barrel flows partly full over the entire length, and the flow profile is sub critical.

\section{The Hydraulics of Outlet Control}

Outlet control hydraulics are best described using full flow in the culvert barrel (Normann, et al., 1985). Outlet control flow conditions can be calculated based on an energy balance. The total energy $\left(H_{L}\right)$ required to pass the flow though the culvert barrel is made up of the entrance losses $\left(H_{e}\right)$, the friction losses through the barrel $\left(H_{f}\right)$, and the exit losses $\left(H_{o}\right)$. Other losses including bend losses $\left(H_{b}\right)$, losses at junctions $\left(H_{j}\right)$, and losses at grates $\left(H_{g}\right)$ should be included when appropriate.

$$
H_{L}=H_{e}+H_{f}+H_{o}+H_{b}+H_{j}+H_{g}
$$

The barrel velocity is calculated by:

$$
V=\frac{Q}{A}
$$

where: $\quad V \quad=$ average velocity in the culvert barrel in $\mathrm{ft} / \mathrm{s}(\mathrm{m} / \mathrm{s})$.

$Q \quad=$ flow-rate in $\mathrm{ft}^{3} / \mathrm{s}\left(\mathrm{m}^{3} / \mathrm{s}\right)$.

A $\quad=$ full cross sectional area of the flow in $\mathrm{ft}^{2}\left(\mathrm{~m}^{2}\right)$.

The velocity head is given by the equation:

$$
H_{v}=\frac{V^{2}}{2 g}
$$


where

$$
g \quad=\text { acceleration due to gravity, } 32.2 \mathrm{ft} / \mathrm{sec}^{2}\left(9.81 \mathrm{~m} / \mathrm{sec}^{2}\right)
$$

The entrance loss is a function of the velocity head in the barrel and is expressed by the following equation:

$$
H_{e}=k_{e}\left(\frac{V^{2}}{2 g}\right)
$$

The minor loss coefficient, $k_{e}$, varies according to the type of entrance at the inlet. These coefficients may be found in most hydraulic references, including Hydraulic Design of Highway Culverts, by (Normann, et al., 1985).

The friction losses throughout the barrel are a function of the velocity head and are given by the equation:

$$
H_{f}=\left(\frac{V^{2}}{2 g}\right) *\left[\frac{29 n^{2} L}{R_{h}^{4 / 3}}\right]
$$

where: $\quad n \quad=$ Manning's roughness coefficient

$L \quad=$ length of the culvert barrel in $\mathrm{ft}(\mathrm{m})$.

$R_{h} \quad=$ hydraulic radius of the full culvert barrel in $\mathrm{ft}(\mathrm{m}) . R_{h}=A / P_{w}$.

$P_{w} \quad=$ wetted perimeter of the barrel in $\mathrm{ft}(\mathrm{m})$.

$V \quad=$ velocity in the barrel in $\mathrm{ft} / \mathrm{s}(\mathrm{m} / \mathrm{s})$.

The exit losses are a function of the changes in velocity at the outlet of the culvert barrel and may be expressed by the following equation:

$$
H_{o}=1.0\left[\frac{V_{u}^{2}}{2 g}-\frac{V_{d}^{2}}{2 g}\right]
$$

where: $\quad V_{u} \quad=$ channel velocity upstream of the culvert in $\mathrm{ft} / \mathrm{s}(\mathrm{m} / \mathrm{s})$.

$V_{d} \quad=$ channel velocity downstream of the culvert in $\mathrm{ft} / \mathrm{s}(\mathrm{m} / \mathrm{s})$.

Losses due to bends are calculated by using a loss coefficient for bends, $K_{b}$ in the following relationship:

$$
H_{b}=K_{b}\left(\frac{V^{2}}{2 g}\right)
$$

Losses due to junctions are calculated by using the following equation: 


$$
H_{j}=y^{\prime}+H_{v_{1}}-H_{v_{2}}
$$

where: $\quad y^{\prime} \quad=$ change in hydraulic grade line through the junction, $\mathrm{ft}(\mathrm{m})$.

$H_{v 1} \quad=$ velocity head in the upstream culvert, $\mathrm{ft}(\mathrm{m})$.

$H_{v 2} \quad=$ velocity head in the downstream culvert, $\mathrm{ft}(\mathrm{m})$.

Head loss due to grates is not of concern in this study and is therefore neglected in the calculation of $H_{L}$.

If equations (2-6) through (2-12) are substituted into equation (2-5), the following equation for loss is obtained:

$$
H_{L}=\left(\frac{V^{2}}{2 g}\right)\left[1+k_{e}+\frac{29 n^{2} L}{R_{h}^{4 / 3}}\right]+y^{\prime}+H_{v_{2}}-H_{v_{2}}
$$

Figure 2.2.6 depicts the energy and hydraulic grade lines for a culvert flowing full. The energy grade line represents the total mechanical energy per unit weight at any point along the culvert barrel.

The headwater is the depth from the inlet invert to the energy grade line. The hydraulic grade line is the height to which water would rise in vertical tubes connected to the sides of the culvert barrel. In full flow scenarios, the energy grade line and the hydraulic grade line are parallel straight lines separated by a distance equal to the velocity head, except in the vicinity of the inlet where the flow passes through the contraction. The headwater and tail water, as well as the entrance, friction, and exit losses are also shown in Figure 2.2.6.

Equating the total energy at section 1 and section 2, upstream and downstream of the culvert barrel, results in the following expression:

$$
H W_{o}+\frac{V_{u}^{2}}{2 g}+S_{o} L=T W+\frac{V_{d}^{2}}{2 g}+H_{L}
$$

where: $\quad H W_{o}=$ headwater depth above the inlet invert in $\mathrm{ft}(\mathrm{m})$.

$V_{u} \quad=$ approach velocity in $\mathrm{ft} / \mathrm{s}(\mathrm{m} / \mathrm{s})$.

$T W \quad=$ tail water depth above the outlet invert in $\mathrm{ft}(\mathrm{m})$.

$V_{d} \quad=$ downstream velocity in $\mathrm{ft} / \mathrm{s}(\mathrm{m} / \mathrm{s})$.

$H_{L} \quad=$ sum of all losses including entrance $\left(H_{e}\right)$, friction $\left(H_{f}\right)$, exit $\left(H_{o}\right)$, and 


$$
\begin{aligned}
& \text { any other losses. } \\
& S_{0} L \quad=\text { difference in elevation from upstream invert to downstream invert in } \mathrm{ft} \text {. }
\end{aligned}
$$

Often, the approach and downstream velocities and their corresponding velocity heads are low and are therefore neglected. When these velocities are neglected, equation (2-14) becomes:

$$
H W_{o}=T W+H_{L}
$$

In this case, $H_{L}$ is the difference of elevation between the water surface at the outlet and at the inlet.

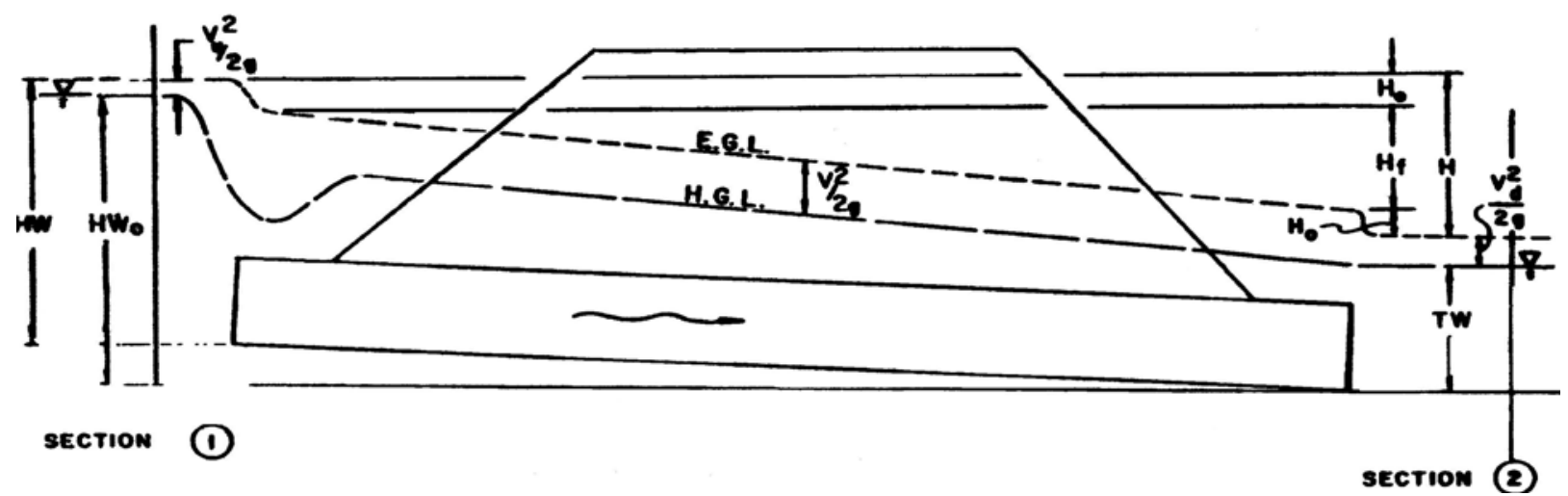

Figure 2.2.6. Full Flow Energy and Hydraulic Grade Lines. Source: (Normann, et al., 1985). 
Equations (2.5) through (2.15) apply to full barrel flow only. Partly full flow conditions may require backwater calculations. These calculations begin at the water surface at the downstream end of the culvert and move upstream to the culvert entrance. The downstream water surface is either the critical depth at the culvert outlet, or the tail water depth, whichever is the greatest. If the calculated backwater profile intersects the top of the barrel, a straight full flow hydraulic grade line extends from that point upstream to the culvert entrance. From equation (2-9), the full flow friction slope may be given by the equation:

$$
S_{f}=\frac{H_{f}}{L}=\left(\frac{V^{2}}{2 g}\right)\left[\frac{29 n^{2} L}{R_{h}^{4 / 3}}\right]
$$

To avoid involved backwater calculations, approximate methods were developed to analyze partly full flow conditions. It has been found that a downstream extension of the full flow hydraulic grade line pierces the plane of the culvert outlet at a point half way between critical depth and the top of the barrel (Normann, et al., 1985). It is possible to begin the hydraulic grade line at a depth of $\left(d_{c}+D\right) / 2$ above the outlet invert and extend the straight, full flow hydraulic grade line upstream to the inlet of the culvert at a slope of $S_{f}$.

If the tail water exceeds $\left(d_{c}+D\right) / 2$, the tail water is used to set the downstream end of the extended full flow hydraulic grade line. The inlet losses and the velocity head are added to the elevation of the hydraulic grade line at the inlet to obtain the headwater elevation.

The approximate method works the best when at least part of the culvert barrel flows full. When the barrel is partly full, over its entire length; the approximate method decreases in accuracy, as the headwater falls farther below the top of the barrel at the entrance. The approximate method gives adequate results down to a headwater of $0.75 \mathrm{D}$. For headwaters lower than these, backwater calculations are required to get accurate headwater elevations.

\subsubsection{Outlet Velocity}

The flow area in a culvert is usually reduced from that of the flow area of the channel, thus increasing the flow velocity in the culvert. Streambed scour and bank erosion in the vicinity of the culvert outlet may be a result of this increased velocity. Scour can be reduced by increasing the barrel roughness, using energy dissipaters, flattening the slope, or some other outlet protection devices. 
In inlet control, backwater, or drawdown, calculations may be needed to determine the outlet velocity. These calculations begin at the inlet and move downstream to the outlet. The flow velocity is obtained from the flow and the cross-sectional area at the outlet.

An approximation can be used in order to avoid backwater calculations. The water surface profile converges toward normal depth as calculations move down the culvert barrel. If the culvert is of adequate length, normal depth will occur at the culvert outlet. Even in short culverts, normal depth may be assumed and used to define the area of flow at the outlet to obtain the outlet velocity (Normann, et al., 1985). The velocity calculated in this way will be slightly higher than the actual velocity at the outlet. Normal depth may be calculated using a trial and error solution of the Manning equation. The known inputs are the flow rate, barrel resistance, slope and geometry.

In outlet control, the geometry of the outlet and either critical depth, tail water depth, or the height of the barrel defines the cross-sectional area of the flow. Critical depth is used when the tail water is less than critical depth and the tail water depth is used when tail water is greater than critical depth but below the top of the barrel. The total barrel area is used when the tail water exceeds the top of the barrel.

\subsubsection{Performance Curves}

A plot of flow rate versus headwater depth for a given flow control device such as a weir, orifice, or a culvert, is known as a performance curve. The performance curve is useful in evaluating the hydraulic capacity of these flow control devices for various headwaters. Sample performance curves for weirs and orifices may be seen in Figure 2.2.7. A weir constricts open channel flow so that the flow passes through critical depth just upstream of the weir. This type of performance curve is demonstrated in Figure 2.2.7a. An orifice is a flow control device, fully submerged on the upstream end, through which flow passes. The orifice performance curve is demonstrated in Figure 2.2.7b. When tail water exists, the control device may be submerged so that more than one flow versus depth relationship exists. At this point, the performance curve is dependent on the variation of the headwater and the tail water. 


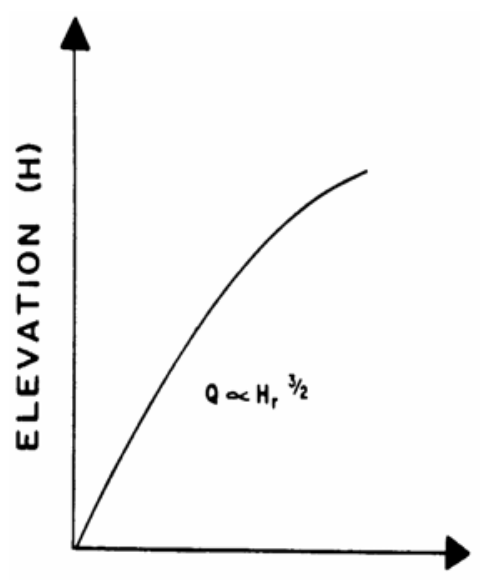

(a)

FLOW RATE (Q)

WEIR

RECTANGULAR WEIR

Equation: $\quad Q=\mathrm{C}_{d} L\left(\mathrm{HW}_{\mathrm{r}}\right)^{3 / 2}$

$\mathrm{Q}=$ flow rate, $\mathrm{ft}^{3} / \mathrm{s}\left(\mathrm{m}^{3} / \mathrm{s}\right)$

$C_{d}=$ weir coefficient

$\mathrm{L}=$ length of weir, $\mathrm{ft}(\mathrm{m})$

$H W_{\mathrm{r}}=$ driving head above

weir crest, ft (m)

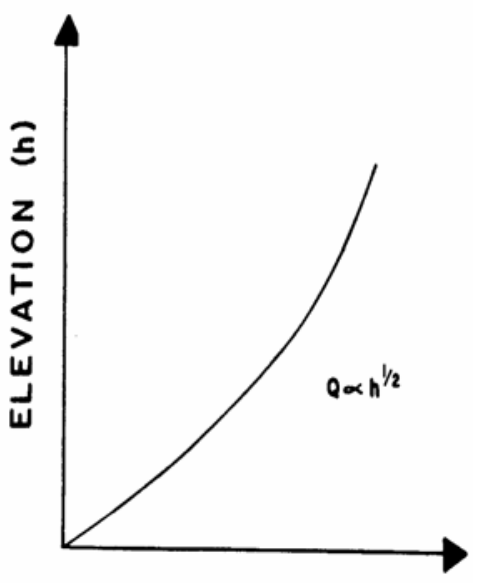

(b)

FLOW RATE (Q)

ORIFICE

QRIFICE

Equation: $Q=\mathrm{kah}^{1 / 2}$

$Q=$ flow rate, $\mathrm{ft}^{3} / \mathrm{s}\left(\mathrm{m}^{3} / \mathrm{s}\right)$

$\mathrm{k}=$ coefficient

$\mathrm{a}=$ area of orifice, $\mathrm{ft}^{2}\left(\mathrm{~m}^{2}\right)$

$h=$ driving head above center of orifice, $\mathrm{ft}(\mathrm{m})$

Figure 2.2.7. Performance Curves for (a) Weirs (b) Orifices. Source: (Normann, et al., 1985).

Culvert performance curves are similar to weir and orifice performance curves since culverts often behave as one of these control devices. Since a culvert has several possible control sections, inlet, outlet or mid-span, a given installation will have a performance curve for each control section as demonstrated in Figure 2.2.8. The overall culvert performance curve is made up of the controlling portion of the individual curves for each control section.

Inlet control performance curves are developed by using either the inlet control equations described earlier in this chapter or by using the inlet control nomographs that may be found in most culvert design references, such as Hydraulic Design of Highway Culverts, (Normann, et al., 1985). If the equations are used, both the un-submerged and submerged flow headwaters must be calculated for a series of flow rates around the design flow. The resultant curves are then connected with a line tangent to both curves. This tangent line represents the transition zone. When the nomographs are used, the headwaters corresponding to the series of flow rates are determined then plotted. The transition zone is inherent in the nomographs. 
The outlet control performance curves are developed using either the equations developed earlier in this chapter, nomographs, or backwater calculations. Several flows bracketing the design flow should be selected. For these flows, the total losses through the barrel are calculated or read from the outlet control nomographs. The losses are added to the elevation of the hydraulic grade line at the culvert outlet to obtain the headwater.

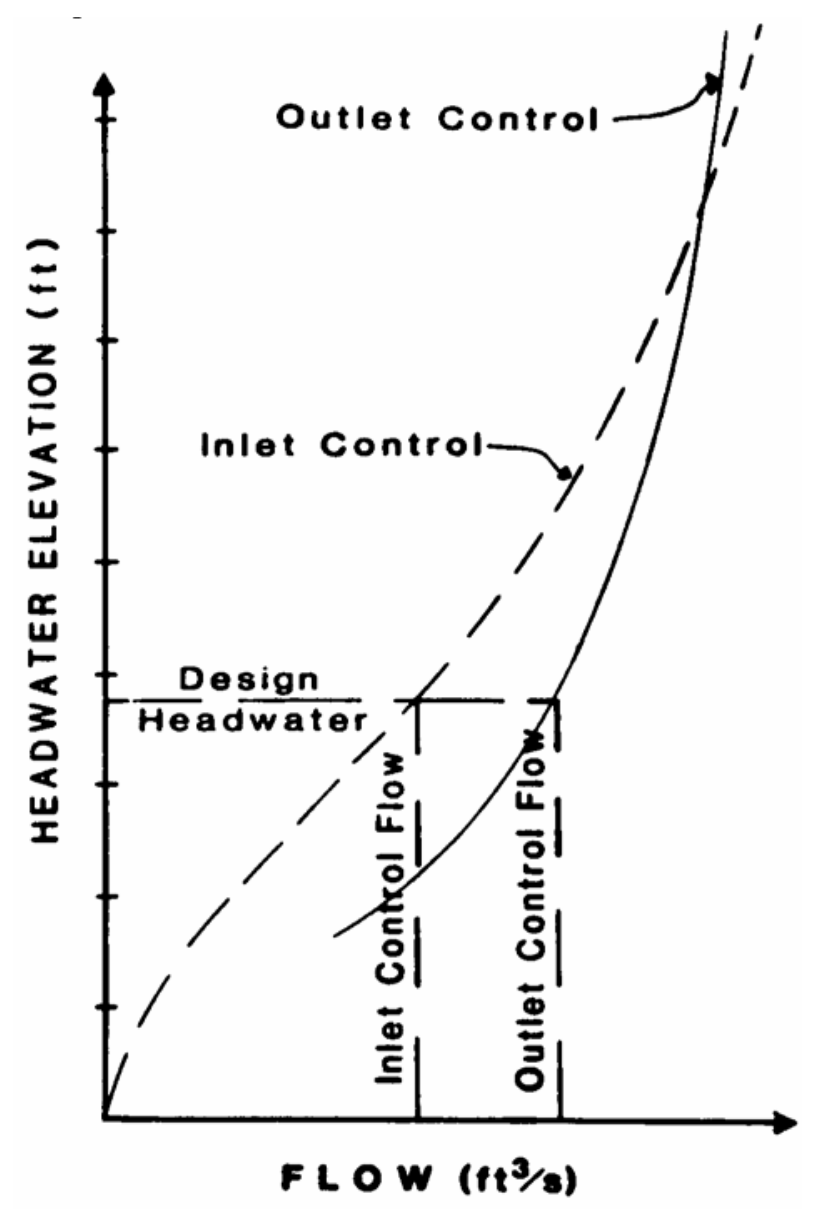

Figure 2.2.8. Culvert Performance Curve. Source: (Normann, et al., 1985). 


\subsection{Culvert Design Considerations}

The Federal Highway Administration's Hydraulic Design of Highway Culverts, (Normann, et al., 1985) specifies two factors that must be considered when designing a culvert. These design considerations for culvert installations include the hydrology and site data. A summary of all of these considerations may be found in Table 2.4. The objective of culvert design is to determine the most economical dimensions that can provide the passage of a design discharge without causing damage to the roadway or adjacent property.

\subsubsection{Hydrology}

Hydrologic analysis involves the estimation of a design flow rate and proper culvert size based on the climate at the site and the watershed characteristics. These are the most important aspects of culvert design. The size is determined by the volume of water that the culvert must pass without exceeding the allowable headwater elevation.

\section{Peak Design Flow}

As a flood wave passes a point along a stream, the flow increases to a maximum and then recedes. This maximum flow is called the peak flow. In culvert design, the structure is sized to pass this peak flow from one side of the roadway embankment to the other with an acceptable headwater elevation. A statistical analysis can be performed on the recorded stream flow data for gauged sites.

\section{Check Flows}

A proposed culvert installation should be evaluated for flows other than the peak design flow. It is good practice to check the culvert performance through a range of discharges to determine the optimal operating conditions. Check flows are determined in the same way as the peak design flow.

\section{Hydrograph}

The entire flood hydrograph at a culvert site must be defined if upstream storage is to be considered in the design. A flood hydrograph is a plot of discharge versus time. Actual hydrographs can be obtained using stream gauge records. These measured storm events can then be used to develop design flood hydrographs. When the site gauge data are not available,

empirical or mathematical methods such as the Snyder or SCS synthetic hydrograph methods can be used to generate a design flood hydrograph. 


\subsubsection{Site Data}

The hydraulic design of a culvert structure requires the evaluation of several factors including culvert location and alignment, waterway data, roadway data, and the design headwater.

\section{Culvert Location and Alignment}

Alignment, slope, and elevation are three important factors to be considered in the location of a culvert for maximum efficiency, economy, and safety. To maintain natural drainage and hydraulic efficiency, a culvert should be located in the existing channel bed. Sometimes the culvert will follow the natural channel alignment; while at other times, the channel is relocated to reduce the culvert length or for some other reason. The slope of a culvert will closely follow the existing channel. The culvert invert is usually installed at the channel bed elevation.

\section{Waterway Data}

The installation of a culvert to convey surface water through an embankment significantly constricts the flood plain. In order to predict this effect, accurate waterway data

must be collected prior to beginning the construction. Waterway data includes cross sectional information, stream slope, the hydraulic resistance of the stream channel and floodplain, any condition affecting the downstream water surface elevation, and the storage capacity upstream of the culvert. Most of these data may be obtained from field surveys, topographic maps, or photographs of the site location.

\section{Roadway Data}

The proposed or existing roadway affects the culvert cost, length, alignment and hydraulic capacity. Some of the data needed relating to the roadway includes the cross sectional information, the culvert length (determined by how the culvert crosses the proposed or existing road), and the roadway profile. This information may be obtained from roadway drawings or from standard details on roadway sections.

\section{Design Headwater}

The most economical culvert is one that will use all of the available headwater to pass the design discharge. The available headwater elevation must be determined because the discharge capacity increases with increasing head. The design headwater elevation depends on economics; critical roadway points from the roadway plans (i.e., high and low points); surrounding buildings 
and structures found from photographs or surveys; regulatory constraints and other arbitrary constraints.

\section{Table 2.4. Data Requirements for Culvert Design * \\ DATA}

\section{SOURCE}

Peak Flow

Check Flows

Hydrographs (if storage routing is utilized)

Culvert Location

Waterway Data

Cross Section

Longitudinal Slope

Resistance

Tail water

Upstream storage

Roadway Data

Cross Section
Profile
Culvert Length
Critical points on roadway
Surrounding buildings or structures
Regulatory Constraints

Arbitrary Constraints
Stream gage analysis or calculated using Rational Formula, SCS Method, regression equations, etc.

From stream gage information or synthetic development methods such as SCS Method, Snyder Method, or computer models.

Based on site characteristics including natural stream section, slope and alignment

Field survey or topographic maps

Field survey or topographic maps

Observation, photographs, or calculation methods

Field survey or topographic maps

Field survey or topographic maps

Roadway plans

Roadway plans

Roadway plans

Roadway plans

Aerial photographs, surveys, or topographic maps

Floodplain and flood insurance regulations for stream reach of interest

State or local regulations for culvert installations

* Source: (Normann, et al., 1985) 


\subsection{Culvert Design Methods}

Several culvert design methods have been developed to aid the designer in selecting an appropriate culvert for a specific location. Each state has developed its own method based on FHWA's Hydraulic Design of Highway Culverts, (Normann, et al., 1985), the American Association of State Highway and Transportation Officials (AASHTO) recommendations, and experience compiled by other states. Since the research presented within the body of this report is for the State of West Virginia, the manual method presented here is the one recommended by the West Virginia Division of Highways (WVDOH) Drainage Manual, 1984.

Procedure for the Selection of a Culvert:

The West Virginia Division of Highways designs and analyzes culvert structures using form DR-4, as demonstrated in Figure 2.3. This form is used in the following manner:

1 List the design data on Form DR-4, Figure 2.3:

A Design discharge $Q$, with the average return period, (i.e., $Q_{25}$ or $Q_{50}$, etc.)

B Approximate length, $L$, of culvert in feet.

C Slope of culvert in $\mathrm{ft} / \mathrm{ft}$.

D Allowable headwater depth in feet. This is the vertical distance from the culvert invert at the entrance to the water surface.

E $\quad$ Mean and maximum flood velocities in the natural stream

F Type of culvert for first trial selection, including barrel material, barrel cross-sectional shape and entrance type.

2 Determine the first trial size culvert. Since the procedure given is one of trial and error, the initial trial size can be determined in several ways:

A By arbitrary selection.

B By using an approximating equation such as $Q / 10=A$ from which the trial culvert dimensions are determined.

C By using inlet control nomographs for the culvert type selected. If this method is used $H W / D$ must be assumed, say $H W / D=1.2$, and using the given $Q$, a trial size is determined.

If the trial size is too large due to limited height of embankment or availability of barrel size, multiple-barrels may be used. The size of the individual barrels is estimated by dividing 
the discharge equally between a number of barrels. Raising the embankment height or the use of pipe arch and box culverts with widths greater than height should also be considered. Final selection should be based on an economic analysis.

3 Find a headwater depth for the trial size culvert.

A Assuming Inlet Control.

(1) Using the trial size from Step 2, find the headwater depth $(H W)$ by use of the appropriate inlet control nomograph. Tail water (TW) conditions are neglected in this determination. HW in this case is found by multiplying HW/D obtained from the nomographs by the height of the culvert, $D$.

(2) If $H W$ is greater or less than the allowable, try another trial size until $H W$ is acceptable for inlet control condition before computing $H W$ for outlet control.

B Assuming Outlet Control.

(1) Approximate the depth of tail water (TW) in feet above the invert at the outlet for the design flood condition in the outlet channel.

(2) For tail water (TW) elevation equal to or greater than the top of the culvert at the outlet, set $h_{o}$ equal to $T W$ and find $H W$ by the following equation:

$$
H W=H+h_{o}-L S_{o}
$$

where: $\quad H W=$ vertical distance from culvert invert at the entrance to the pool surface in $\mathrm{ft}(\mathrm{m})$.

$H \quad=$ head loss determined from appropriate nomograph in $\mathrm{ft}(\mathrm{m})$.

$h_{o} \quad=$ vertical distance from the culvert invert at the outlet to the hydraulic grade line in $\mathrm{ft}(\mathrm{m})$. (In this case, $h_{o}=T W$ measured above the culvert invert.)

$S_{o} \quad=$ slope of the barrel in $\mathrm{ft} / \mathrm{ft}(\mathrm{m} / \mathrm{m})$.

$L \quad=$ culvert length in $\mathrm{ft}(\mathrm{m})$.

(3) For tail water (TW) elevations less than the top of the culvert at the outlet, find headwater $(H W)$ by the equation in B (2) above except that:

$h_{o}=\frac{d_{c}+D}{2} \quad$ or $T W$, whichever is greater.

Where: $\quad d_{c} \quad=$ critical depth in $\mathrm{ft}(\mathrm{m}) .\left(d_{c}\right.$ cannot exceed $\left.D\right)$ 


$$
D \quad=\text { height of the culvert opening in } \mathrm{ft}(\mathrm{m}) \text {. }
$$

Note: The headwater depth determined in B (3) becomes increasingly less accurate as the headwater computed by this method falls below the value of:

$$
D+\left(1+k_{e}\right) \frac{V^{2}}{2 g}
$$

C. Compare the headwaters found in Step 3a and Step 3b (inlet and outlet control). The higher headwater governs and indicates the flow control existing under the given conditions for the trial size selected.

D. If outlet control governs and the $H W$ is higher than is acceptable, select a larger trial size and find $H W$ as instructed under step 3B. (Inlet control need not be checked, since the smaller size was satisfactory for this control as determined under Step 3A.)

4 Try a culvert of another type or shape and determine the size and $H W$ by the above procedure.

5 Compute the outlet velocities for size and types to be considered in the selection and determine the need for channel protection.

A If outlet control governs in Step 3c above, the outlet velocity equals $Q / A_{o}$, where $A_{o}$ is the cross-sectional area of flow in the culvert barrel at the outlet. If dc or $T W$ depth is less than the height of the culvert barrel use $A_{o}$ corresponding to dc or $T W$ depth, whichever gives the greater area of flow. $A_{o}$ should not exceed the total cross-sectional area $(A)$ of the culvert barrel.

B If inlet control governs in Step 3c, the outlet velocity can be assumed to equal the mean velocity in open-channel flow in the barrel as computed by Manning's equation for the rate of flow, barrel size, roughness and slope of culvert selected.

6 Record the final selection of the culvert with the size, type, required headwater, outlet velocity, and economic estimate justifications. 


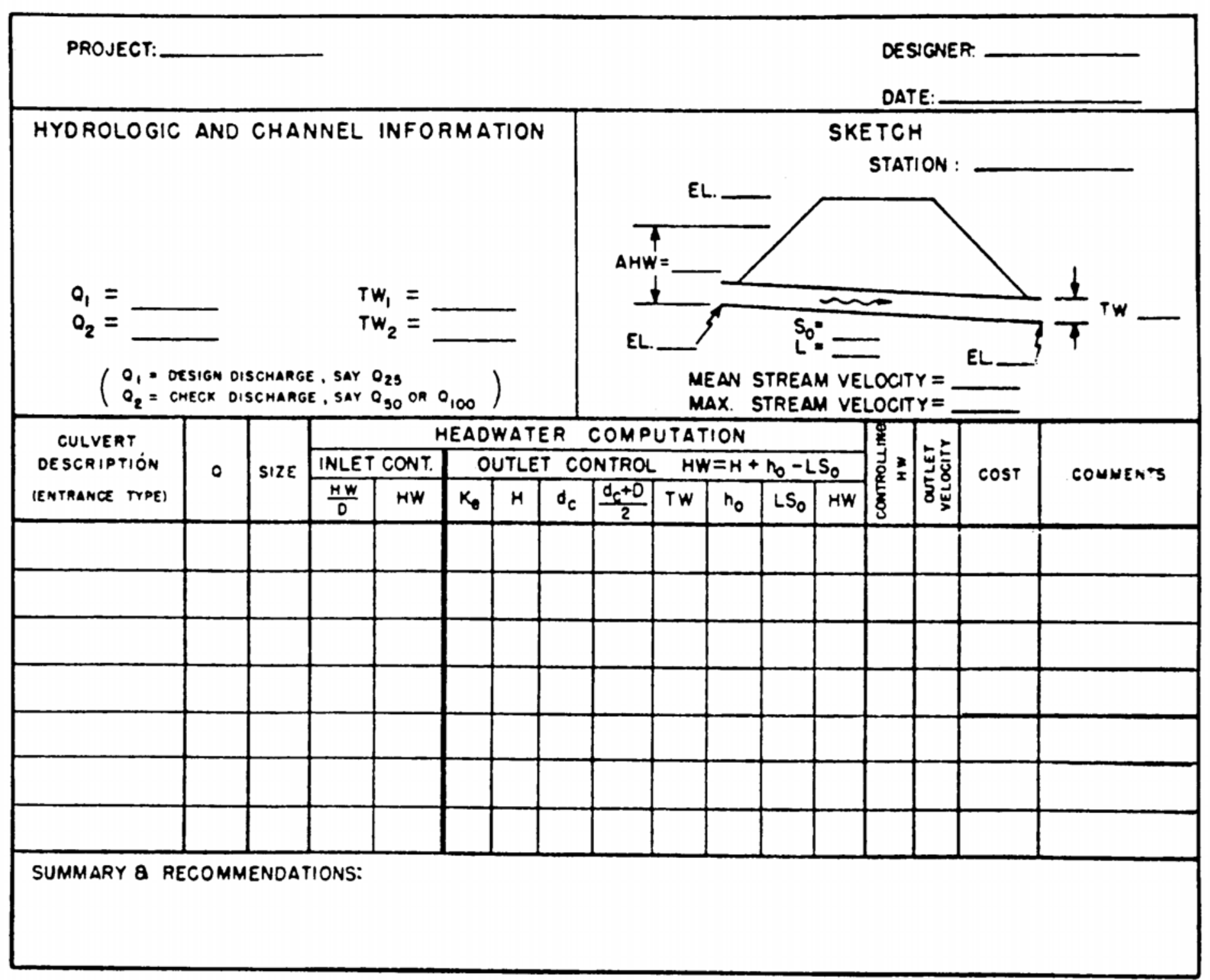

Figure 2.3. Form DR -4. Source: (Normann, et al., 1985). 


\subsubsection{Computer Models}

There are several different computer programs available for the design and analysis of culvert systems. Many of these software programs are compared to the capabilities pertinent to this project in this section.

HYDRAIN integrates nine separate hydrologic and hydraulic programs within a software shell. The sub-programs HYCLV and HY8 deal specifically with culvert design and analysis. These programs will analyze and design circular, rectangular, elliptical, and arch culvert shapes. They also allow the investigation of conventional and improved inlets for these culvert types. The hydraulic characteristics of different culvert types occurring at the same site can also be investigated.

HYCLV is based on the theoretic weir and orifice inlet coefficients, step backwater methods, and submerged weir theory (Young and Krolak, 1993).

HY8 allows storage and routing considerations, as well as energy dissipation alternatives, by using hydrologic principles such as the hydrograph routing (Young and Krolak, 1993). This program will simultaneously analyze up to six different culvert design scenarios at a given site with up to fifteen barrels each in a scenario. HY-8 contains a wide range of features that can be used by both beginning and experienced users familiar with the design methods described in HDS No. 5, HEC No. 14, and HEC No. 19. This program analyzes any shape of culvert such as circular, box, elliptical, arch, and many others. It also allows for the design of energy dissipaters. A variety of variables can be inputted; for example, stations and elevations, inlet edge conditions, maximum discharge, tail water elevation, and headwater elevation. HY-8 generates performance tables for individual and multiple culverts and plots curves for inlet and outlet control. It also generates storm hydrographs.

THYSYS is a tool for analyzing and designing inlets, storm sewer systems, culverts, and open channels. It can develop design flows using the Rational Method, gauged data, or flows can be entered directly. THYSYS can compute the hydraulic grade line for storm sewer networks and takes into account inlet capture and carryover. Pipe or inlet sizes can be entered directly, or the program can estimate the required sizes. The program performs inlet-outlet control computations using standard circular, arch, or box shaped culverts. Culverts can be analyzed separately or included in an entire series of open channel backwater computations. 
Haestad Methods has software called Culvert Master that can solve for different culvert configurations. They use the HDS-5 methods to perform hydraulic calculations for both inlet and outlet control. Culvert Master is a Windows-based program that helps design and analyzes culverts. This program is an easy-to-use tool that can solve culvert hydraulic problems from single barrel to complex multiple barrel culverts with roadway overtopping. It also provides the ability to size pipes and compute performance curves. All output can be graphically displayed both on the screen and in printed reports. The program will determine inlet or outlet control, based on the input data.

FHWA has an interactive CD-ROM that is an electronic version of the publication, Hydraulic Design of Highway Culverts, (Normann, et al., 1985). This software is designed as a tool for the user to have the ability to perform the same analysis as the HDS-5 manual.

However, the CD-ROM will solve for head for culverts greater than 500 feet in length, whereas the charts are limited to 500 feet or less.

The United States Geological Society has software entitled Culvert Analysis Program, CAP that follows USGS standardized procedures for computing flow through culverts. It can be used to develop stage-discharge relationships for culverts and to determine discharge through culverts from high water marks. It will compute flows for rectangular, circular, pipe arch, and other nonstandard shaped culverts. The program solves the 1-D steady-state energy and continuity equations for upstream water-surface elevation given a discharge and a downstream water-surface elevation. 


\section{CHAPTER 3 - INTRODUCTION TO FUZZY LOGIC}

\subsection{Defined}

Fuzzy logic is a powerful problem-solving methodology with a myriad of applications in embedded control and information processing. It provides a remarkably simple way to draw definite conclusions from vague, ambiguous or imprecise information. In a sense, fuzzy logic resembles human decision making with its ability to work from approximate data and find precise solutions. It is a convenient way to map an input space to an output space. Fuzzy logic does a remarkable job of trading off between significance and precision - which humans have been managing for centuries.

Precision describes exactly what is happening. For example, consider a large truck that is about to merge into your lane, while driving on an interstate highway. The precise statement may be: “A 3,456-pound truck is merging into your lane at an angle of ten degrees and will strike the front of your vehicle in two seconds." However the significance is a quick method to describe the same situation. In the same example, the significant statement may be: "LOOK OUT!”

Unlike classical logic which requires a deep understanding of a system, exact equations, and precise numeric values, fuzzy logic incorporates an alternative way of thinking, which allows modeling complex systems using a higher level of abstraction originating from our knowledge and experience. Fuzzy logic allows expressing this knowledge with subjective concepts such as very hot, bright red, and a long time which are mapped into exact numeric ranges.

Fuzzy logic has been gaining increasing acceptance during the past few years. There are thousands of commercially available products using fuzzy logic, ranging from washing machines to high speed trains. Nearly every application can potentially realize some of the benefits of fuzzy logic, such as performance, simplicity, lower cost, and productivity.

Fuzzy logic has been found to be very suitable for embedded control applications. Several manufacturers in the automotive industry are using fuzzy technology to improve quality and reduce development time. In aerospace, fuzzy enables very complex real time problems to be tackled using a simple approach. In consumer electronics, fuzzy logic improves time to market and helps reduce costs. In manufacturing, fuzzy logic is proven to be invaluable in increasing equipment efficiency and diagnosing malfunctions. 


\subsection{Beginnings}

Fuzzy logic was developed by Dr. Lotfi A. Zadeh, of the University of California in Berkley. He was a professor in the Graduate School for the Department of Electrical Engineering and Computer Sciences. Dr. Zadeh's first important work was his doctoral dissertation on the frequency analysis of time-varying networks, (Zadeh, 1950). In this work, he introduced the concept of a time-varying transfer function, a concept which in the intervening years has found significant applications in the analysis of linear time-varying systems, and has gained him his first international recognition. He described an important generalization of Wiener's theory of prediction. This work has found numerous applications in the design of finitememory filters and predictors and is widely regarded as a classic in its field (Zadeh and Ragazzini, 1950). He pioneered in the development of the z-transform approach to the analysis of sampled-data systems. This approach has become a standard method for the analysis of such systems and is widely used in the design of control systems and digital filters. Later, he developed a novel approach to the design of nonlinear filters and constructed a hierarchy of nonlinear systems based on the Volterra-Wiener representation. This approach has provided a basis for the design of optimal nonlinear processors for the detection of signals in noise (http://www.cis-ieee.org/eit2003/zadeh.asp).

In 1963, Lotfi Zadeh co-authored with Charles Desoer their classic text on the state-space theory of linear systems. This book is widely regarded as a landmark in the development of the state-space approach and its application to control and systems analysis. The state-space approach is now the standard tool in optimal control and is widely used in the analysis of a variety of systems ranging from industrial robots to space guidance control (Zadeh and Desoer, 1963).

Prior to the publication of his seminal paper on fuzzy sets in 1965, Dr. Zadeh was recognized both nationally and internationally as one of the leading contributors to the development of system theory and its applications. His paper on fuzzy sets marked the beginning of a new direction; by introducing the concept of a fuzzy set, that is, a class with un-sharp boundaries, he provided a basis for a qualitative approach to the analysis of complex systems in which linguistic rather than numerical variables are employed to describe system behavior and performance. 
Subsequent to his 1965 publication, Dr. Zadeh has made a number of basic contributions to the theory of fuzzy sets and its applications. A measure of the wide-ranging impact of Dr. Zadeh's work on fuzzy logic is the number of papers in the literature on the subject of fuzzy logic. There were over 38,000 literary works cited between 1970 and 2000, (http://www.cisieee.org/eit2003/zadeh.asp).

\subsection{Overview}

Many decision-making and problem-solving tasks are too complex to be understood quantitatively, however, people succeed by using knowledge that is imprecise rather than precise. Fuzzy set theory resembles human reasoning in its use of approximate information and uncertainty to generate decisions. It was specifically designed to mathematically represent uncertainty and vagueness and provide formalized tools for dealing with the imprecision intrinsic to many problems. By contrast, traditional computing demands precision down to each bit. Since knowledge can be expressed more naturally by using fuzzy sets, many engineering and decision problems can be greatly simplified.

Fuzzy set theory implements classes or groupings of data with boundaries that are not sharply defined, thus the nickname 'fuzzy' was created. Any methodology or theory implementing crisp definitions such as classical set theory, arithmetic, and programming, may be utilized with fuzzy logic, by generalizing the concept of a crisp set to a fuzzy set with blurred boundaries. The benefit of extending crisp theory and analysis methods to fuzzy techniques is the strength in solving real-world problems, which inevitably entail some degree of imprecision and noise in the variables and parameters measured and processed for the application. Accordingly, linguistic variables are a critical aspect of some fuzzy logic applications, where general terms such a large, medium, and small are each used to capture a range of numerical values. While similar to conventional quantization, fuzzy logic allows these stratified sets to overlap. For example, a 185-pound person may be classified in both the large and medium categories, with varying degrees of belonging or membership to each group. Fuzzy set theory encompasses fuzzy logic, fuzzy arithmetic, fuzzy mathematical programming, fuzzy topology, fuzzy graph theory, and fuzzy data analysis, though the term fuzzy logic is often used to describe all of these.

Fuzzy logic emerged into the mainstream of information technology in the late 1980's and early 1990's. Fuzzy logic is a departure from classical Boolean logic in that it implements soft linguistic variables on a continuous range of truth values which allows intermediate values to be 
defined between conventional binary variables. It can often be considered a superset of Boolean or crisp logic in the way fuzzy set theory is a superset of conventional set theory. Since fuzzy logic can handle approximate information in a systematic way, it is ideal for controlling nonlinear systems and for modeling complex systems where an inexact model exists or systems where ambiguity or vagueness is common. A typical fuzzy system consists of a rule base, membership functions, and an inference procedure.

\subsection{Neural Networks}

An artificial neural network is an information-processing paradigm inspired by the way the densely interconnected, parallel structure of the human brain processes information. Neural networks are collections of mathematical models that emulate some of the observed properties of biological systems and draw on the analogies of adaptive learning. The key element of the neural network paradigm is the novel structure of the information processing system. It is composed of a large number of highly interconnected processing elements that are analogous to neurons and are tied together with weighted connections that are analogous to synapses (Carling, 1992).

The most basic components of neural networks are modeled after the structure of the brain. Neural networks have a strong similarity to the biological brain and therefore a great deal of the terminology is borrowed from neuroscience.

Learning in systems involves adjustments to the synaptic connections that exist between the neurons. This is true of neural networks as well. Learning typically occurs by example through training, or exposure to a tested set of input/output data where the training algorithm iteratively adjusts the connection weights (synapses). These connection weights store the knowledge necessary to solve specific problems.

Although neural networks have been around since the late 1950's, it wasn't until the mid1980's that algorithms became sophisticated enough for general applications. Today they are being applied to an increasing number of real- world problems of considerable complexity. They are good pattern recognition engines and robust classifiers, with the ability to generalize in making decisions about imprecise input data. They offer ideal solutions to a variety of classification problems such as speech, character and signal recognition, as well as functional prediction and system modeling where the physical processes are not understood or are highly complex. Neural networks may also be applied to control problems, where the input variables are measurements used to drive an output actuator, and the network learns the control function. 
The advantage of neural networks lies in their resilience against distortions in the input data and their capability of learning. They are often good at solving problems that are too complex for conventional technologies, meaning problems that do not have an algorithmic solution or for which an algorithmic solution is too complex to be found. Additionally, they are often well suited to problems that humans are good at solving, but for which traditional methods are not (http://www.ieee-nns.org).

\subsection{Neuro-Adaptive Learning Techniques}

When it is desired to apply fuzzy logic to a system for which there is a known set of input/output data that is desired to be used for modeling, there is a neuro-adaptive learning technique that may be used. The basis behind this learning technique is to provide a method for the fuzzy modeling procedure to learn information about a data set, in order to compute the membership function parameters that best allow the associated fuzzy inference system to track the given input/output data. This method is similar in nature to that of neural networks. This cross-pollination between fuzzy logic and neural networks has spawned a new approach to modeling: Adaptive Neuro-Fuzzy Inference System (ANFIS). ANFIS takes a given input/output data set and constructs a fuzzy inference system whose membership function parameters are tuned, or adjusted, using either a back propagation algorithm alone or in combination with a least squares type of method (Mathworks, 2001).

\subsection{Example}

The MatLab fuzzy logic toolbox, (from Math Works, Inc.), was utilized to provide Fuzzy Logic modeling capability for this study. In order to explain how the MatLab Neural Fuzzy logic editor operates, a simple example is provided. This example uses inputs of Discharge and Headwater to determine a culvert diameter. Figure 3.1 shows the logic behind how the model arrives at an output. If the discharge is small and the headwater is low, then the diameter will be small. If the discharge is moderate and there is no headwater, then the diameter will be medium. If the discharge is large or if the headwater is extreme, then the diameter will be high. At the bottom of each of the two inputs and one output are the descriptions in "fuzzy" terms, such as small, medium, or large. The final output is a weighted average which transforms the "fuzzy" input values via membership functions, and combines them to produce a final numerical value. A final numerical value is more useful in culvert design. If a culvert designer were to specify 
that a 'small' pipe needed to be placed under a roadway fill, it would not suit the needs of the contractor, who may have a different interpretation of a 'small' pipe.

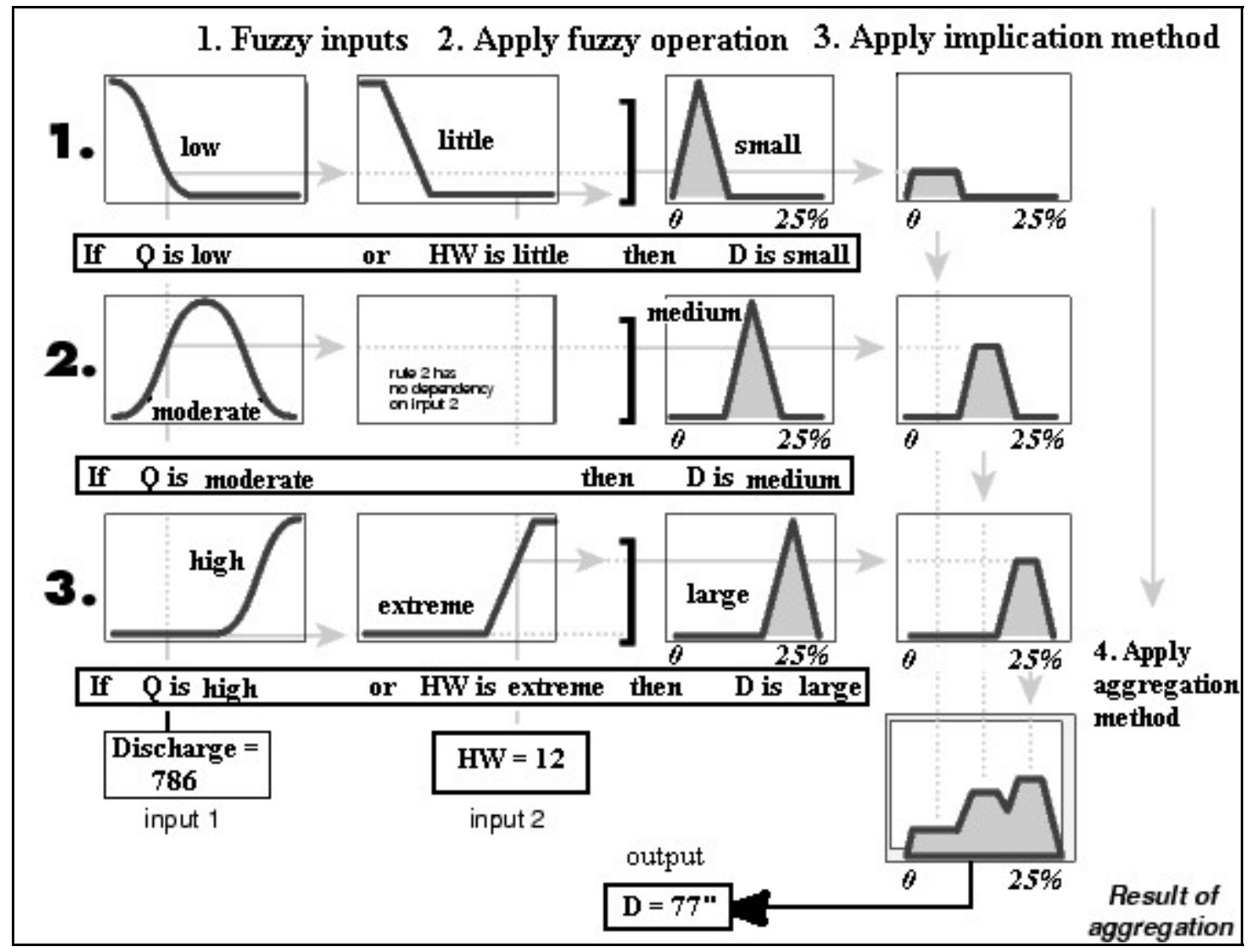

Figure 3.1. Example of how the MatLab Neural-Fuzzy logic editor processes data and arrives at an output.

The example data shown in Figure 3.1 were processed in the ANFIS editor and the results are shown below in Figure 3.2. A discharge of 786 cubic feet per second, and a headwater of 12 feet result in a diameter of 76.8 inches. This is a screen capture from Type five data that was analyzed and will be reported later. Another useful note is that the input variables may be adjusted on this MatLab screen to accommodate a particular situation. The corresponding output diameter is displayed with each change in input variables. 


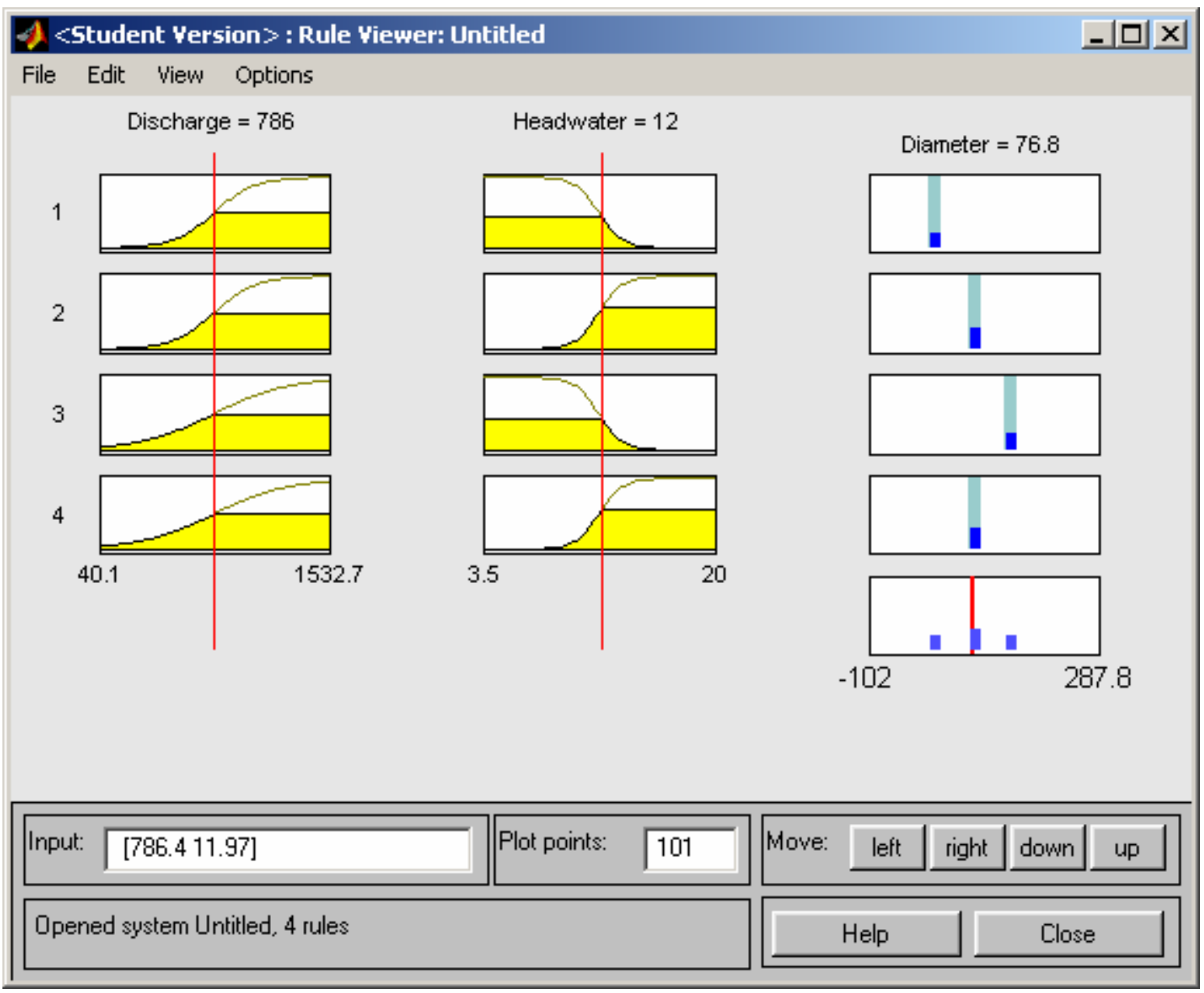

Figure 3.2. Screen capture of results from two input variables and one output variable from the ANFIS editor for example of Figure 3.1. 


\section{CHAPTER 4 - EXPERIMENTAL PROCEDURES}

The software selected to utilize Fuzzy Logic was MatLab from Math Works, Inc. Part of the MatLab package is the toolbox function: Adaptive Neural-Fuzzy Inference System (ANFIS). This powerful tool takes a given input and output data set and constructs a Fuzzy Inference System (FIS) whose Membership Functions (MF) are adjustable. This allows the fuzzy system to learn from the data it is modeling. The specific procedure for analyzing a data set in MatLab can be found in Appendix A.

\subsection{Membership Functions}

An investigation of all available Membership Functions (MF) was conducted in an attempt to determine the optimum type of function for use with the present model. The different available membership functions and their description are provided. A representative plot showing the shape of the membership functions can be found in Appendix B. Triangular (trimf) is a collection of three points forming a triangle, Figure B.1. The trapezoidal (trapmf) has a flattened top and is a truncated triangle curve, Figure B.2. The advantage of these two straight membership functions is simplicity. The generalized bell membership function is specified by three parameters and has the function name (gbellmf), Figure B.3. A simple gaussian curve is represented by the (gaussmf) membership function, Figure B.4. A two-sided composite of two different gaussian curves describes the (gauss $2 \mathrm{mf}$ ) membership function, Figure B.5. The pi function (pimf), Figure B.6 which is named because of its shape, has zero on both extremes with a rise in the middle. The sigmoidal function, which can be open to the right or left, results in two functions; the difference between two sigmoidal functions (dsigmf), Figure B.7, and finally the product of two sigmoidal functions (psigmf), Figure B.8.

The difference between two sigmoidal functions (dsigmf), Figure B.7, was selected as the type to be used for all initial model runs. Appendix B shows a comparison of all of the membership functions run against a representative data set. It was initially concluded that the dsigmf was the best membership function for use in modeling culvert data, based on subjective comparison of the goodness of performance. Therefore, this membership function was used for modeling in the first set of computational experiments.

\subsection{Number of Membership Functions}

In addition to comparing the different types of MF's, the number of MF's used in the fuzzy model was also studied. In general, the model error is reduced as the number of MF's 
increases. However, there are limitations to increased numbers of MF's. The more MF's selected, the longer the model will take to compute the fitting parameters of each MF. It was therefore decided to minimize the number of MF's, since levels of improvement were judged not to be significant in using higher numbers. Therefore, two membership functions were utilized for consistency across all models analyzed during the first set of computational experiments.

\subsection{Number of Training Epochs Used}

In the ANFIS editor, there is the option of number of epochs used during training. An epoch is defined as one presentation of the set of training data to the neural-fuzzy network, and the calculation of new weights and biases, that determine the change in MFD parameters. The optimum number of epochs used is determined when both the training and checking error definitions are reduced to a minimum. This error reduction over time will approach a minimum as the number of epochs continues to increase. A model can become over trained, if the number of epochs is allowed to exceed the point at which the checking data set error reaches a minimum value and then begins to increase. In order to graphically show this type of over training, a screen capture of the ANFIS editor is presented. The error decreases as the epochs increase for the training and checking data sets loaded into the ANFIS editor. As training proceeds, the training error decreases to a minimum; however this can be misleading, because the checking error will usually begin to increase after a minimum is reached. The optimal number of epochs corresponds to the point where the checking error is a minimum, before it begins to increase. In Figure 4.1 below, this point would be at approximately 160 epochs. 


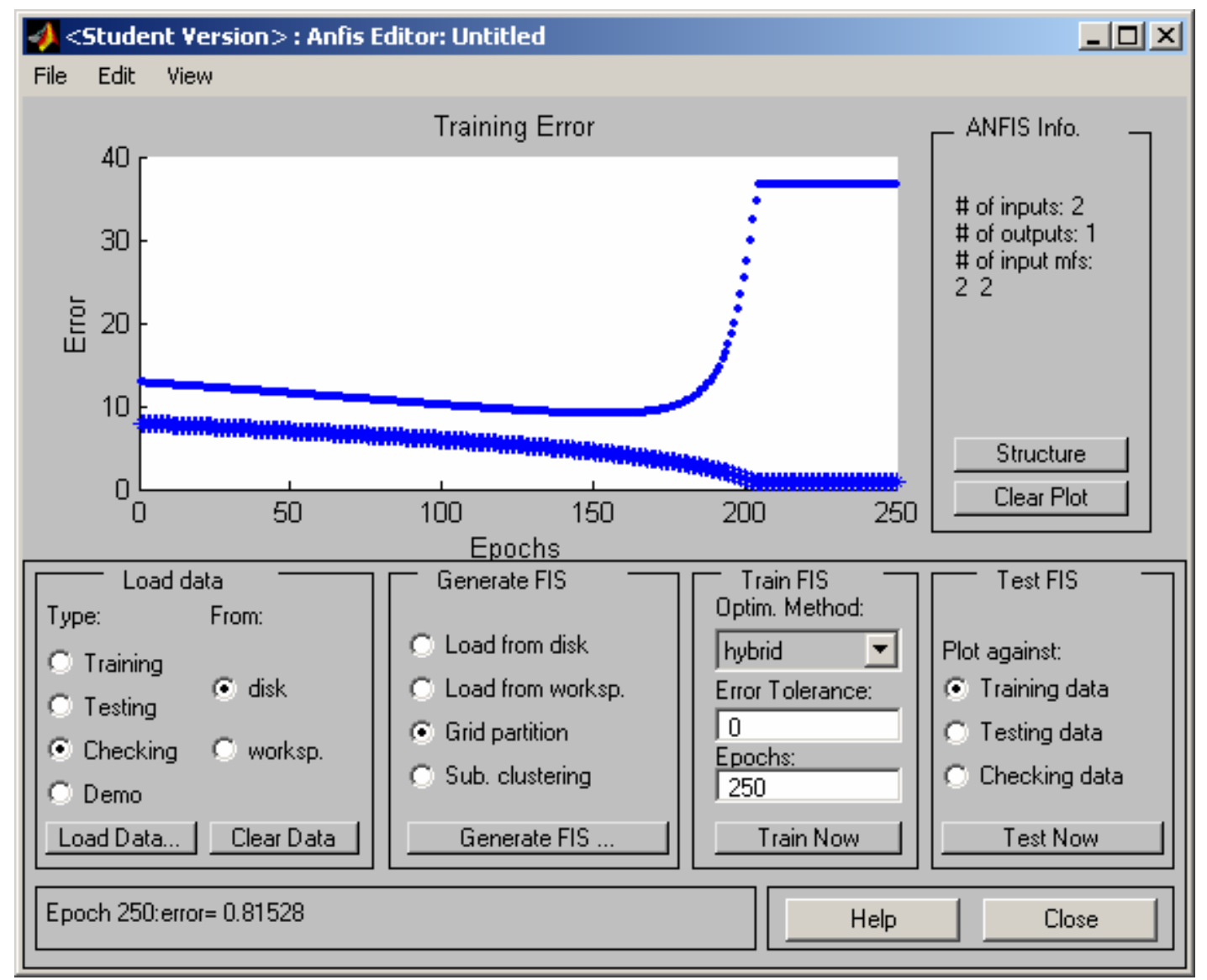

Figure 4.1. Screen capture of ANFIS editor showing the increase in checking error after minimum error was achieved.

An analogy to overtraining is over fitting a continuous function to a set of discrete data. This can be demonstrated by fitting a trend line to a curve by using a higher order polynomial an effort to achieve a better fit, or $\mathrm{R}^{2}$ value. This results in a better $\mathrm{R}^{2}$ value; however, as can be seen from the Figure 4.2 below, this resulting function will not do as good a job in interpolating values as compared to the lower order polynomial, as illustrated in Figure 4.3.

Figure 4.3 shows how well the curve follows the trend of the training, as well as the checking data sets, for a second order polynomial fit. This visual quality of the curve fit is better than the $\mathrm{R}^{2}$ value would otherwise indicate.

When comparing the results in Figure 4.2, to that in Figure 4.3, it will be noted that the mathematical fit in Figure 4.2 is perfect, as shown by the $\mathrm{R}^{2}$ value of 1.0 , while the visual fit leaves something to be desired. This comparison illustrates that while the mathematical fit may be better for a higher order polynomial, the true 'best-fit' lies with the simpler expression. 


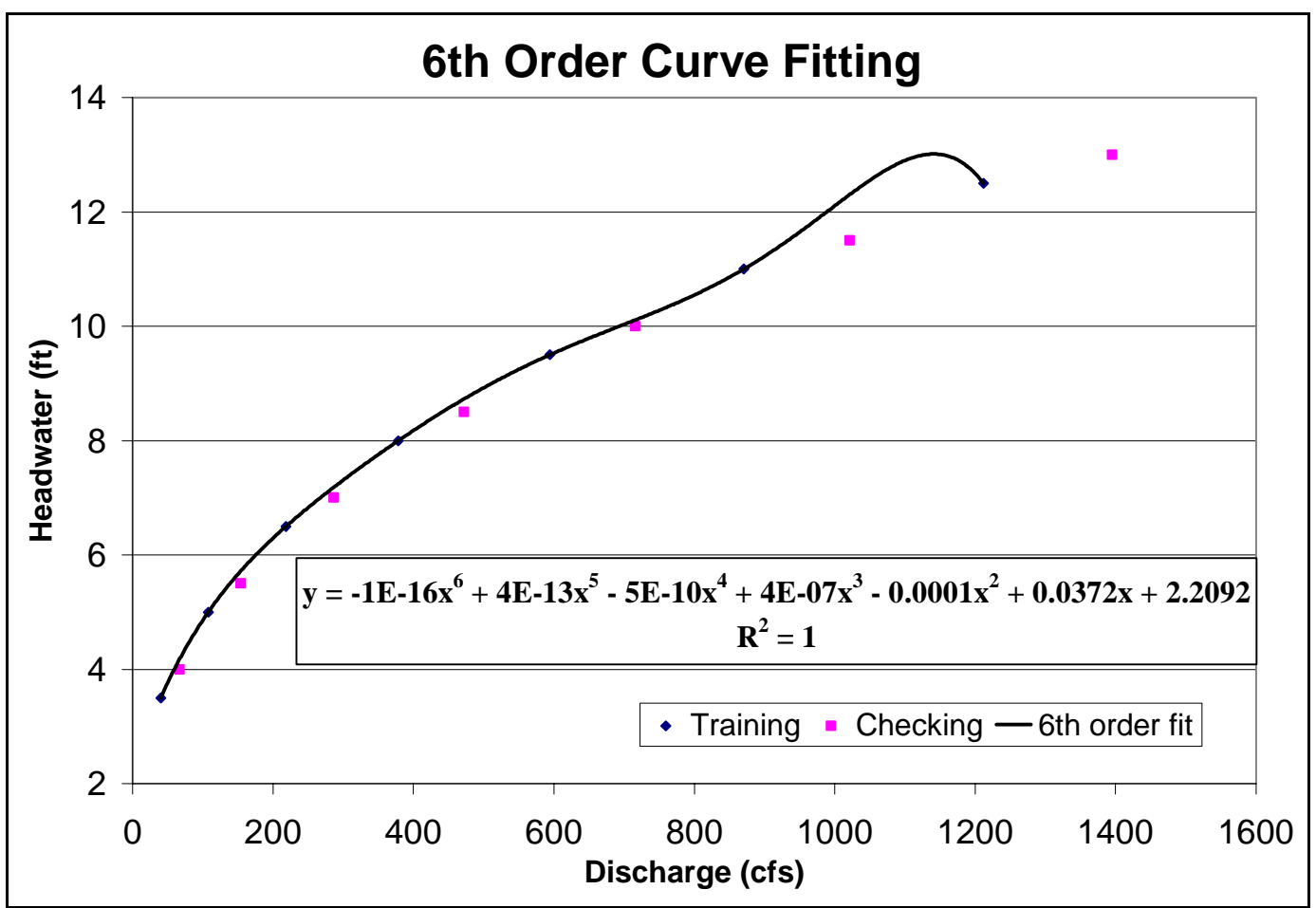

Figure 4.2. Plot of data with a sixth order trend line.

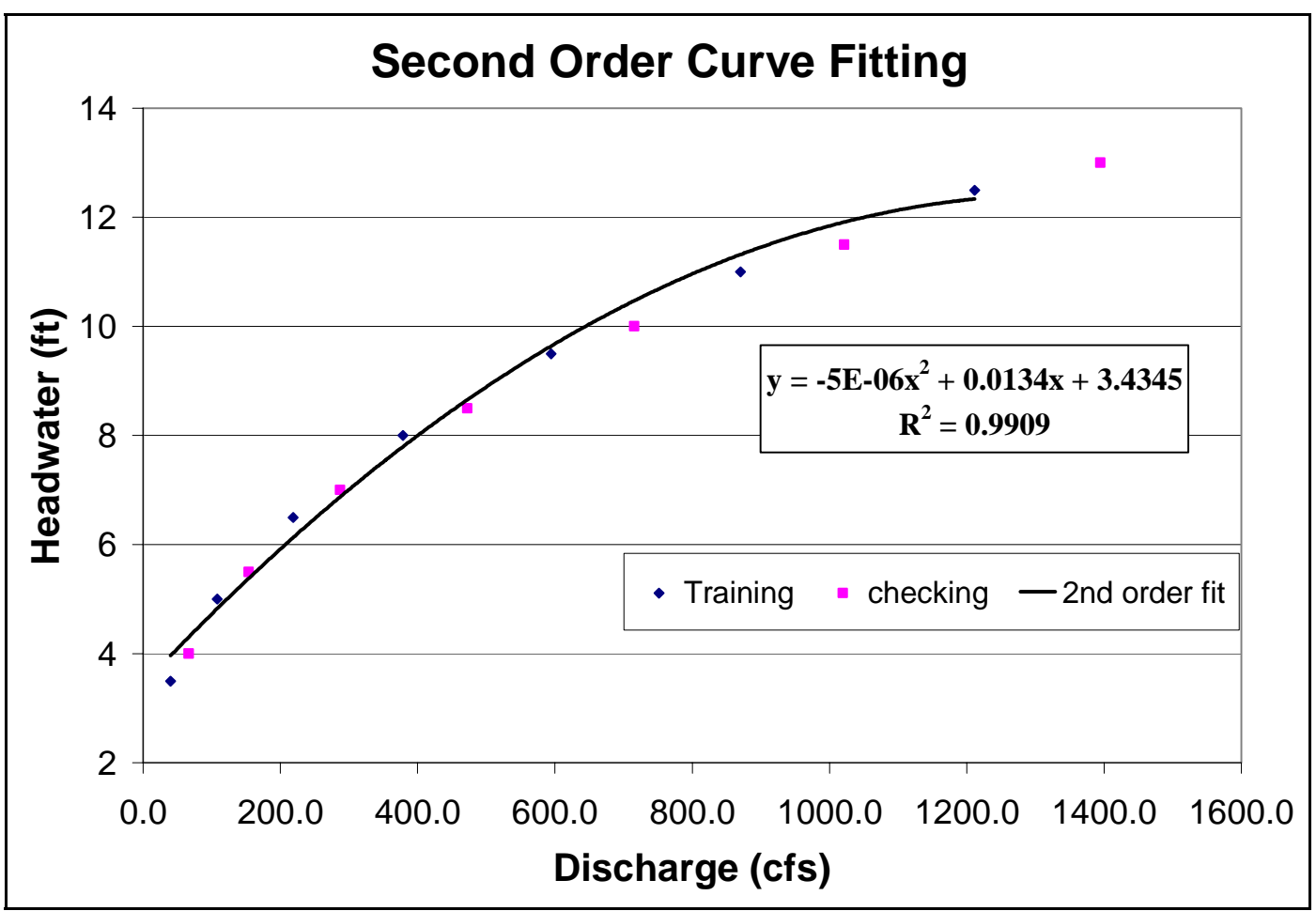

Figure 4.3. Plot of data with a second order trend line. 


\subsection{Data Generation Method}

In order to generate the data for use in training and checking the fit of the present neuralfuzzy logic model, the software Culvert Master, version 2.0 from Haestad Methods, was employed to calculate the head-water - discharge relationships. Haestad Methods required inputs of diameter, length, slope, headwater, and tail water to calculate discharge. To achieve results from as broad a spectrum as possible, the culvert diameters varied from 24 inches to 96 inches, incrementing by 12 inches. These seven diameters were the basis for the training data set that was produced. In addition to the variance in diameter, the headwater depth varied from zero to 20 feet, in two foot increments. The tail water depth values ranged from zero to nine feet using one foot increments. The values for length were 100, 250, 500, 750 and 1000 feet. These values of length caused the slope to vary according to the difference in elevation between the upstream invert and the downstream invert, $\Delta \mathrm{z}$. Values of $\Delta \mathrm{z}$ were $-0.1,-0.5$, and -1.0 feet. Haestad Methods allows the user to increment the headwater in 2 foot increments, which allowed eleven calculations at a time. Inputs of diameter, length, tail water, and $\Delta \mathrm{z}$, the calculated slopes, plus a range of headwaters, produced a set of eleven discharges. This process was repeated for each iteration, until the data set was complete. There were 11,550 lines of data in the data set, each one corresponding to a particular unique culvert flow condition.

In addition to this training data set, there had to be a set of data that was used as the checking data. This latter data set was computed by offsetting the diameter by six inches. The purpose of providing checking data is to prevent the ANFIS from over training. The checking data used also served as a validation of goodness of fit of the particular ANFIS model. These offset diameters began at 30 inches and increased in increments of twelve inches until reaching a maximum diameter of 102 inches. This checking data set was computed in the same manner as the training data set, but assigned a different file name. Table 4.1 shows the constraints of the input variables used to compile the data sets. In the end, this process was repeated 2,100 times to complete the entire training and checking data sets. These data were then exported into an Excel spreadsheet, which was then used to sort the data into columnar format, so that it could be exported as a text data file, for loading into the ANFIS editor.

Table 4.1. Range of input values for compilation of culvert data.

\begin{tabular}{|l|l|l|l|l|l|}
\hline Variable & Diameter (in) & Length (ft) & Head water (ft) & Tail water (ft) & Slope \\
\hline Range & $24-102$ & $100-1000$ & $0-20$ & $0-9$ & $0.0001-0.01$ \\
\hline
\end{tabular}


As already explained, the slope varied according to a relationship between length and difference in elevation. The range of slopes is derived from the difference in upstream and downstream inverts, $\Delta \mathrm{z}$, using the three values $-0.1,-0.5$ and -1 feet. A progression of complexity was introduced by using four separate representative data sets. The step1 data set had three variables; headwater, discharge and diameter. The tail water, slope and length were held constant at arbitrarily selected values. The step 2 data set had four variables; headwater, discharge, diameter, and tail water - holding slope and length constant. The step 3 data set had five variables; headwater, discharge, diameter, tail water slope - holding only the length constant. The final step, step 4, includes all six variables. Table 4.2 below summarizes the four different data sets, the variables held and varied, as well as the file size.

Table 4.2. Progression of variable complexity with corresponding row and column size for different data sets.

\begin{tabular}{|c|l|l|l|l|}
\hline Step & Hold & Vary & Rows & Columns \\
\hline 1 & $\mathrm{~S}_{\mathrm{o}}=0.004, \mathrm{~L}=250^{\prime}, \mathrm{TW}=2^{\prime}$ & HW, Q, D & 77 & 3 \\
\hline 2 & $\mathrm{~S}_{\mathrm{o}}=0.004, \mathrm{~L}=250^{\prime}$ & HW, Q, TW,D & 770 & 4 \\
\hline 3 & $\mathrm{~L}=250^{\prime}$ & HW, Q, TW, S, $\mathrm{D}$ & 2,310 & 5 \\
\hline 4 & N/A & HW, Q, TW, S, L, D & 11,550 & 6 \\
\hline
\end{tabular}

To provide an additional comparison, the data step 4 was expanded and analyzed using four new variables, defined based on combinations of the base variables. These new variables, the corresponding variables that were eliminated and resulting file size are listed in Table 4.3. The original six column file was also kept in order to compare the results of utilizing these combinations of variables. By combining variables, the idea was to reduce the number of input variables while not losing information content. Several relationships were utilized in order to combine variables. The total available head across the length of the culvert is described as the net head, Equation 4-1. A non-dimensional relationship relating the length and slope is also utilized, and characterized as the inverse elevation, Equation 4-2. The cubic root of the length and multiple of 100 times the slope are introduced in order to scale the magnitude of the variable to convenient values. The newly defined variables are listed in Table 4.3.

$$
\begin{gathered}
H_{n e t}=H W+S_{o} L-T W \\
z^{-1}=\frac{\sqrt[3]{L}}{100 S_{o}}
\end{gathered}
$$




\begin{tabular}{|c|l|l|}
\hline \multicolumn{3}{|c|}{ Table 4.3. } \\
\hline New variable & Variables eliminated & Resulting file size \\
\hline $\mathrm{Q} / \mathrm{H}_{\text {net }}$ & HW, TW, $\mathrm{S}_{0}, \mathrm{~L}, \mathrm{Q}$ & 8397R X 2C \\
\hline $\mathrm{H}_{\text {net }}$ & $\mathrm{HW}, \mathrm{TW}, \mathrm{S}_{0}, \mathrm{~L}$ & 8397R X 3C \\
\hline $\mathrm{HW}-\mathrm{TW}$ & $\mathrm{HW}, \mathrm{TW}$ & 8397R X 4C \\
\hline $\mathrm{z}^{-1}$ & $\mathrm{~L}, \mathrm{~S}_{0}$ & 8397R X 5C \\
\hline
\end{tabular}

\subsection{Classification of Culvert Types}

In order to describe the flow regime for a particular culvert, there are several variables that must be taken into account. Culverts can be generally described based on inlet or outlet control. According to Chow, (1959), and the United States Geological Survey, (1976), they can be further broken down into six different types. These different types were used to separate the data generated and each was analyzed separately according to type. The representative data for each type was extracted from the total data set, according to the constraints associated with that particular type. This provided a more detailed analysis for comparison purposes. The different types are summarized in the Table 4.4, and are illustrated in Figure 4.4.

\begin{tabular}{|c|l|l|l|}
\hline \multicolumn{5}{|c|}{ Table 4.4. Culvert types and their conditions. } \\
\hline Type & Description & Headwater relation & Tail water relation \\
\hline 1 & Critical Depth at Inlet & HW/D $<1.5$ & TW/ $/ \mathrm{y}_{\mathrm{c}}<1.0$ \\
\hline 2 & Critical Depth at Outlet & HW/D $<1.5$ & TW/y $\mathrm{y}_{\mathrm{c}}<1.0$ \\
\hline 3 & Tranquil flow throughout & HW/D $<1.5$ & TW/D $\leq 1.0$ \\
\hline 4 & Submerged Outlet & HW/D $>1.0$ & TW/D $>1.0$ \\
\hline 5 & Rapid flow at inlet & HW/D $\geq 1.5$ & TW/D $\leq 1.0$ \\
\hline 6 & Full flow - free outfall & HW/D $\geq 1.5$ & TW/D $\leq 1.0$ \\
\hline
\end{tabular}




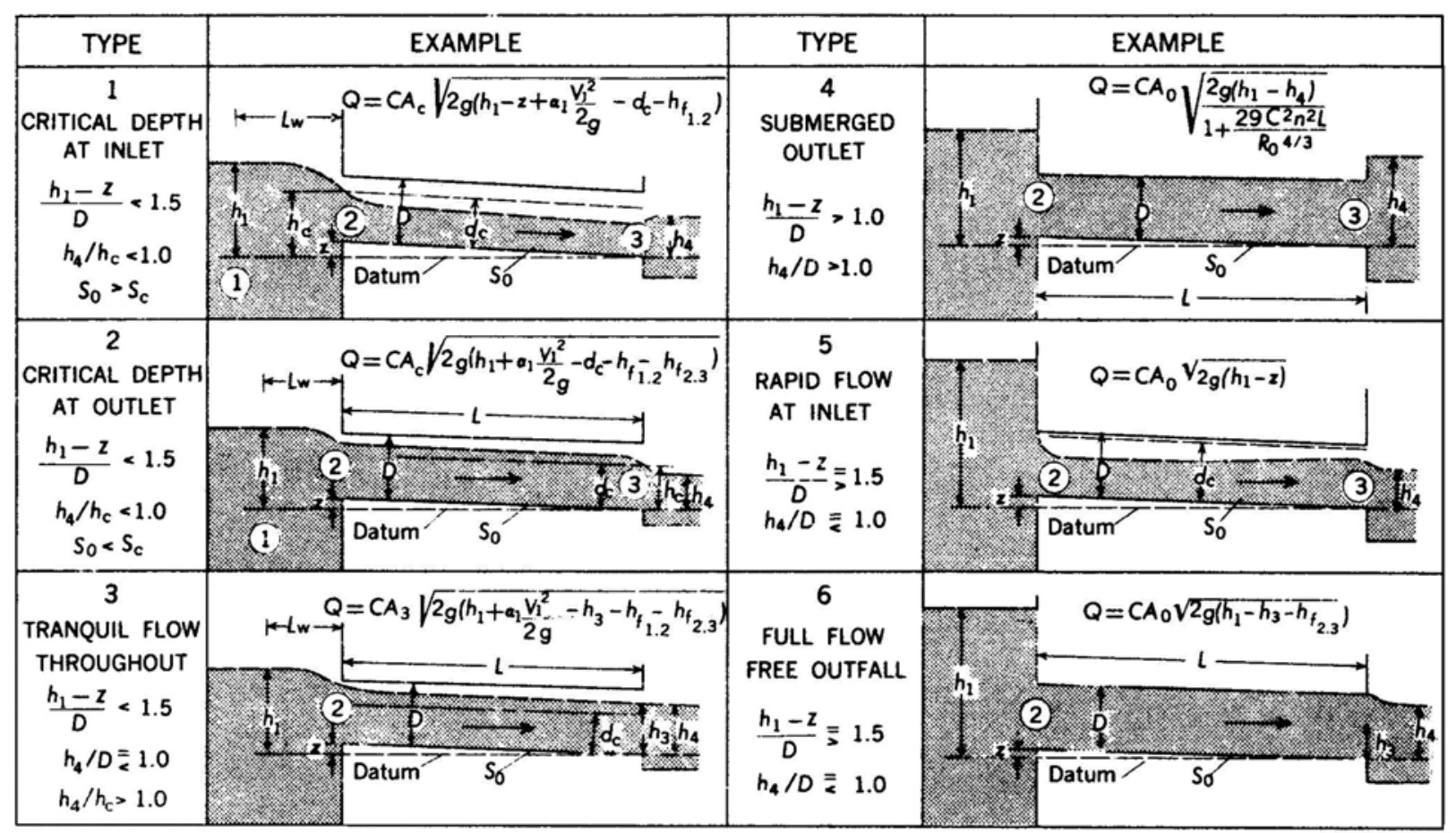

Figure 4.4. Six different culvert types and their description. Source: USGS, 1976.

The ANFIS models were collected and combined into an application method. The input variables are first checked for validity to ensure that they fall into the ranges that were discussed in section 4.4 and listed in Table 4.1. This method determines the culvert type by evaluating the input variables based on the conditions of each culvert type, which were listed in Table 4.4, and Figure 4.4. Then the corresponding fuzzy inference system is accessed to determine the culvert diameter. This process is depicted below in the flow chart in Figure 4.5. 


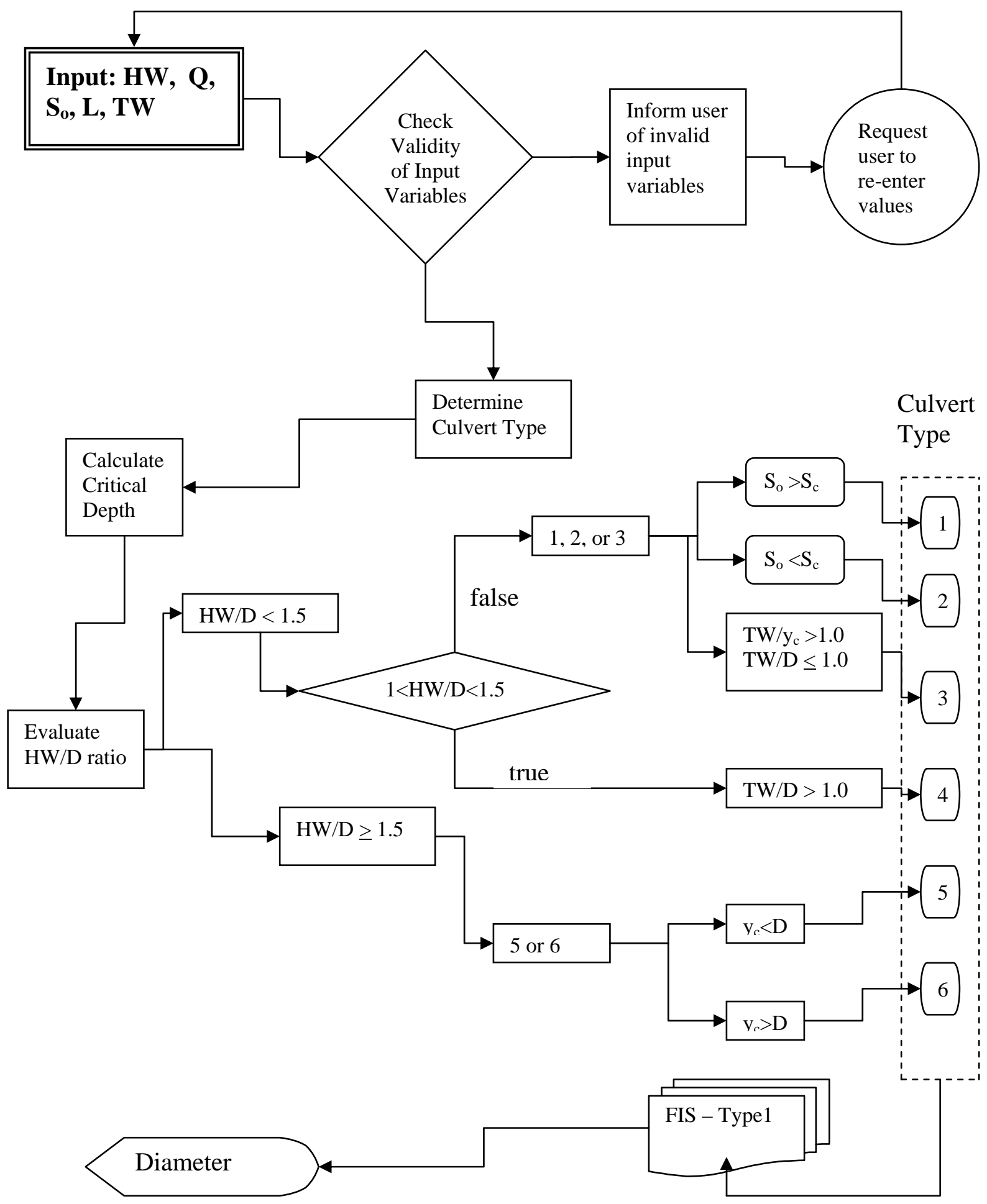

Figure 4.5. ANFIS Model Flow Chart. 


\subsection{Training on Diameter, $D$-vs- Training on Flow Rate, $Q$}

Because the governing equations for type four and type five culvert flow (Figure 4.4) were simple to calculate, these two data sets served as the starting point for the AFIS analysis. The first experiment to be accomplished was to determine if there was a significant difference in error results comparing the ANFIS model trained on diameter with that trained on flow rate. First, the two data sets, type four and type five, were studied using flow rate as the output variable in the data set. The output variable (right most) in the data file is the one on which the ANFIS editor trains on. The results are shown below in Figures 4.6 and 4.7.

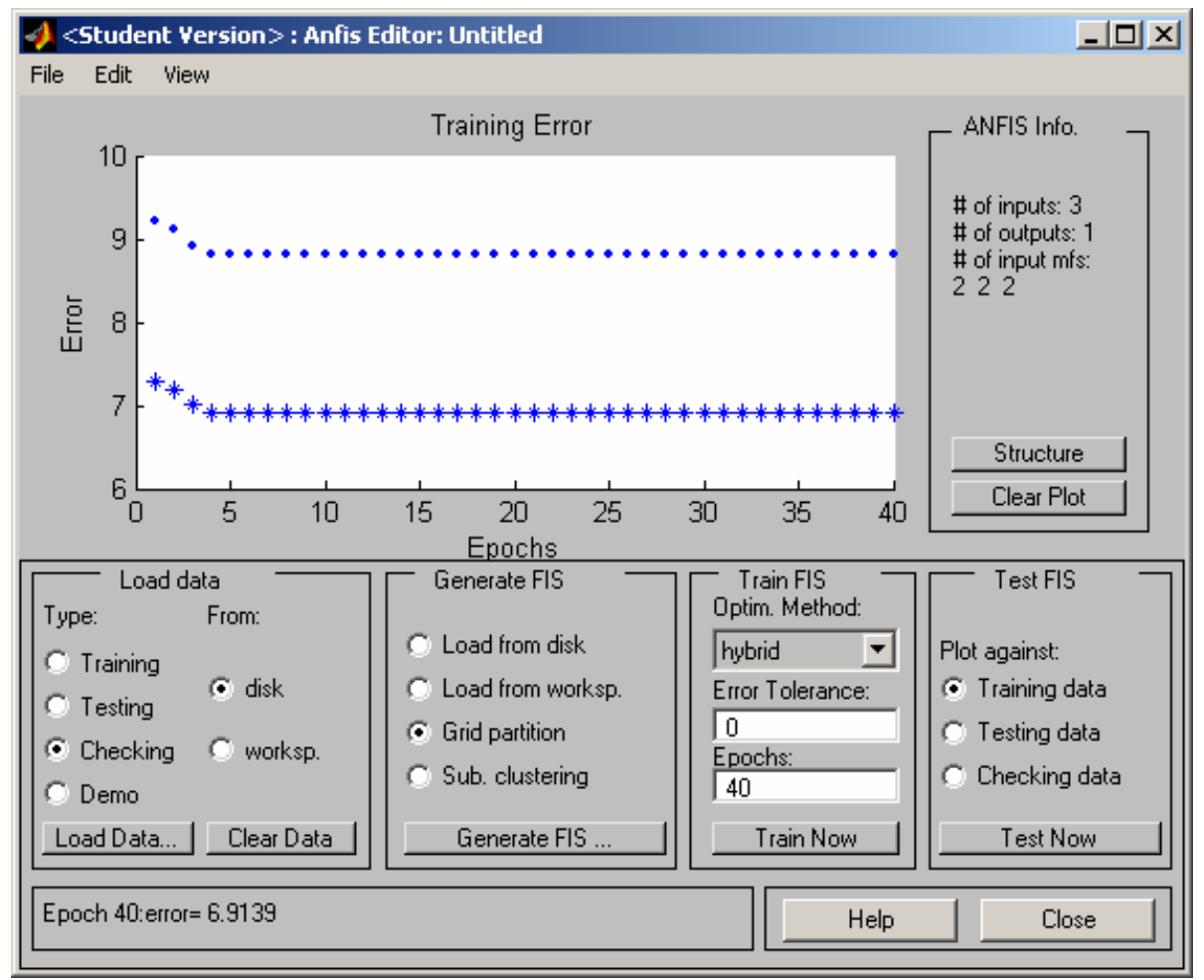

Figure 4.6. Screen capture after training on flow rate of Type 4 data. 


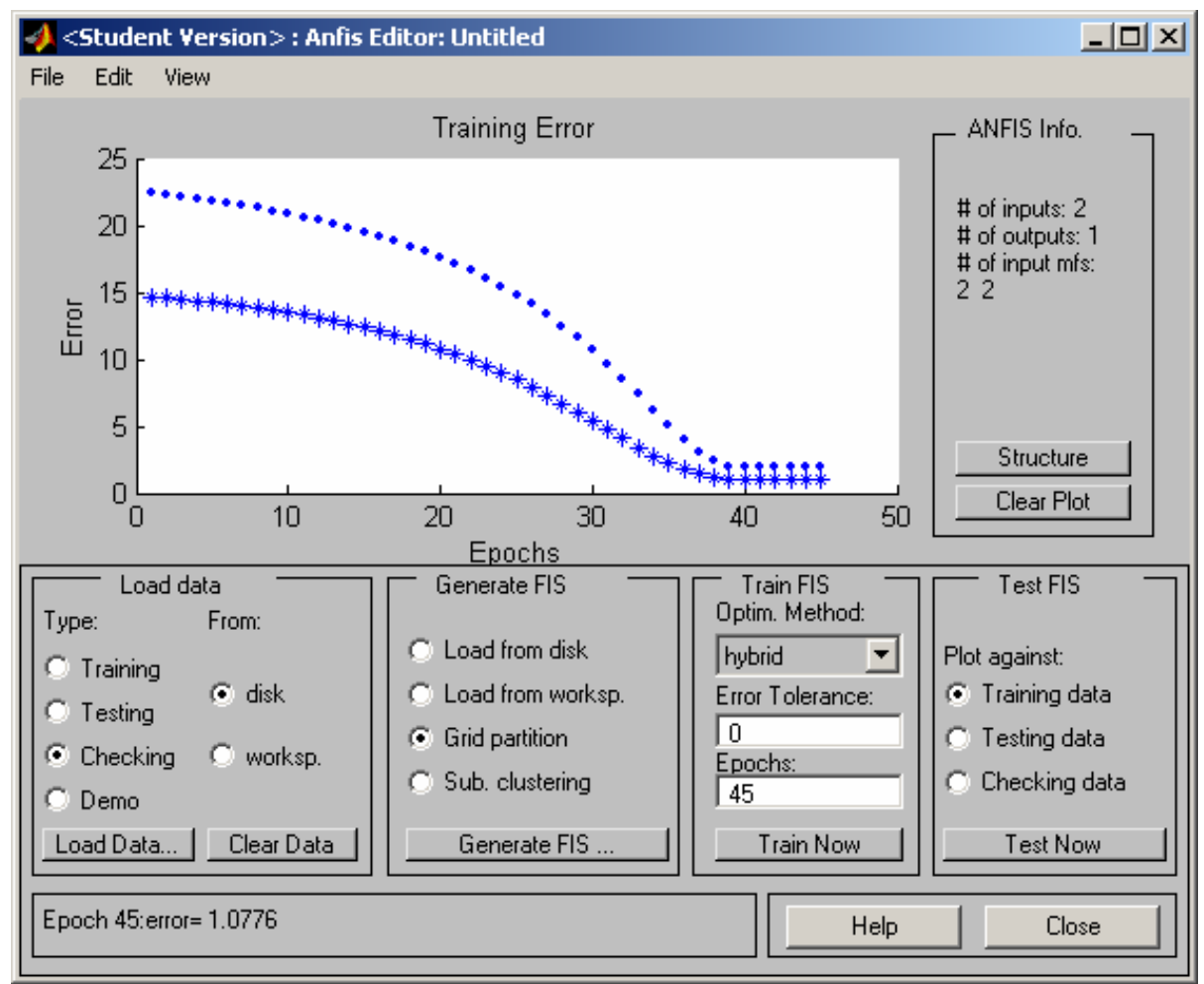

Figure 4.7. Screen capture after training on flow rate of Type 5 data.

The two data sets were then re-configured to present the diameter as the output variable in the data set. The results of training on diameter are provided in Figures 4.8 and 4.9.

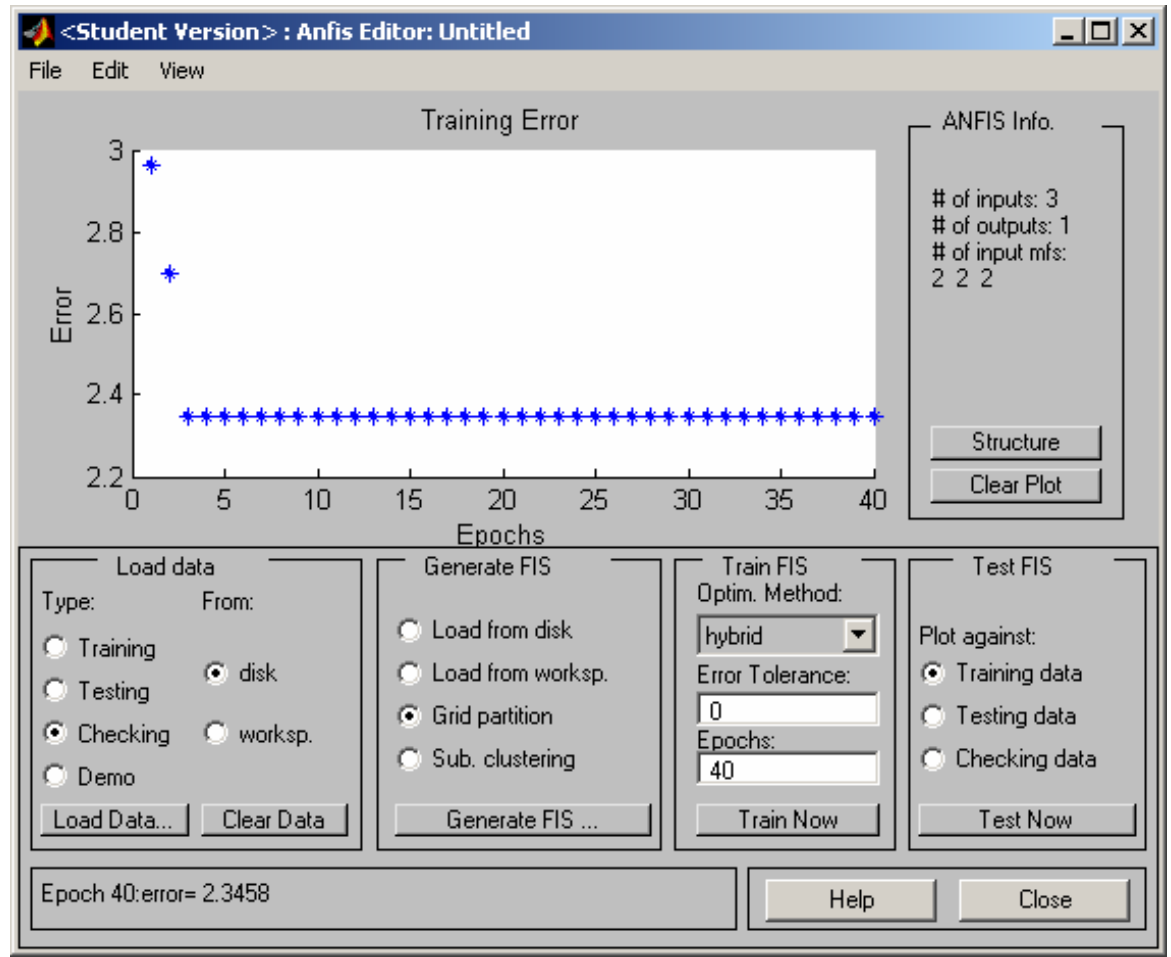

Figure 4.8. Screen capture after training on diameter of Type 4 data. 


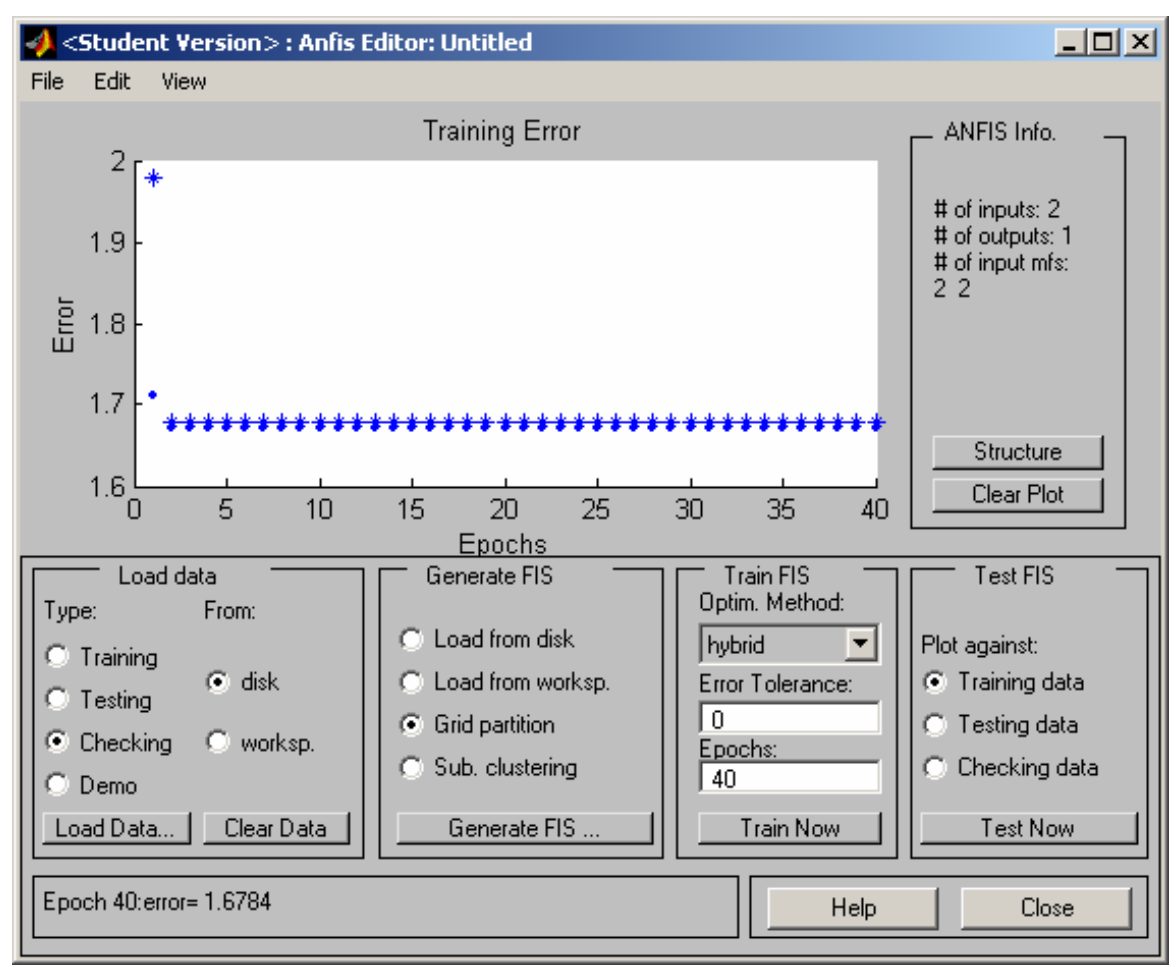

Figure 4.9. Screen capture after training on diameter of Type 5 data.

Since the scope of this dissertation was to resolve if a neural-fuzzy logic model could be used to determine culvert diameters, and there was no significant difference between which variable the ANFIS model trained on, the selection of training on diameter was deemed appropriate. This decision governed the remainder of the data sets, in order to maintain consistency in analysis between different sets of data. 


\section{CHAPTER 5 - RESULTS COMPARISON}

In order to determine how well the model fits the computed data, the ANFIS editor reports the epoch error as well as the checking error. Additionally, the use of a root mean squared error (RMSE) was utilized. There were two different comparisons conducted. The first was the comparison of the four different step data sets, which were outlined earlier in Table 4.2. The second comparison was of the six different USGS culvert types, which was discussed earlier in section 4.5. Results from the four step data sets and the six different culvert types are both presented in Table 5.1.

Table 5.1 is arranged in chronological order. The first two rows are the results for type 4 and 5, which were solved explicitly. Both the step data sets and the six types were generated using code. The step data sets are presented in the center of the table, with the combination of variables from Table 4.3 for step 4 data. Finally the six different culvert types are presented at the bottom of the table. These results were better than the step data sets and gave very similar accuracies for type 4 and type 5 that were solved explicitly.

These results are the error above or below the expected result, in inches, that were tabulated from results of each MatLab model run and the corresponding RMSE calculations. Additionally, X-Y scatter plots were produced showing the predicted diameter plotted against the actual diameter. A perfect fit, indicated by the 45 degree line, is provided for a visual comparison to show the error resulting from the application of the training and checking data to the ANFIS model. 
Table 5.1. Error Results, in Inches of Diameter, For All Data Sets Analyzed.

\begin{tabular}{|c|c|c|c|c|}
\hline Nomenclature & Variables Used & Size & Training RMSE & Checking RMSE \\
\hline Explicit Type 4 & HW-TW, Q, L, D & 175R X 4C & 2.362 & 3.004 \\
\hline Explicit Type 5 & HW, Q, D & 175R X 3C & 1.848 & 1.59 \\
\hline Step 1 & HW, Q, D & 63R X 3C & 7.346 & 9.287 \\
\hline Step 2 & HW, Q, TW, D & 560R X 4C & 6.126 & 6.879 \\
\hline Step 3 & HW, Q, TW, S, D & 1680R X 5C & 6.028 & 6.885 \\
\hline \multirow{5}{*}{ Step 4} & $\mathbf{Q} / \mathbf{H}_{\text {net }}, \mathbf{D}$ & $8400 R$ X 2C & 10.572 & 11.769 \\
\hline & $\mathbf{H}_{\text {net }}, \mathbf{Q}, \mathbf{D}$ & 8400R X 3C & 9.332 & 10.173 \\
\hline & HW-TW, Q, z ${ }^{-1}$, D & $8400 R \times 4 C$ & 8.942 & 9.816 \\
\hline & HW, Q, TW, $\mathbf{z}^{-1}, \mathbf{D}$ & 8400R X 5C & 6.993 & 7.52 \\
\hline & HW, Q, TW, S, L, D & 8400R X 6C & 6.232 & 7.081 \\
\hline & nin & 徂盂 & . & (U) \\
\hline Type 1 & 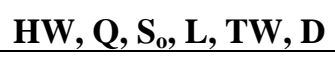 & 173R X 6C & 1.527 & 2.66 \\
\hline Type 2 & HW, Q, S, L, TW, D & 896R X 6C & 4.069 & 4.013 \\
\hline Type 3 & HW, Q, S, L, TW, D & 413R X 6C & 0.983 & 1.46 \\
\hline Type 4 & HW-TW, Q, L, D & 2850R X 6C & 2.132 & 3.296 \\
\hline Type 5 & HW, Q, D & 2569R X 6C & 1.848 & 2.228 \\
\hline Type 6 & HW, Q, S, L, TW, D & 863R X 6C & 0.355 & 1.001 \\
\hline
\end{tabular}

* Denotes formula generated data sets 


\subsection{Formula Generated Data Sets}

The fourth type of data, Type 4 - Submerged Outlet, was produced from the equation given in the Figure 4.4.

$$
Q=C A_{o} \sqrt{\frac{2 g(H W-T W)}{1+\frac{29 C^{2} n^{2} L}{R_{h}^{\frac{4}{3}}}}}
$$

$$
\text { where: } \quad \begin{array}{ll}
Q & =\text { Volumetric flow rate in } \mathrm{ft}^{3} / \mathrm{s}\left(\mathrm{m}^{3} / \mathrm{s}\right) . \\
C & =\text { The discharge coefficient }(0.85) . \\
A_{o} & =\text { Full flow cross sectional area in } \mathrm{ft}^{2}\left(\mathrm{~m}^{2}\right) . \\
g & =\text { acceleration due to gravity in } \mathrm{ft} / \mathrm{s}^{2}\left(\mathrm{~m} / \mathrm{s}^{2}\right) . \\
H W & =\text { Headwater depth in } \mathrm{ft}(\mathrm{m}) . \\
T W & =\text { Tail water depth in } \mathrm{ft}(\mathrm{m}) . \\
n & =\text { Manning's roughness coefficient } \\
L & =\text { Length of culvert barrel in } \mathrm{ft}(\mathrm{m}) . \\
R_{h} & =\text { Hydraulic Radius in } \mathrm{ft}(\mathrm{m}) .
\end{array}
$$

This data set required three inputs; difference in headwater and tail water, discharge, and length, which produced an output of diameter. This data set has four columns and 175 rows. The training and checking root mean squared error are presented as Figures 5.1 and 5.2. 


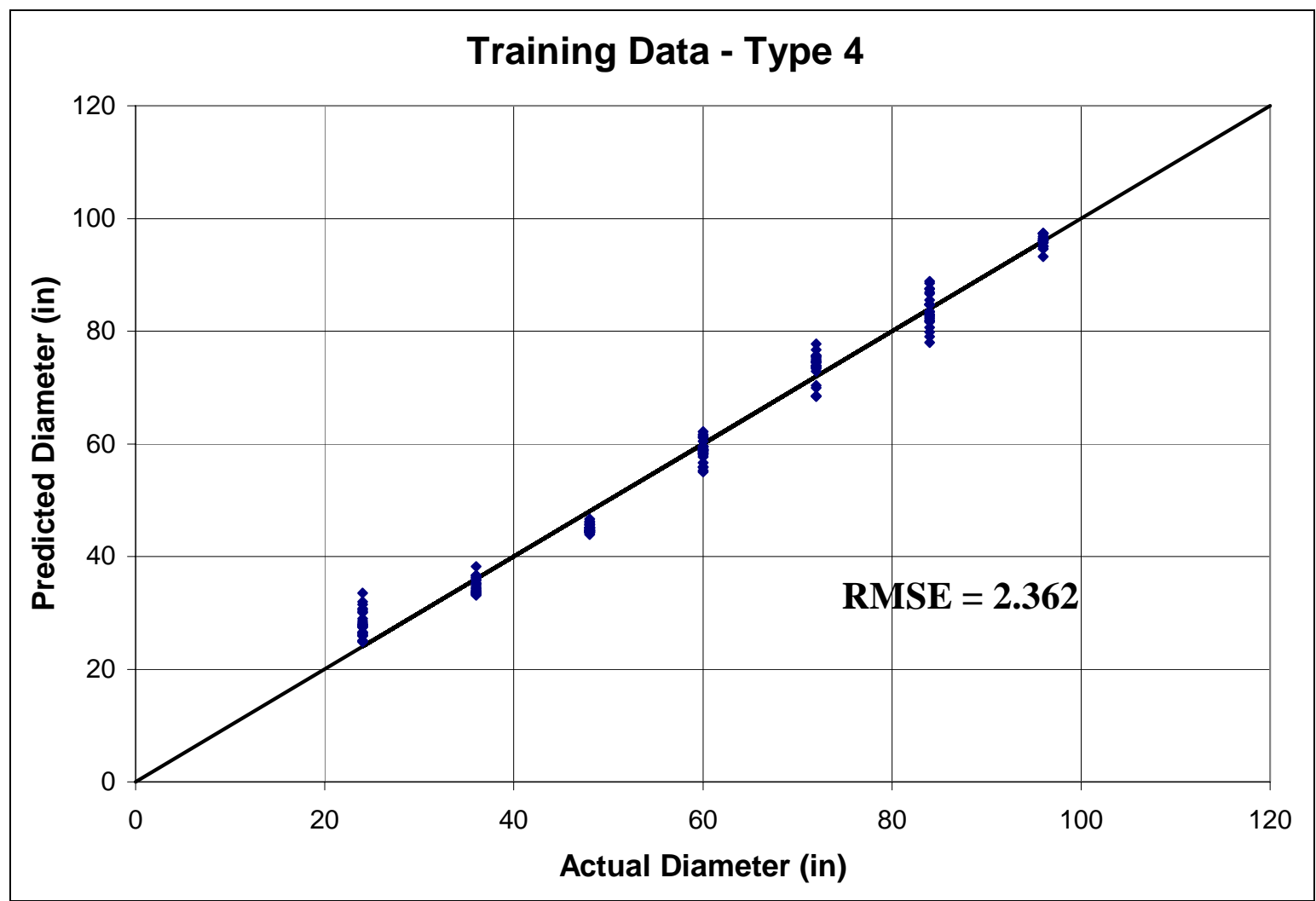

Figure 5.1. Training data set of formula generated Type 4 data.

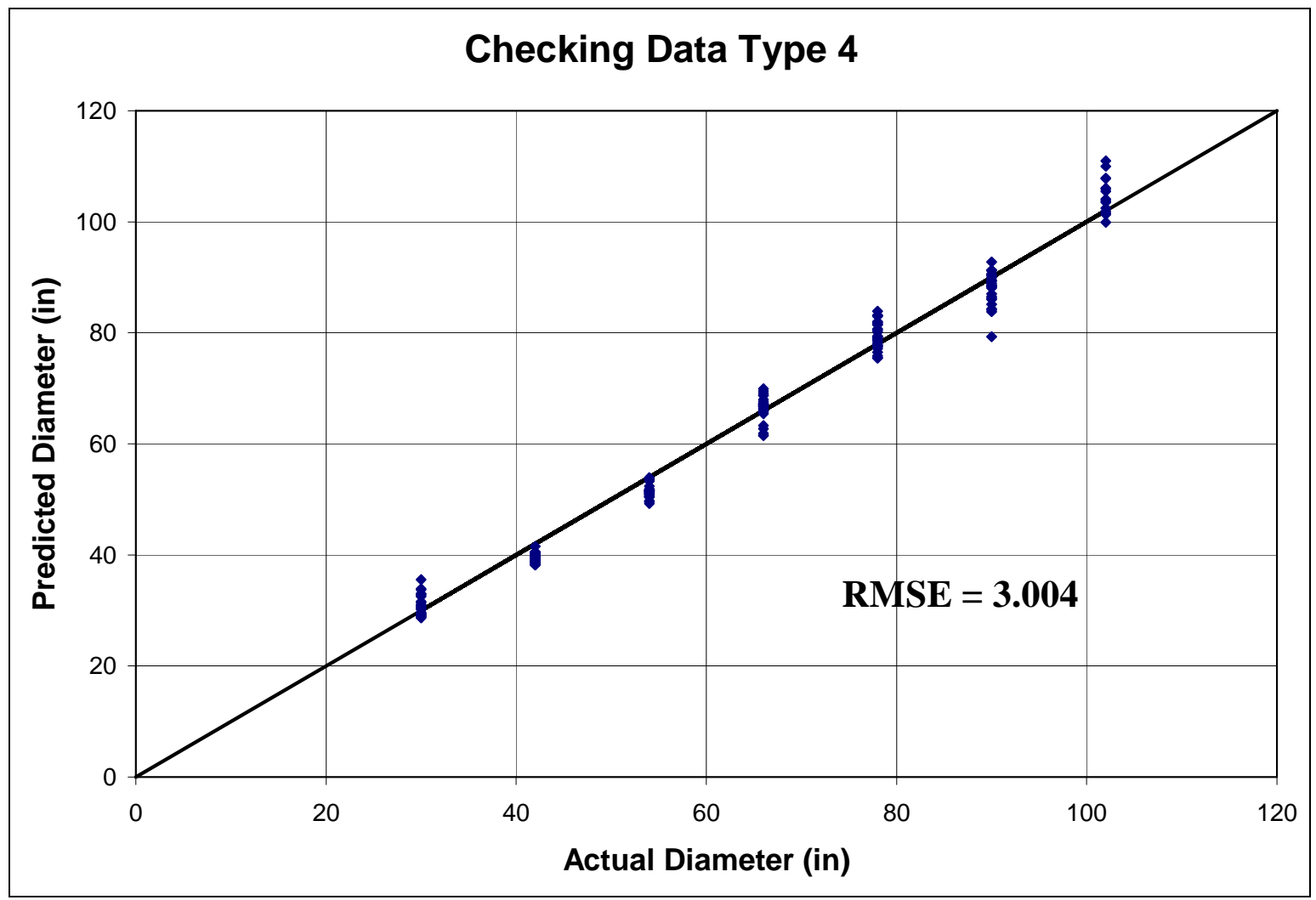

Figure 5.2. Checking data set of formula generated Type 4 data. 
The fifth type of data, Type 5 - Rapid Flow at Inlet, was also produced from the equation given in the Figure 4.4.

$$
Q=C A_{o} \sqrt{2 g H W}
$$

where: $Q=$ Volumetric flow rate in $\mathrm{ft}^{3} / \mathrm{s}\left(\mathrm{m}^{3} / \mathrm{s}\right)$.

$C \quad=$ The discharge coefficient (0.85).

$A_{o} \quad=$ Full flow cross sectional area in $\mathrm{ft}^{2}\left(\mathrm{~m}^{2}\right)$.

$g \quad=$ acceleration due to gravity in $\mathrm{ft} / \mathrm{s}^{2}\left(\mathrm{~m} / \mathrm{s}^{2}\right)$.

$H W=$ Headwater depth in $\mathrm{ft}(\mathrm{m})$.

This data set required two inputs; headwater and discharge, which produced an output of diameter. This data set has three columns and 175 rows. The training and checking root mean squared errors are presented as Figures 5.3 and 5.4. 


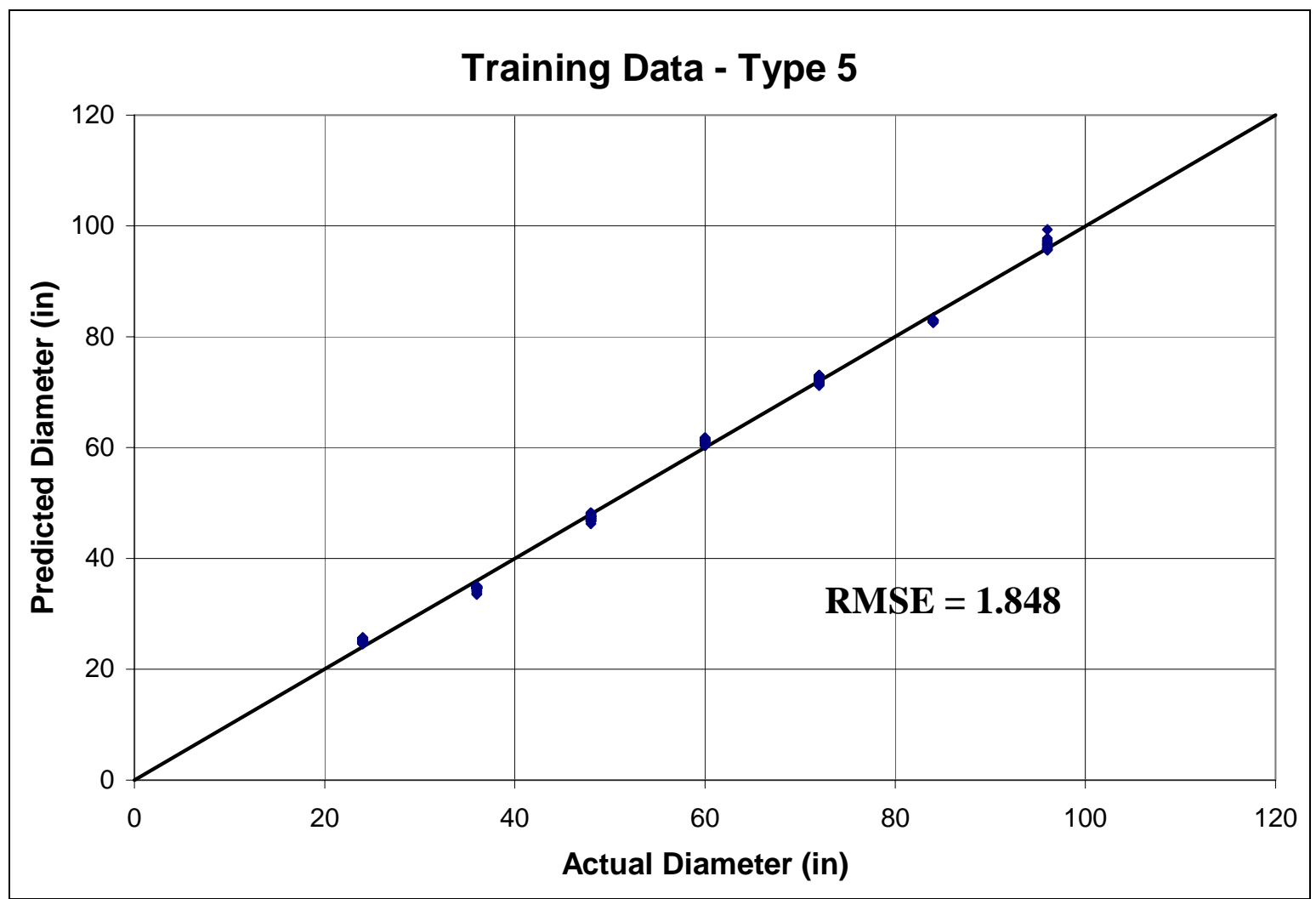

Figure 5.3. Training data set of formula generated Type 5 data.

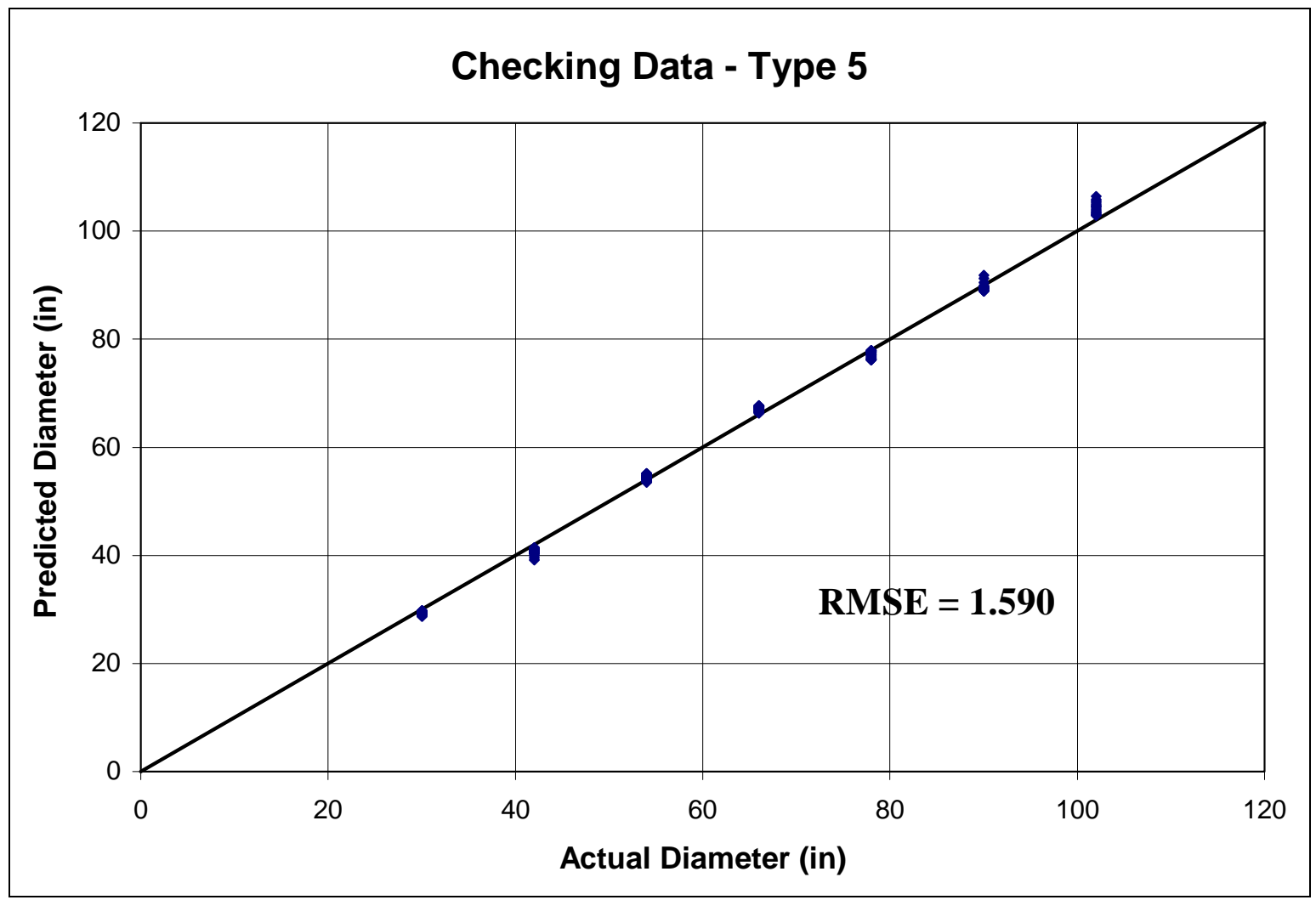

Figure 5.4. Checking data set of formula generated Type 5 data. 


\subsection{Data Sets Generated From Method of Steps}

This section contains plots resulting from data dissected from the large compilation of data produced from Haestad Methods discussed in section 4.4 and specifically the data presented in Table 4.2. The RMSE values are summarized in Table 5.1. Step 1 data are plotted in Figures 5.5 and 5.6. Step 2 data are plotted in Figures 5.7 and 5.8. Step 3 data are plotted in Figures 5.9 and 5.10. Step 4 data, which was expanded to include the combination of variables, as described in section 4.4 and listed in Table 4.3, are plotted in Figures 5.11 through 5.20. Step 4 data with two variables are plotted in Figures 5.11 and 5.12. Step 4 data with three variables are plotted in Figures 5.13 and 5.14. Step 4 data with four variables are plotted in Figures 5.15 and 5.16. Step 4 data with five variables are plotted in Figures 5.17 and 5.18. Step 4 data with all six variables are plotted in Figures 5.19 and 5.20.

The results of the step data sets do not meet acceptable design standards. Additionally, an attempt to reduce the number of input variables, in hopes that a less distorted model would produce more accurate results, had the opposite effect. The combined variables of step 4 data were worse than the largest six variables data set. The overall weighted average RMSE was 8.293 inches for the training data sets and 9.151 inches for the checking data sets. Because these results were not acceptable, the six type data sets were analyzed in order to obtain more accurate results, which are presented in the next section. 


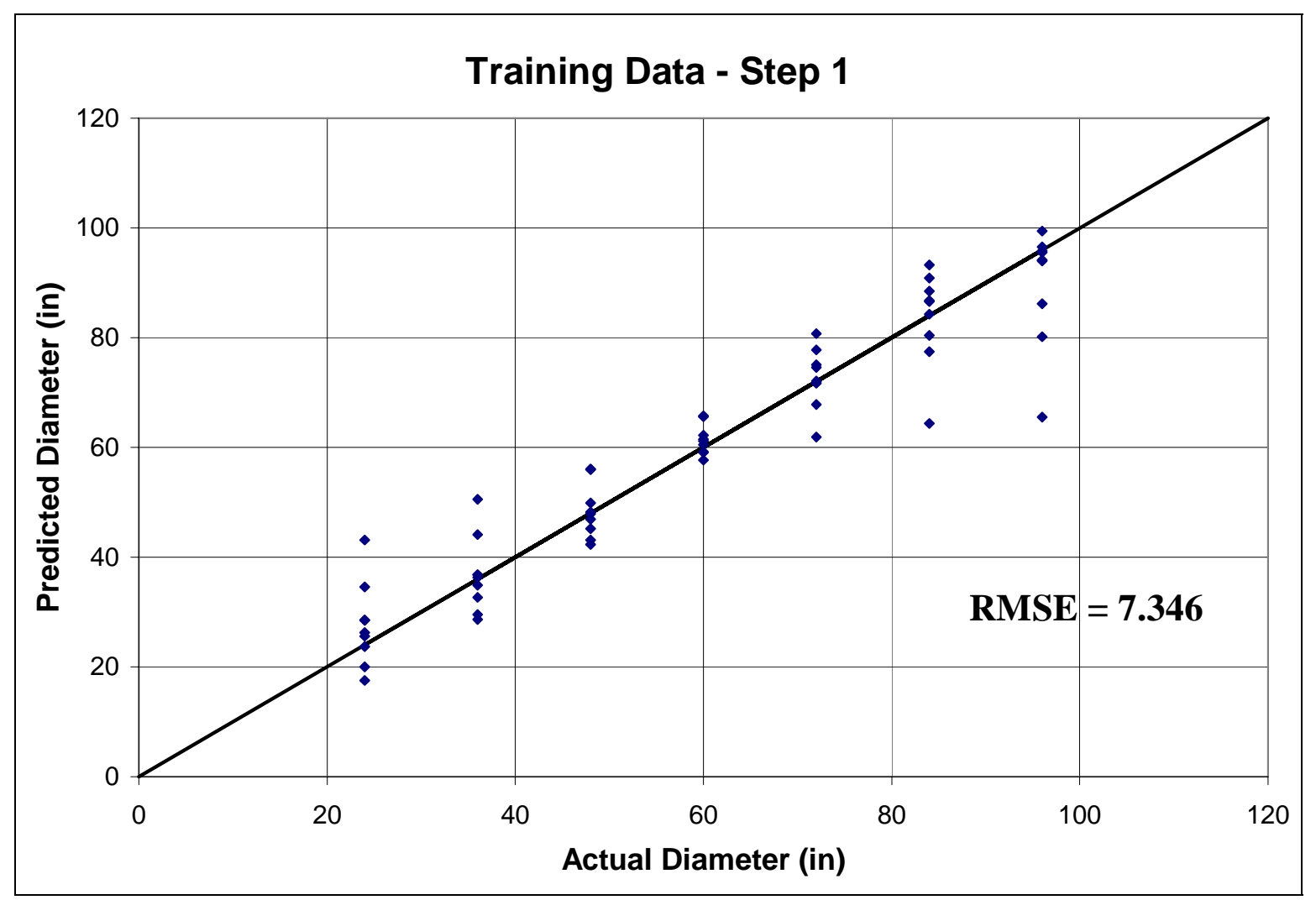

Figure 5.5. Training data set for Step 1 data.

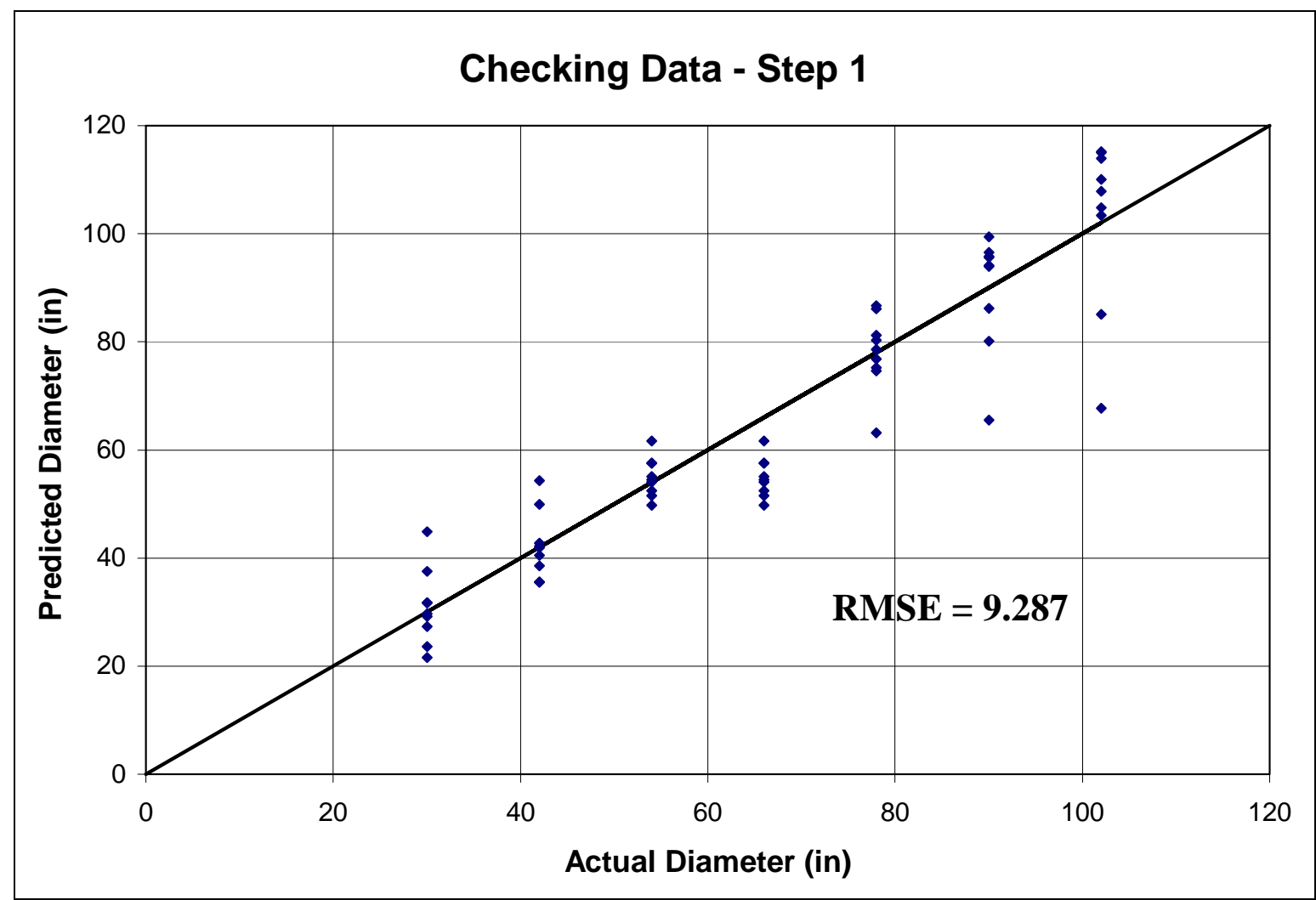

Figure 5.6. Checking data set for Step 1 data. 


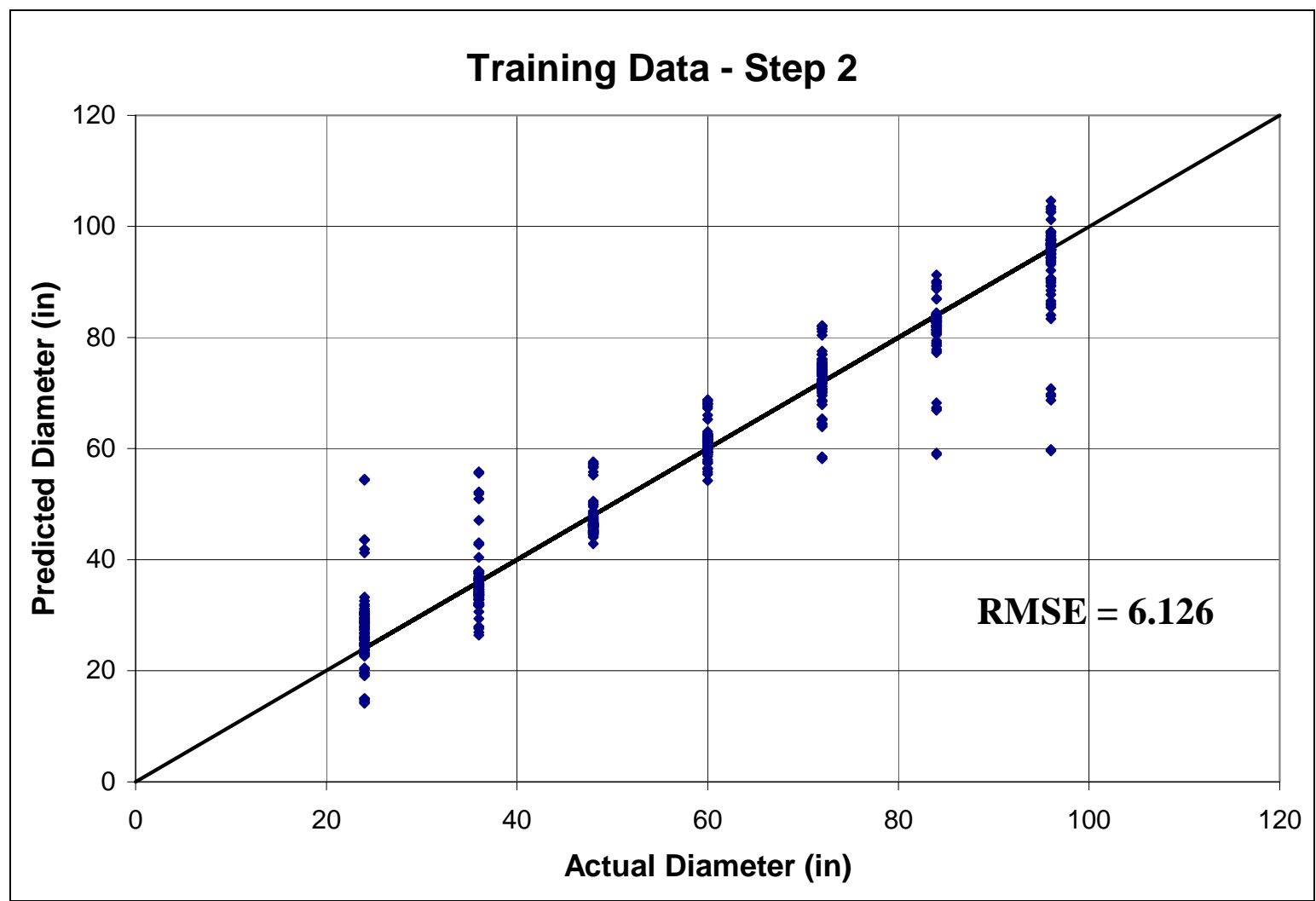

Figure 5.7. Training data set for Step 2 data.

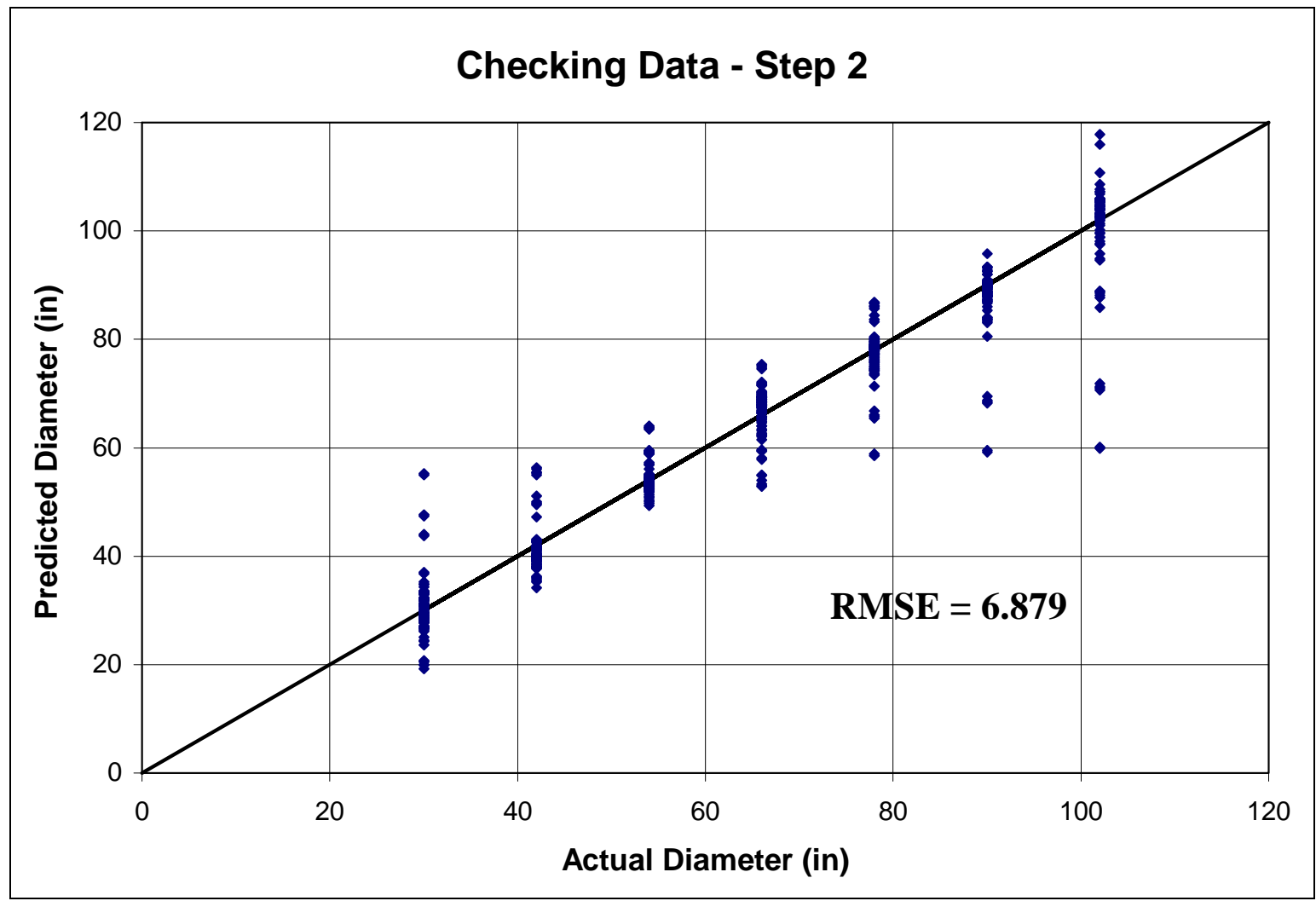

Figure 5.8. Checking data set for Step 2 data. 


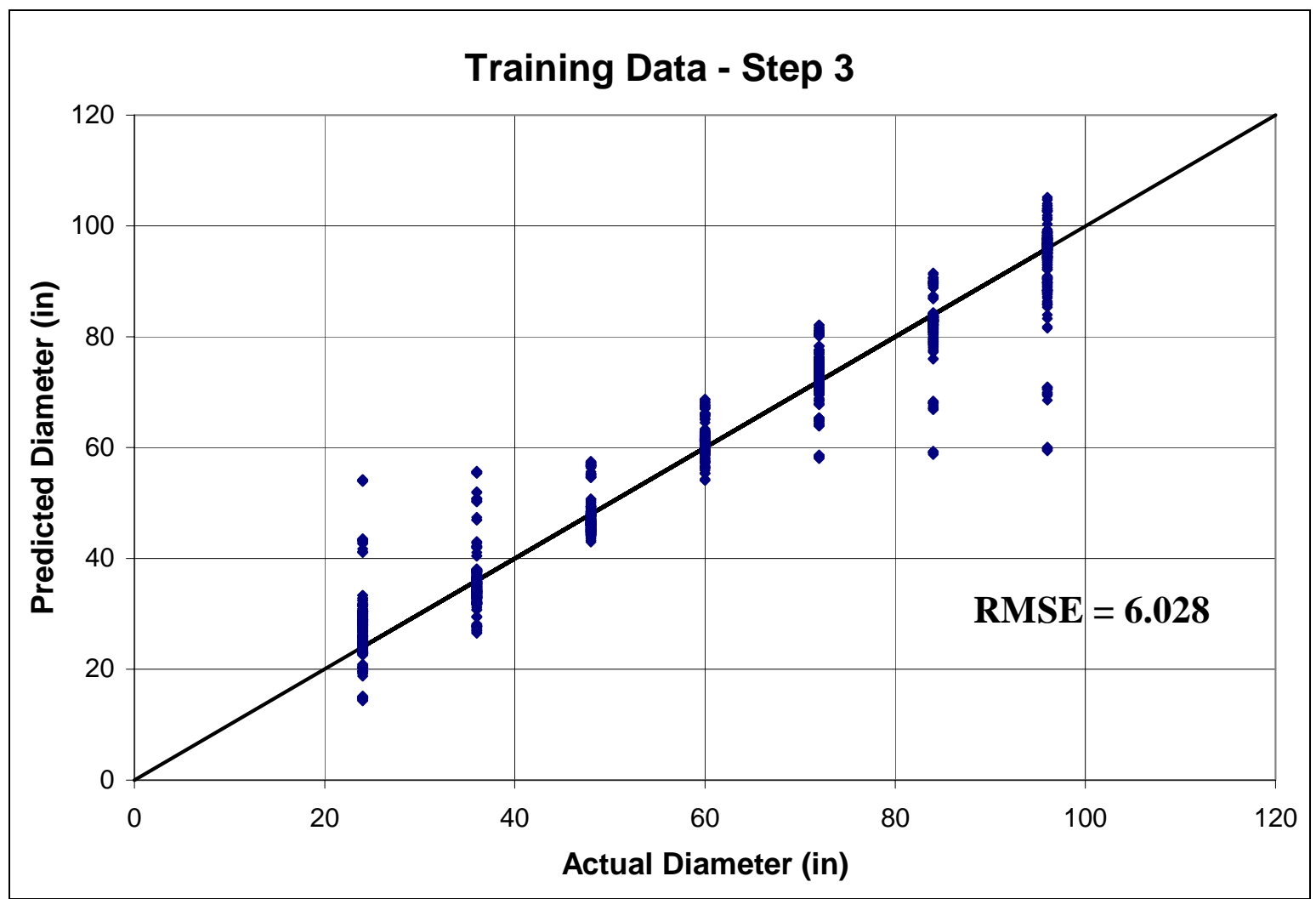

Figure 5.9. Training data set for Step 3 data.

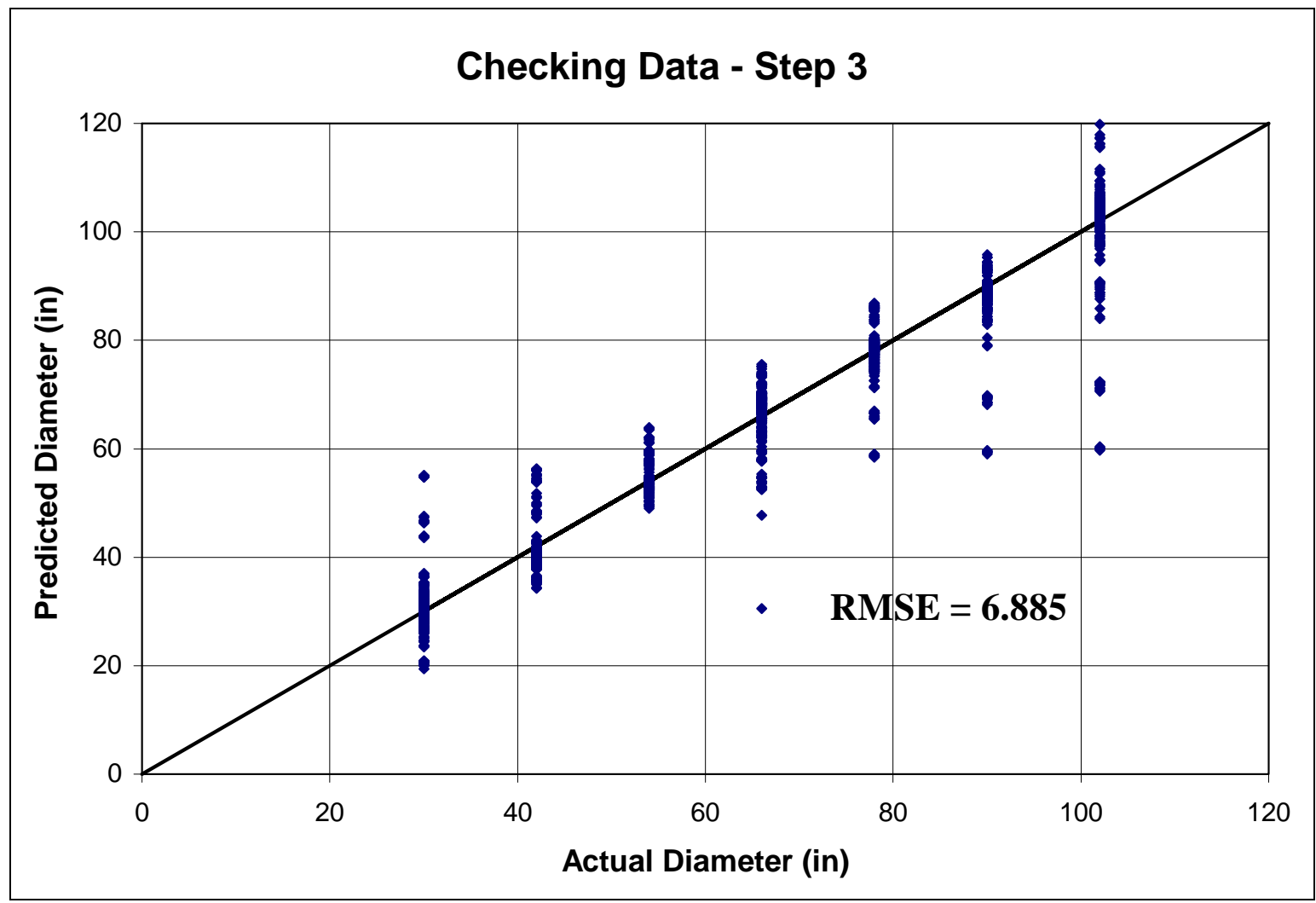

Figure 5.10. Checking data set for Step 3 data. 


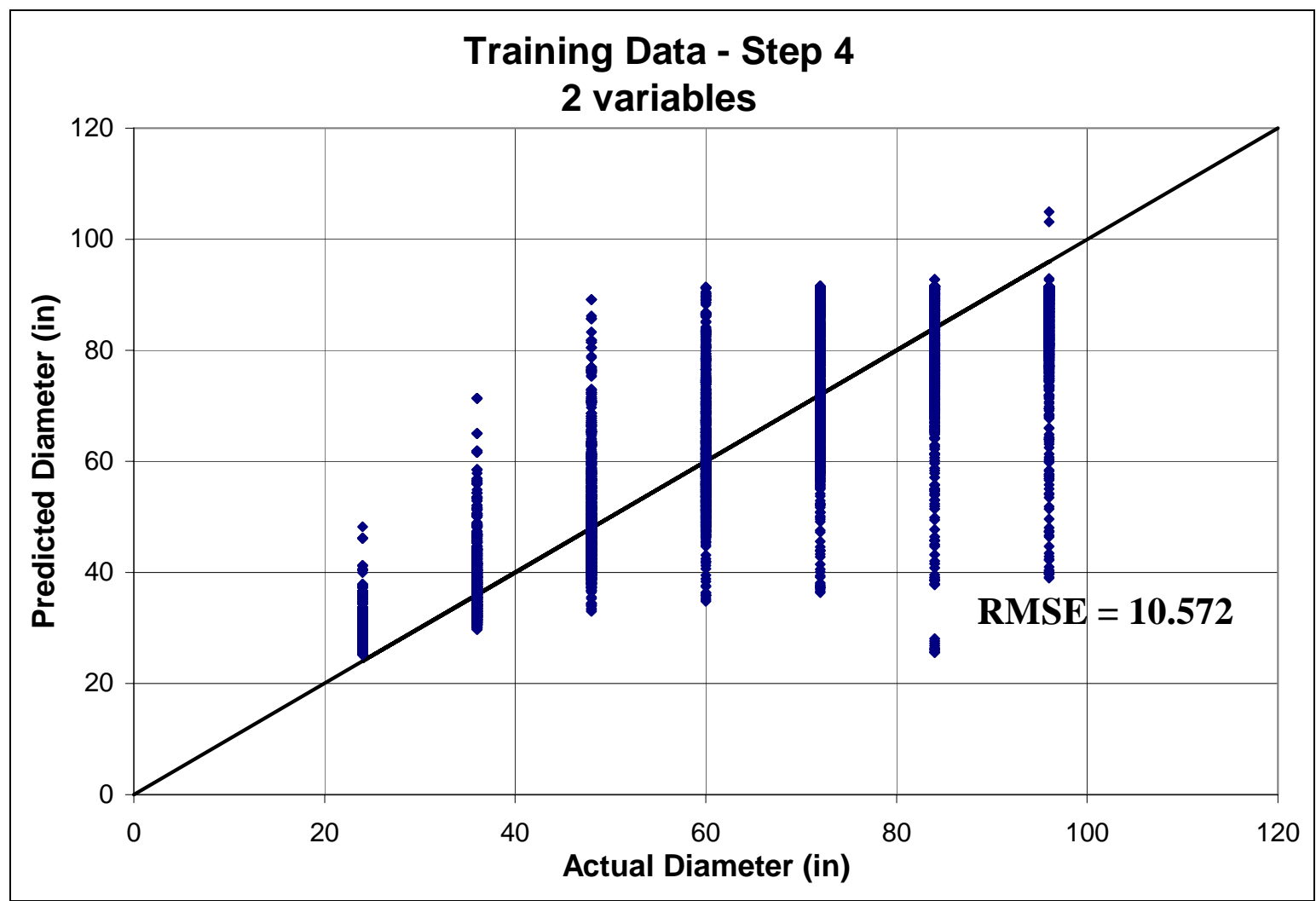

Figure 5.11. Training data set with two variables, for Step 4 data.

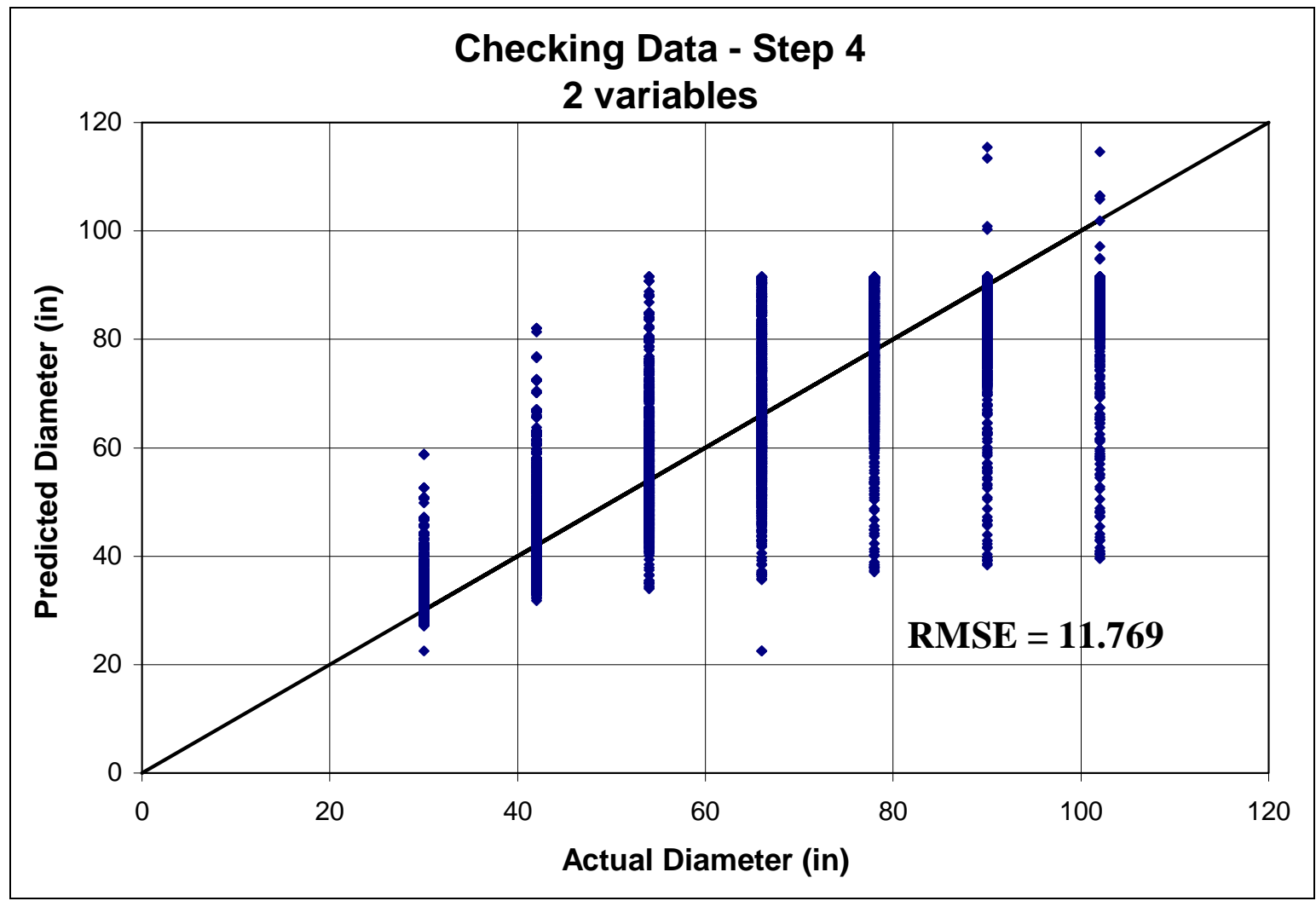

Figure 5.12. Checking data set with two variables, for Step 4 data. 


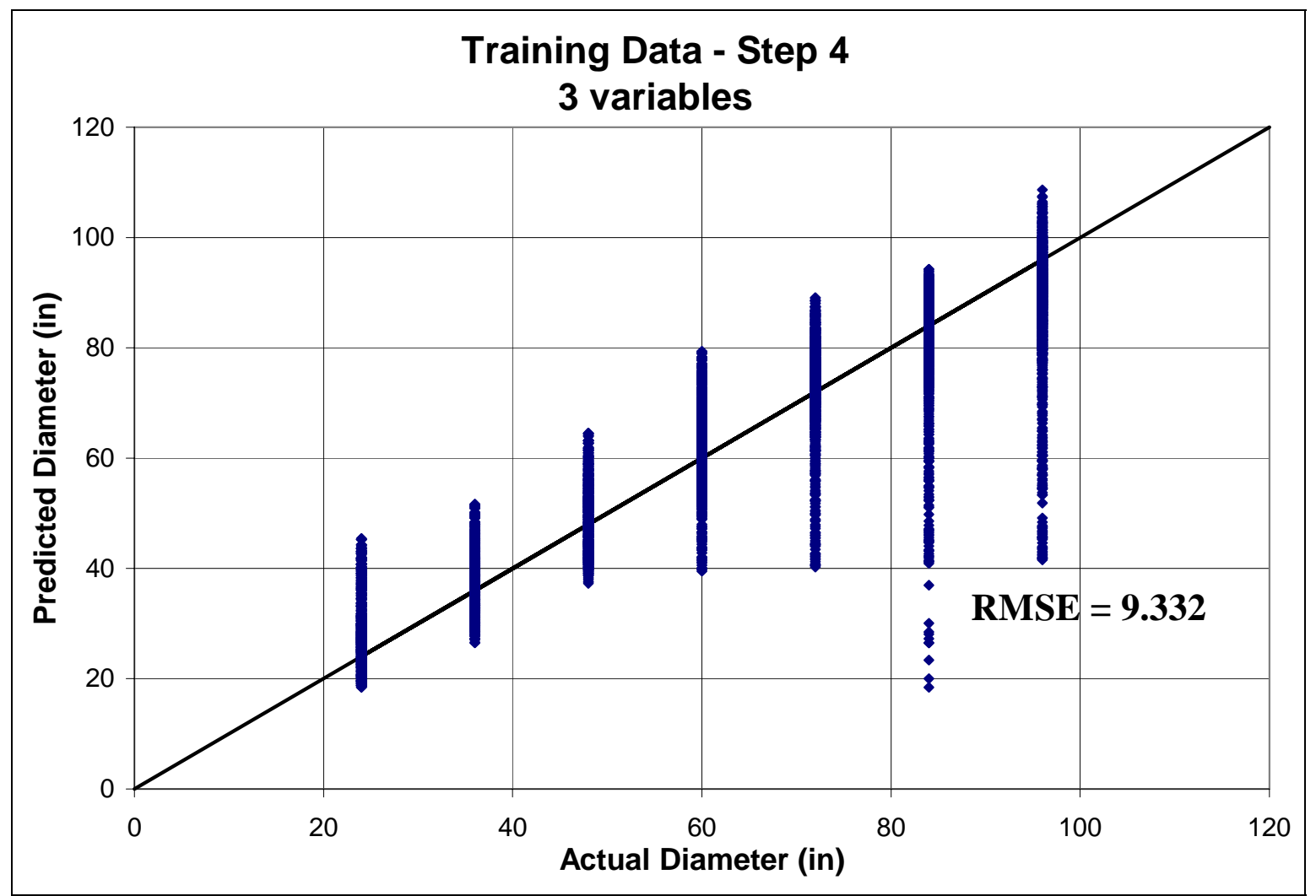

Figure 5.13. Training data set with three variables, for Step 4 data.

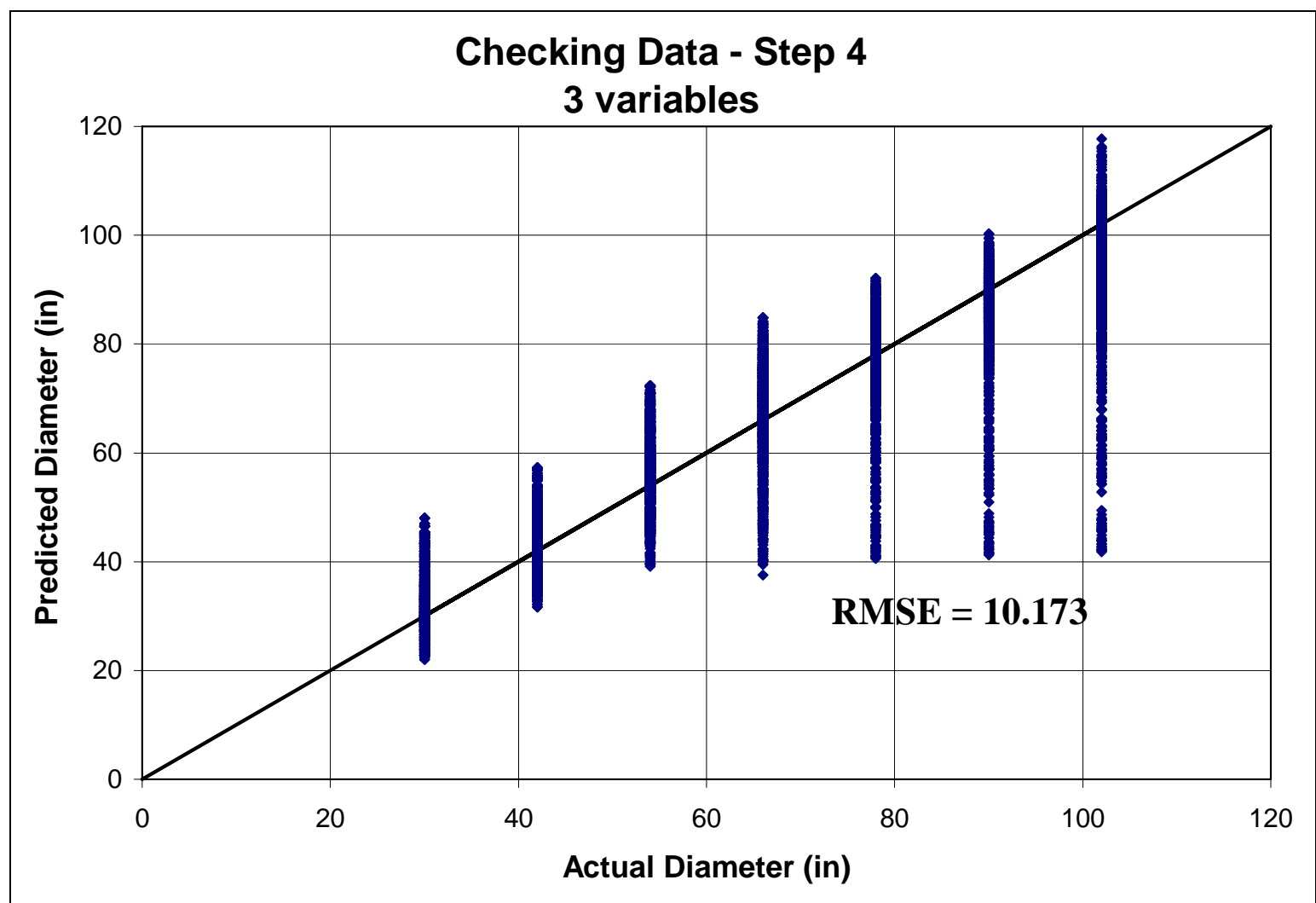

Figure 5.14. Checking data set with three variables, for Step 4 data. 


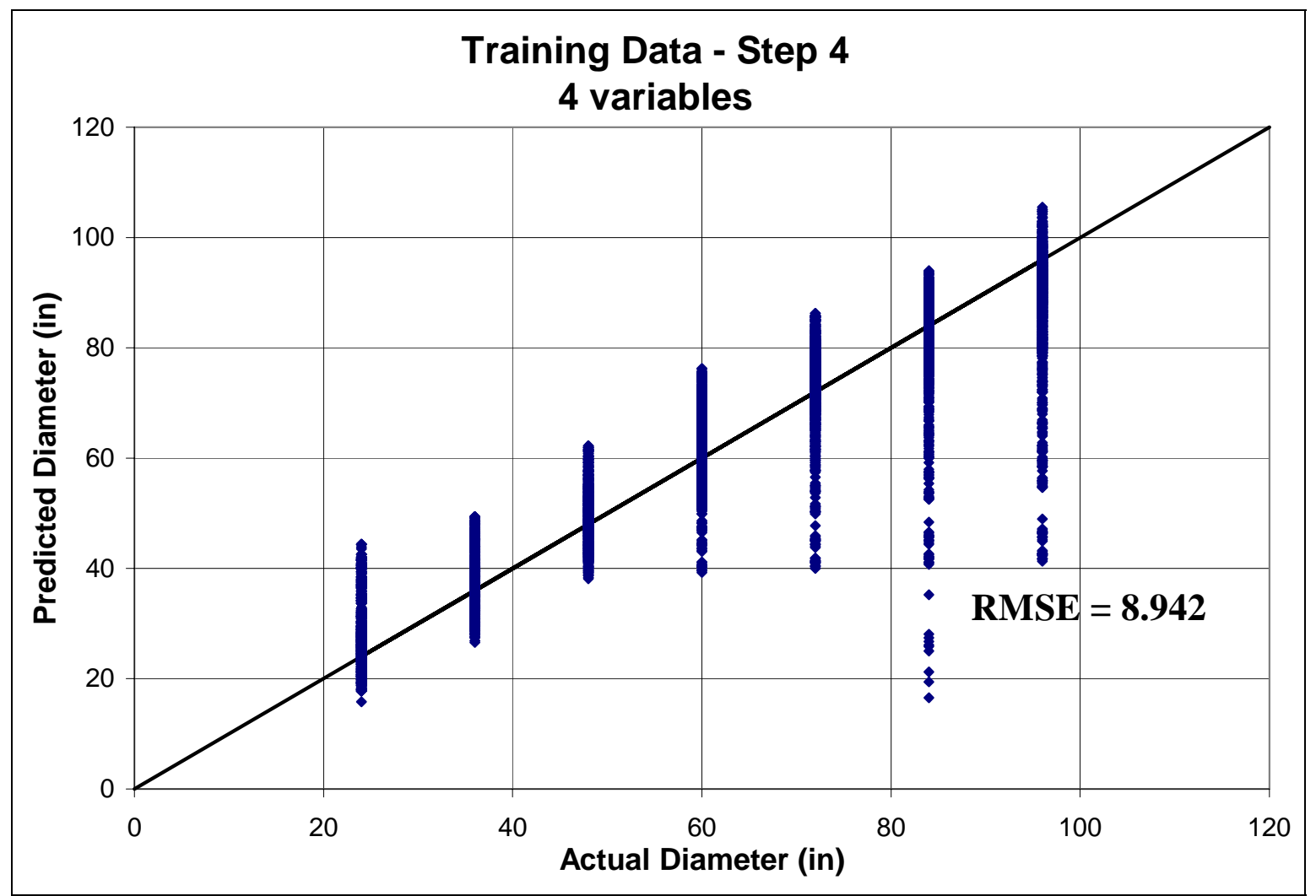

Figure 5.15. Training data set with four variables, for Step 4 data.

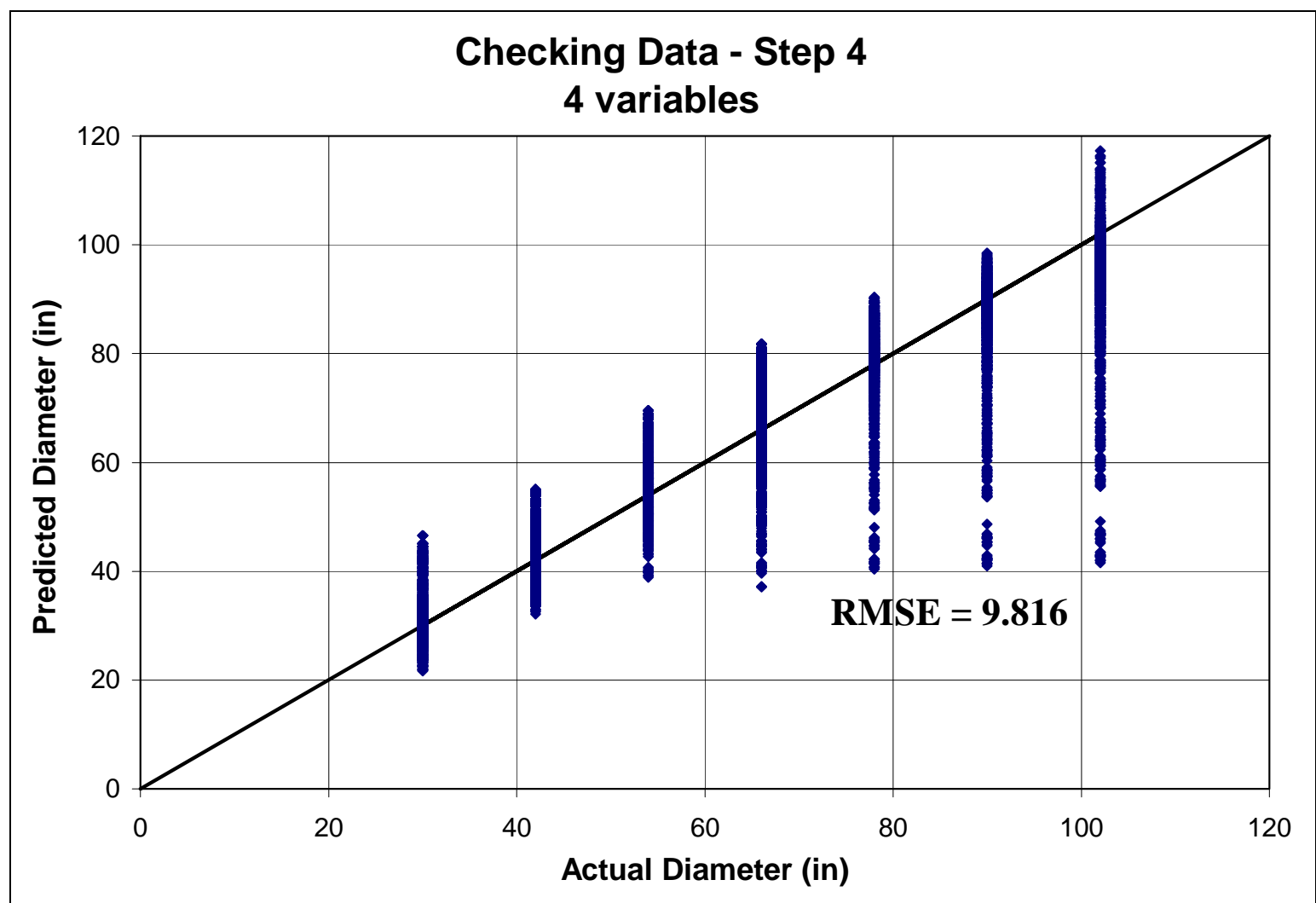

Figure 5.16. Checking data set with four variables, for Step 4 data. 


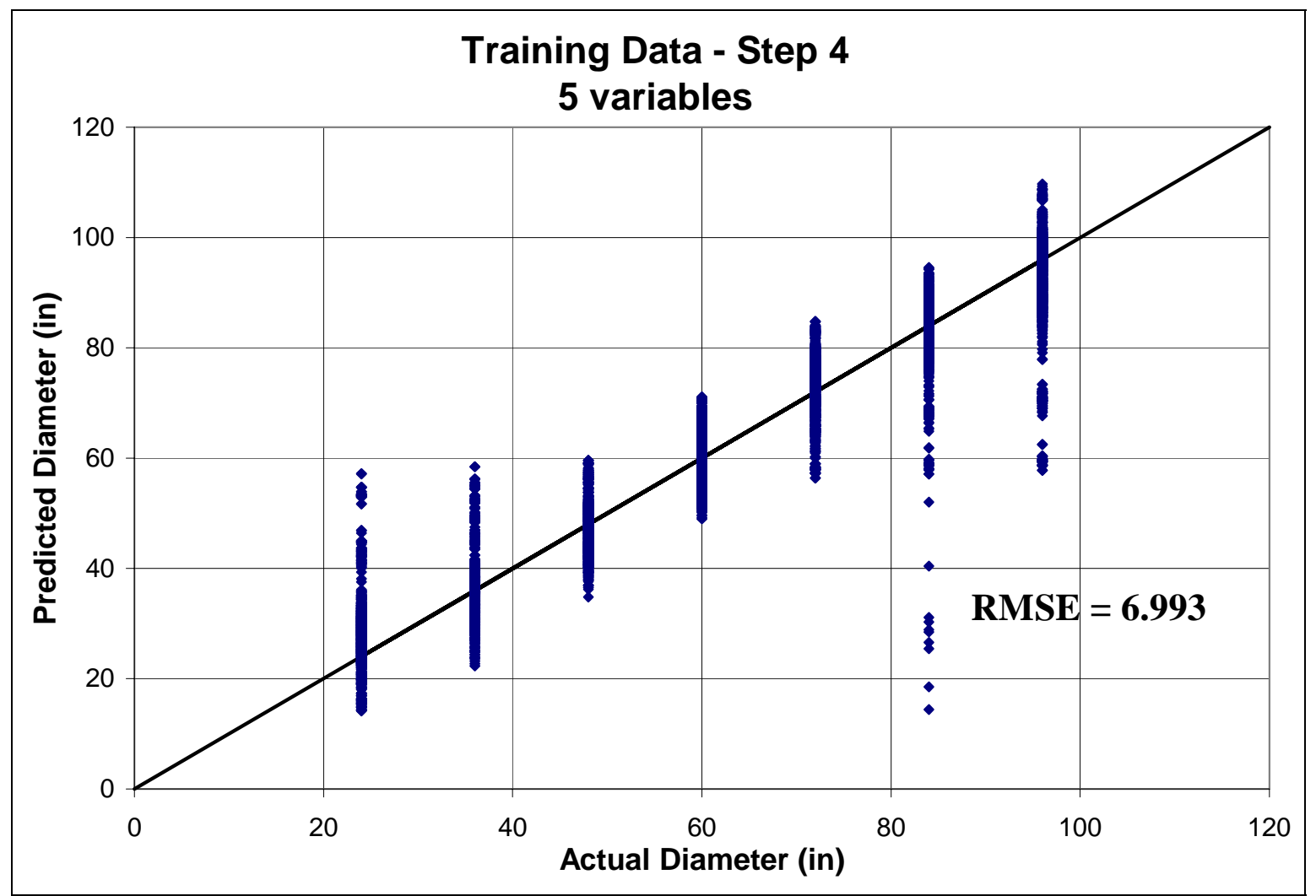

Figure 5.17. Training data set with five variables, for Step 4 data.

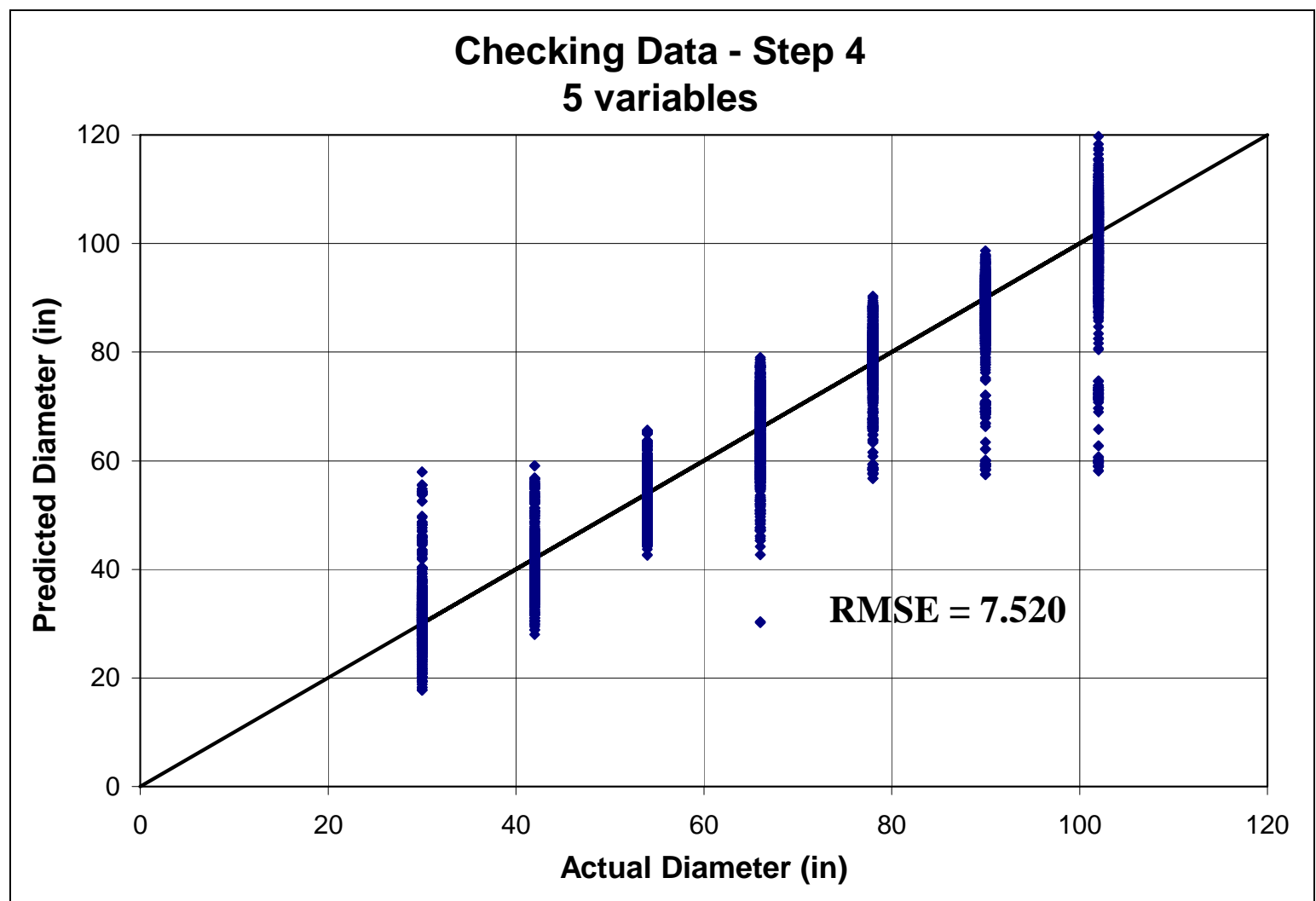

Figure 5.18. Checking data set with five variables, for Step 4 data. 


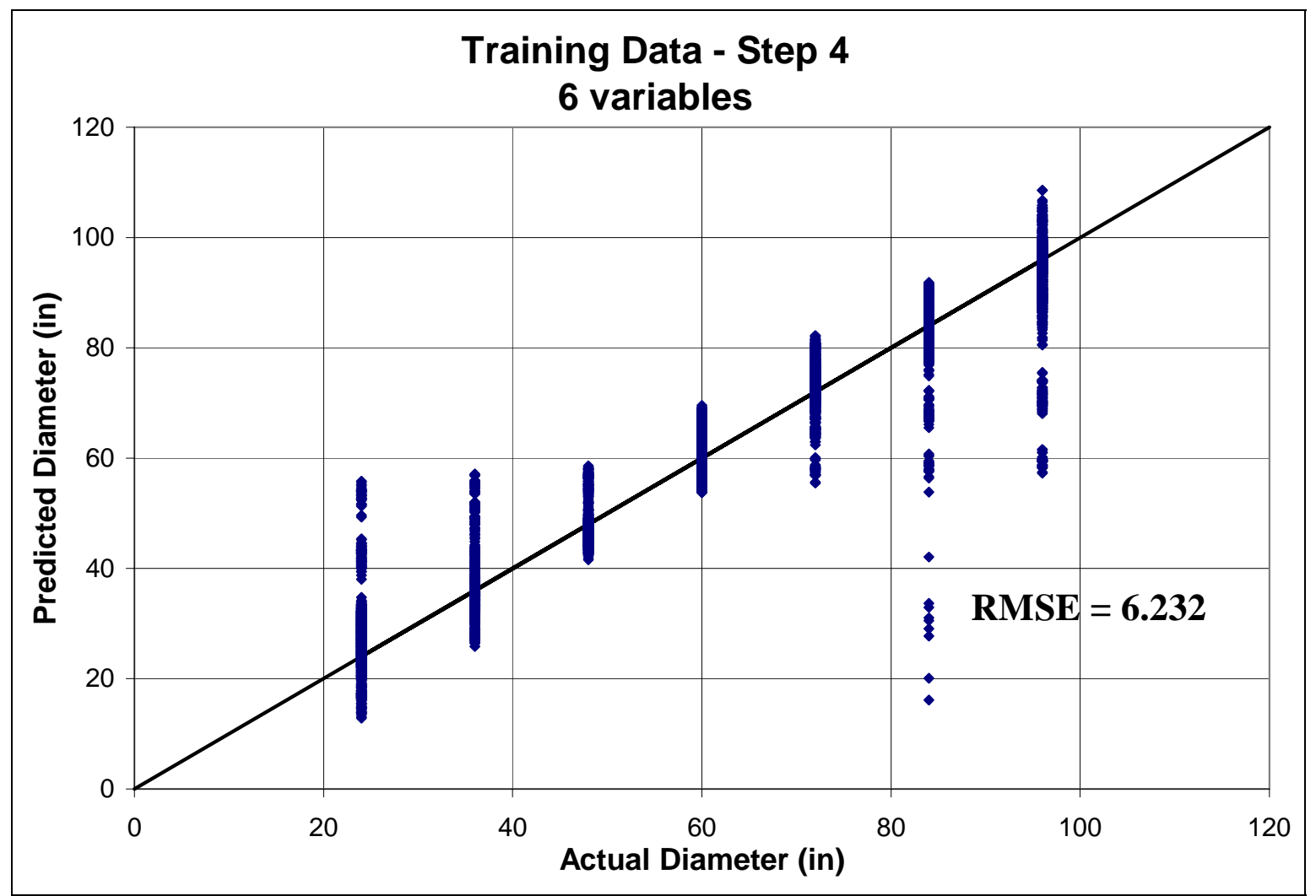

Figure 5.19. Training data set with six variables, for Step 4 data.

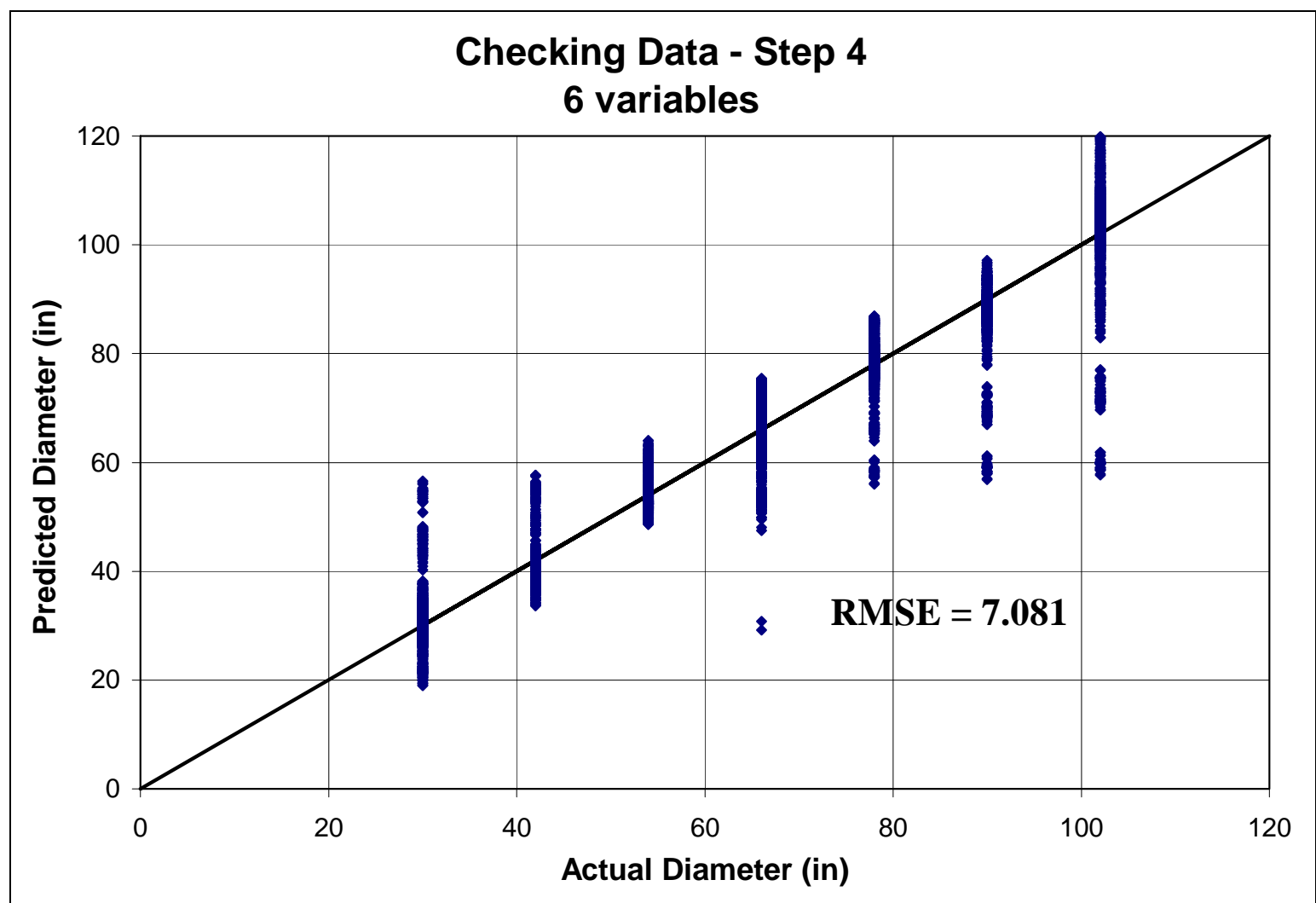

Figure 5.20. Checking data set with six variables, for Step 4 data. 


\subsection{USGS Culvert Type Data Sets}

Modeling results up to this point resulted in RMSE values that, in many cases, would not be suitable for design use. To better, and more consistently, evaluate the performance of the ANFIS modeling approach using two membership functions (dsigmf) per input variable, the Haestad data set was used as the source of data sets corresponding to each of the six culvert flow types.

The first culvert type, Type 1 - Critical Depth at Inlet, was evaluated to determine the optimum modeling procedure. These data were taken from the 11,550 line compilation of all data produced from the Haestad software. This data set encompasses every possible culvert configuration. Type 1 data were dissected out of the large 11,550 line data set by use of the three conditions presented in Figure 4.4. The three conditions are:

$$
\begin{array}{cl}
\text { First Condition, Type 1: } & \frac{H W}{D}<1.5 \\
\text { Second Condition, Type 1: } & \frac{T W}{y_{c}}<1.0 \\
\text { Third Condition, Type 1: } & S_{o}>S_{c}
\end{array}
$$

These three conditions were checked against every row of the 11,550 lines of data. The ones that met the three conditions were separated and saved as the data set for use in neuralfuzzy modeling. Those not meeting the conditions were separated and set aside. This produced a data set that had 173 rows. The data set had inputs of headwater, discharge, bed slope, length, and tail water; which produced an output of diameter. Figures 5.21 and 5.22, below are plots of actual diameter inputs plotted against the predicted diameters, showing the relationship between the two. Type 1 data produced adequate results. 


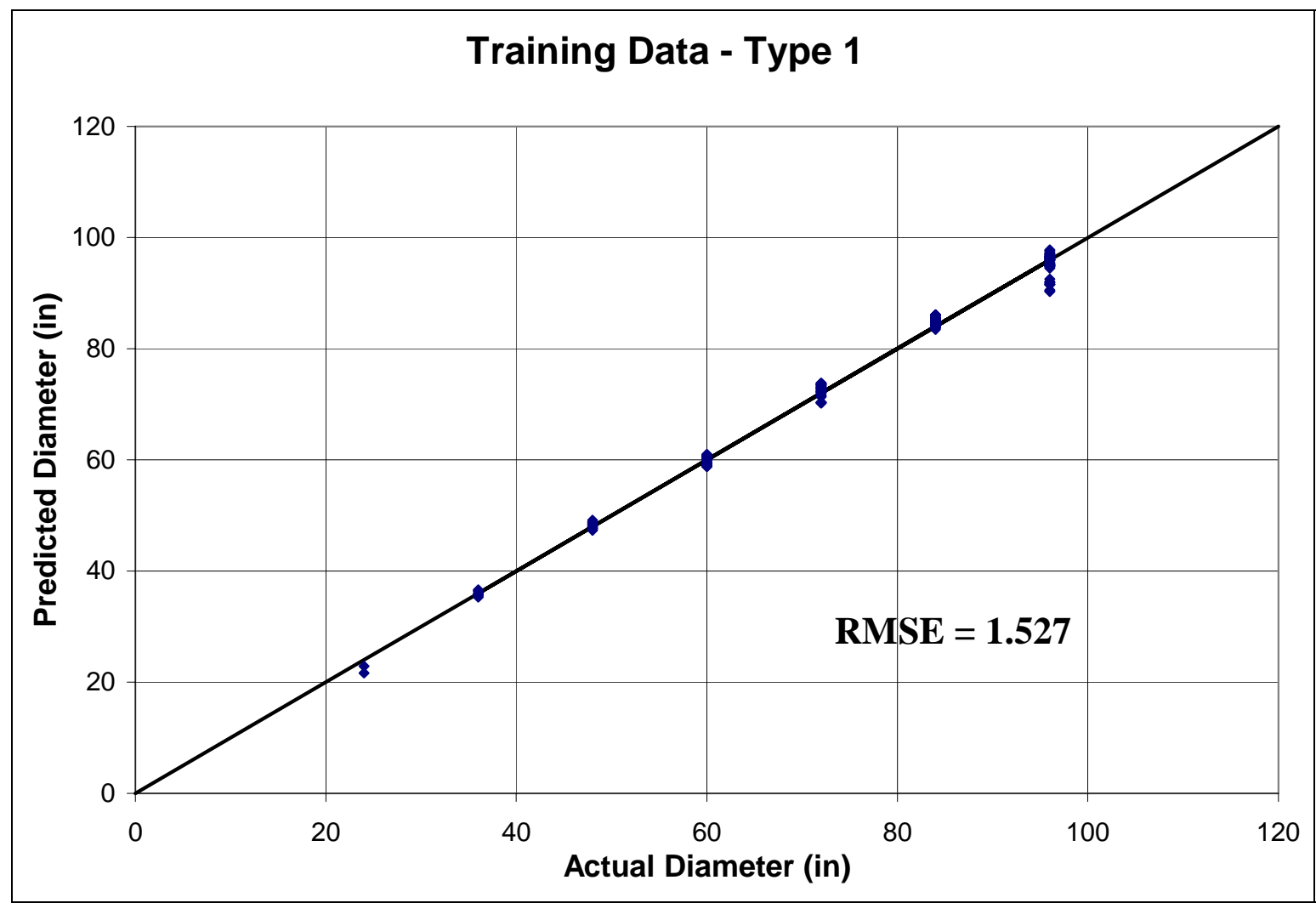

Figure 5.21. Training data of Type 1 data.

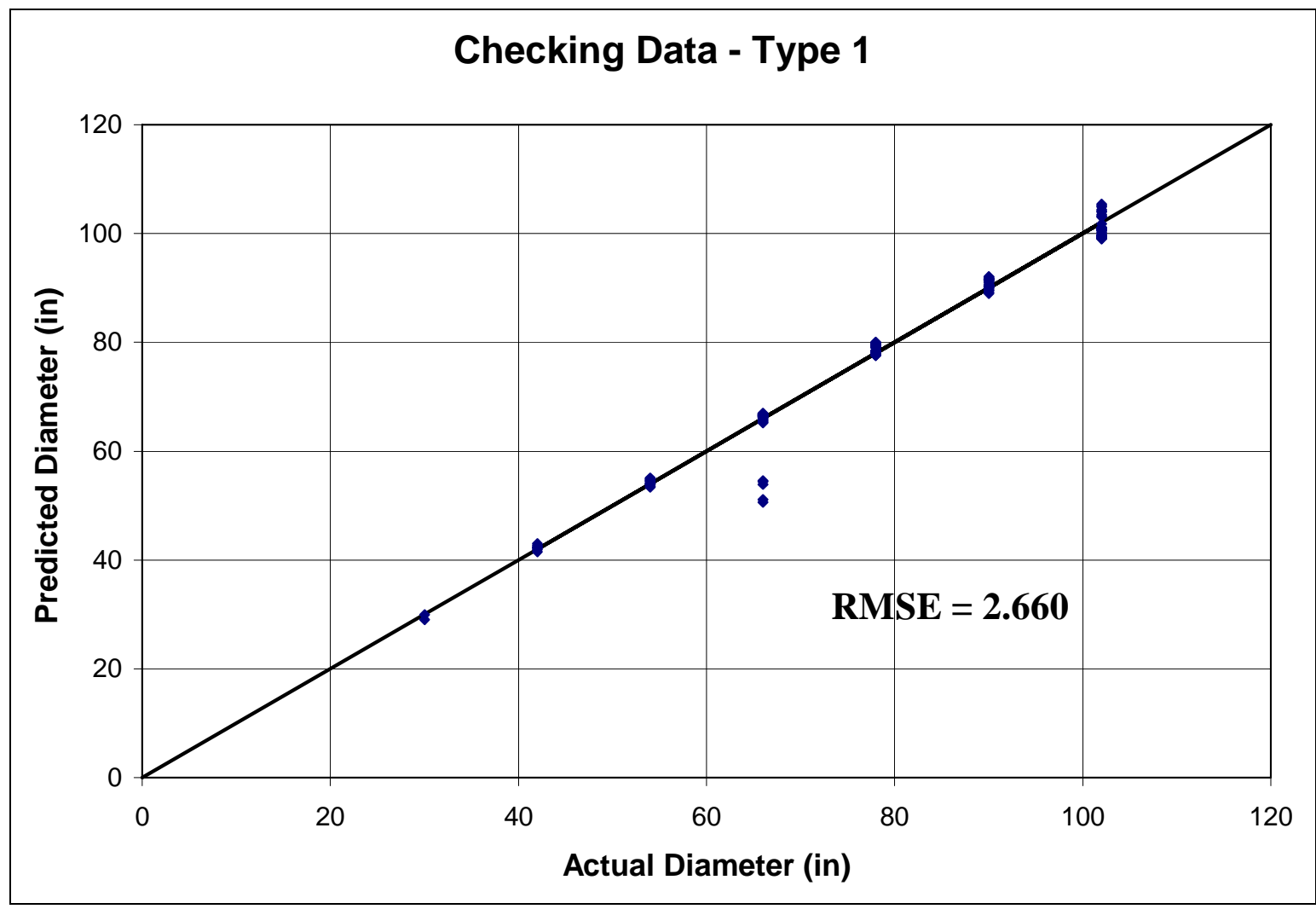

Figure 5.22. Checking data set of Type 1 data. 
The second type of culvert, Type 2 - Critical Depth at Outlet, was evaluated with all six columns of data.. These data were also taken from the 11,550 line compilation of all data produced from Haestad Methods. The type 2 data were also dissected out of the large 11,550 line data set by use of the three conditions presented in Figure 4.4. The difference between Type 1 and Type 2 is the slope. The three conditions are:

$$
\begin{array}{cl}
\text { First Condition, Type 2: } & \frac{H W}{D}<1.5 \\
\text { Second Condition, Type 2: } & \frac{T W}{y_{c}}<1.0 \\
\text { Third Condition, Type 2: } & S_{o}<S_{c}
\end{array}
$$

These three conditions were checked against every row of the 11,550 lines of data. This data set has six columns and 892 rows. The ones that met the three conditions were separated and saved as the data set for use in neural-fuzzy modeling. Those not meeting the conditions were separated and set aside. The results of the training and checking root mean squared error are presented as Figures 5.23 and 5.24.

This data set initially resulted in less than favorable results; therefore an exhaustive study was conducted to determine the optimum membership function and number of MF's. This study resulted in the gaussmf membership function with 3221 , which was utilized for type 2 data. This was the only type of data that deviated from using two membership functions (dsigmf) per input variable. After refining the modeling procedure, the results obtained were acceptable. They were, however, the worst of all six types analyzed. 


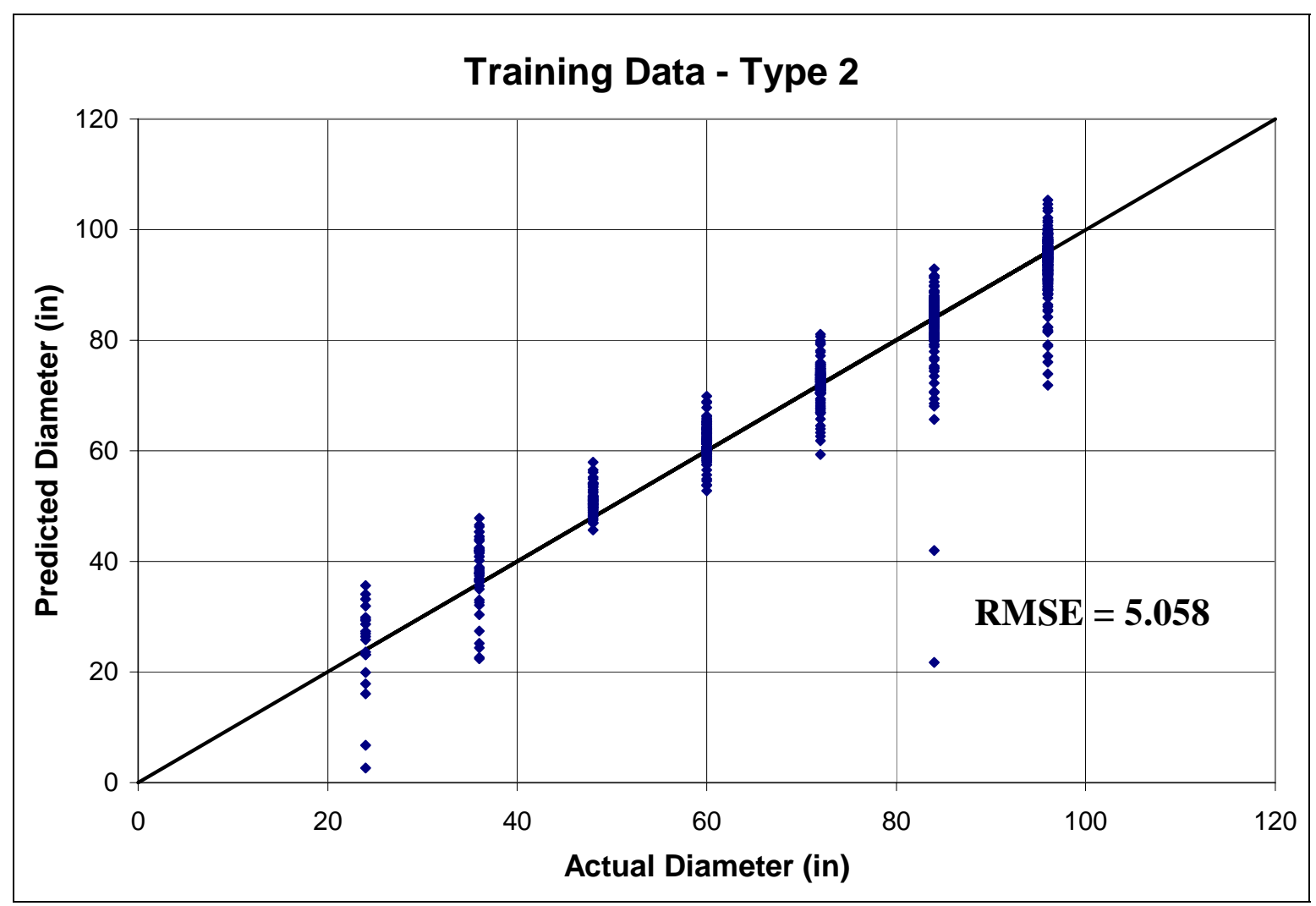

Figure 5.23. Training data set of Type 2 data.

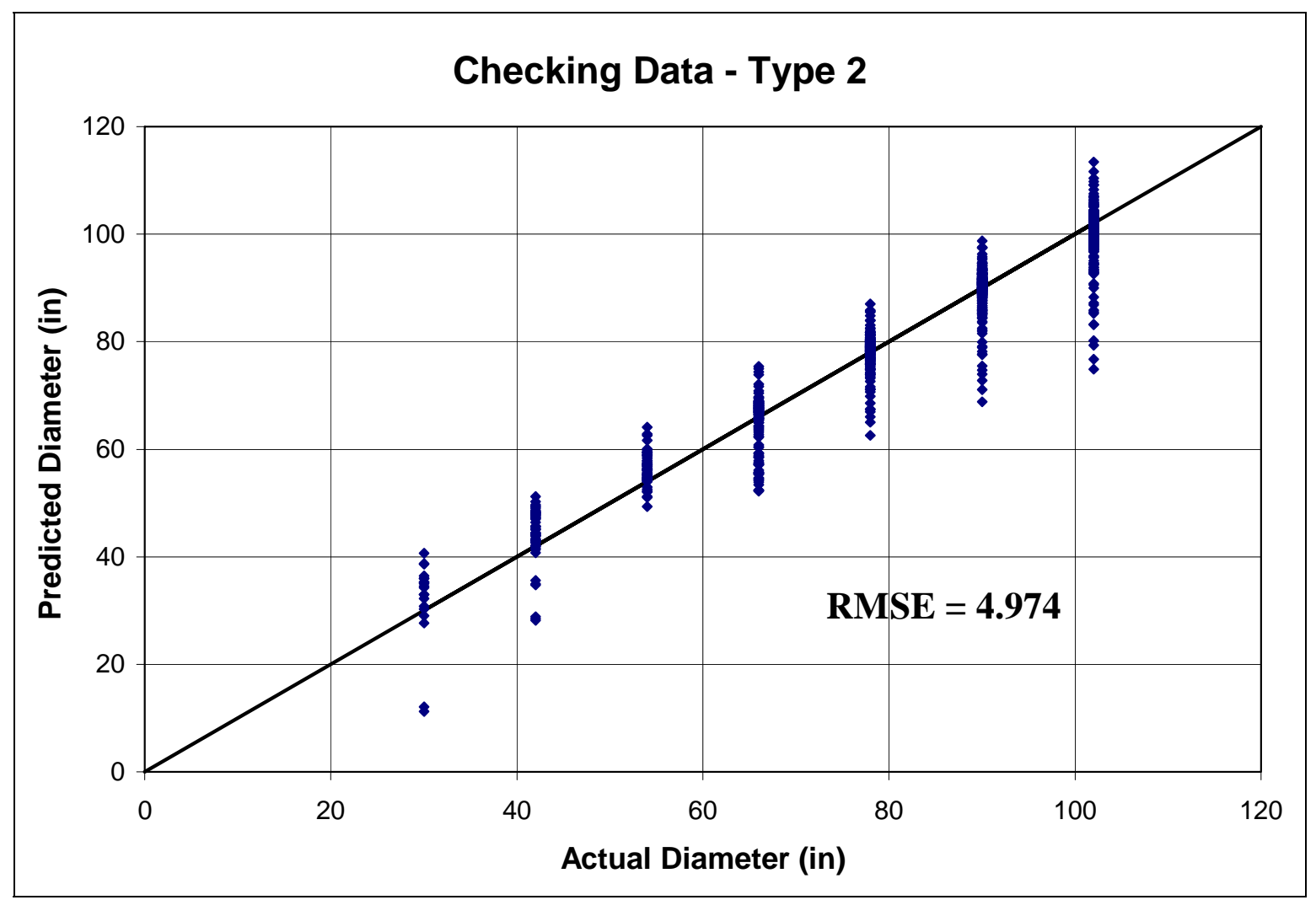

Figure 5.24. Checking data set of Type 2 data. 
The third type of culvert, Type 3 - Tranquil Flow Throughout, was analyzed with all six columns as well. These data were taken from the 11,550 line compilation of all data produced from Haestad Methods. The Type 3 data were dissected out of the large 11,550 line data set by use of the three conditions presented in Figure 4.4. The difference between Type 1 and 2, and type 3 is that the tail water is deeper than the critical depth. The three conditions for type 3 are:

$$
\begin{array}{ll}
\text { First Condition, Type 3: } & \frac{H W}{D}<1.5 \\
\text { Second Condition, Type 3: } & \frac{T W}{D} \leq 1.0 \\
\text { Third Condition, Type 3: } & \frac{T W}{y_{c}}>1.0
\end{array}
$$

These three conditions were checked against every row of the 11,550 lines of data. The ones that met the three conditions were separated and saved as the data set for use in neuralfuzzy modeling. Those not meeting the conditions were separated and set aside. The results of the training and checking root mean squared error are presented as Figures 5.25 and 5.26. Type 3 data produced impressive results. 


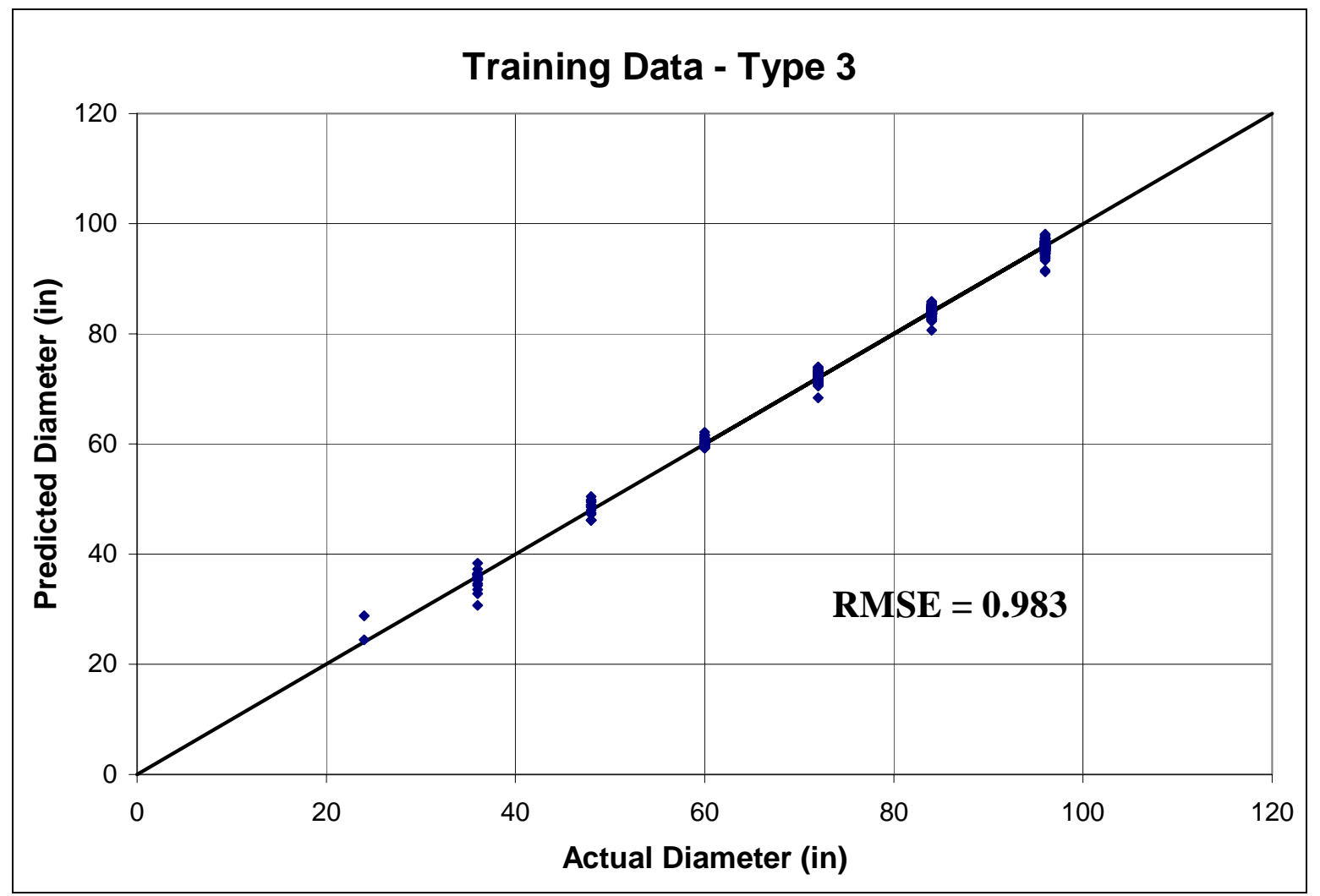

Figure 5.25. Training data set of Type 3 data.

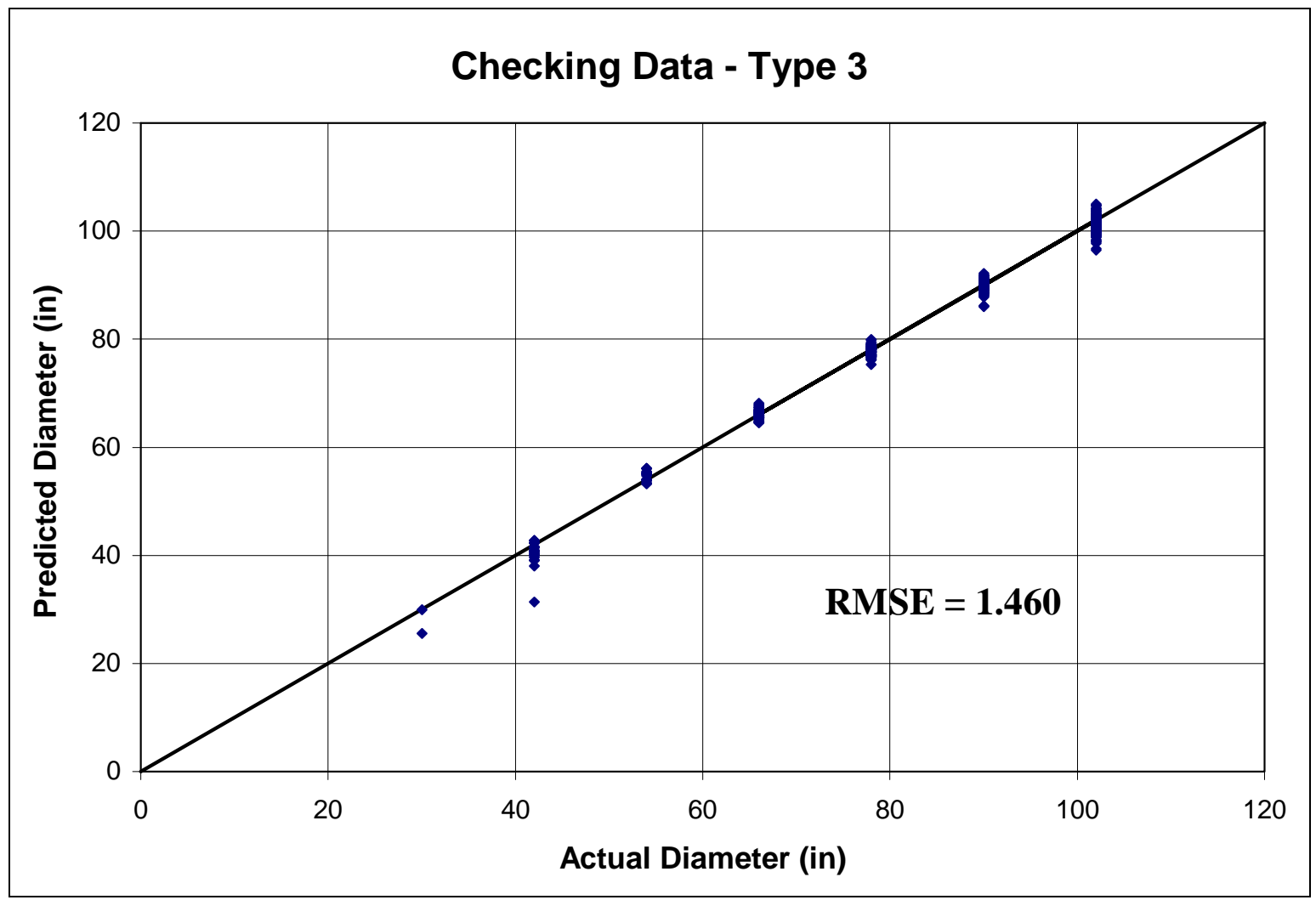

Figure 5.26. Checking data set of Type 3 data. 
The fourth type of data, Type 4 - Submerged Outlet, was analyzed with all six columns as well. These data were also taken from the 11,550 line compilation of all data produced from Haestad Methods. The type 4 data was dissected out of the large 11,550 line data set by use of the two conditions presented in Figure 4.4. The two full flow conditions are:

$$
\begin{array}{ll}
\text { First Condition, Type 4: } & \frac{H W}{D}>1.5 \\
\text { Second Condition, Type 4: } & \frac{T W}{D} \geq 1.0
\end{array}
$$

These two conditions were checked against every row of the 11,550 lines of data. The ones that met the three conditions were separated and saved as the data set for use in neuralfuzzy modeling. Those not meeting the conditions were separated and set aside. The results of the training and checking root mean squared error are presented as Figures 5.27 and 5.28. Type 4 results were not as good as types 1 and 3 , but were better than type 2 . As a confirmation, these results were comparable to the results obtained using the formula generated type 4 data set. 


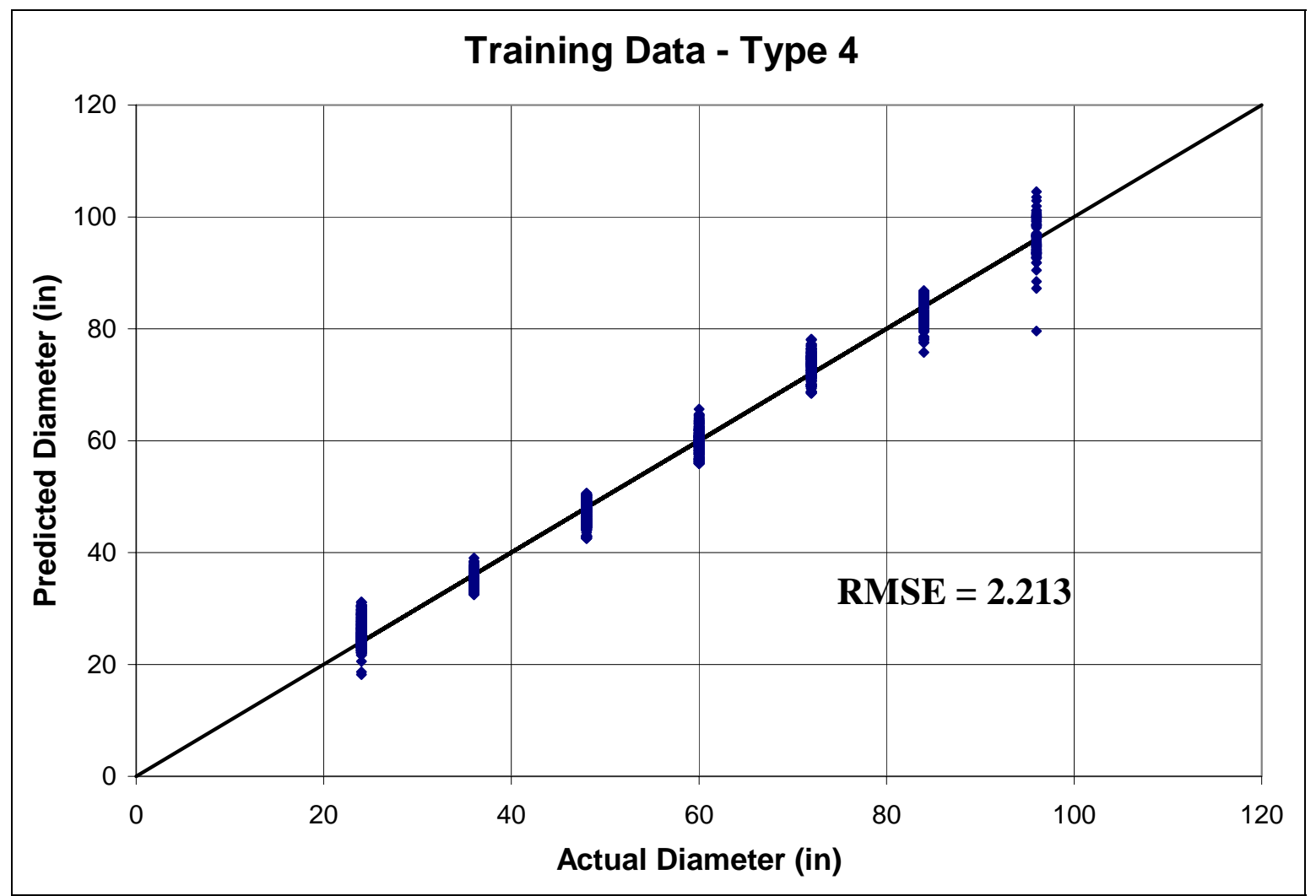

Figure 5.27. Training data set of Type 4 data.

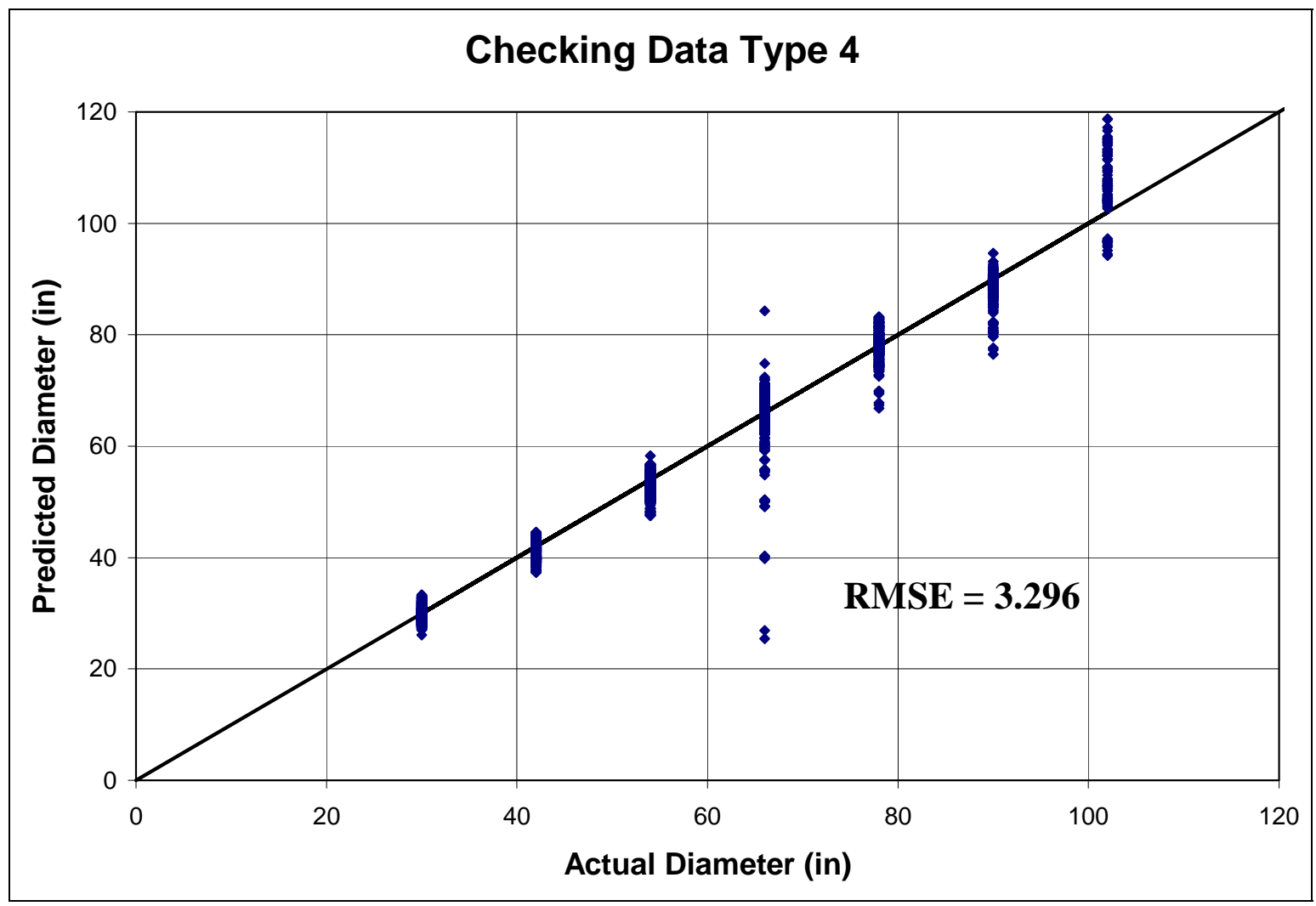

Figure 5.28. Checking data set of Type 4 data. 
The fifth type of data, Type 5 - Rapid Flow at Inlet, was analyzed with all six columns as well. These data were also taken from the 11,550 line compilation of all data produced from Haestad Methods. The type 5 data was dissected out of the large 11,550 line data set by use of the two conditions presented in Figure 4.4. The two conditions are:

$$
\begin{array}{ll}
\text { First Condition, Type 5: } & \frac{H W}{D} \geq 1.5 \\
\text { Second Condition, Type 5: } & \frac{T W}{D} \leq 1.0
\end{array}
$$

These two conditions were checked against every row of the 11,550 lines of data. The ones that met both of the conditions were separated and saved as the data set for use in neuralfuzzy modeling. Those not meeting the conditions were separated and set aside. The results of the training and checking root mean squared error are presented as Figures 5.29 and 5.30. Type 5 data produced good results. They were not as good as type 3 or 6 , but better than type 2 and 4 . As a confirmation, these results also were comparable to the results obtained using the formula generated type 5 data set. 


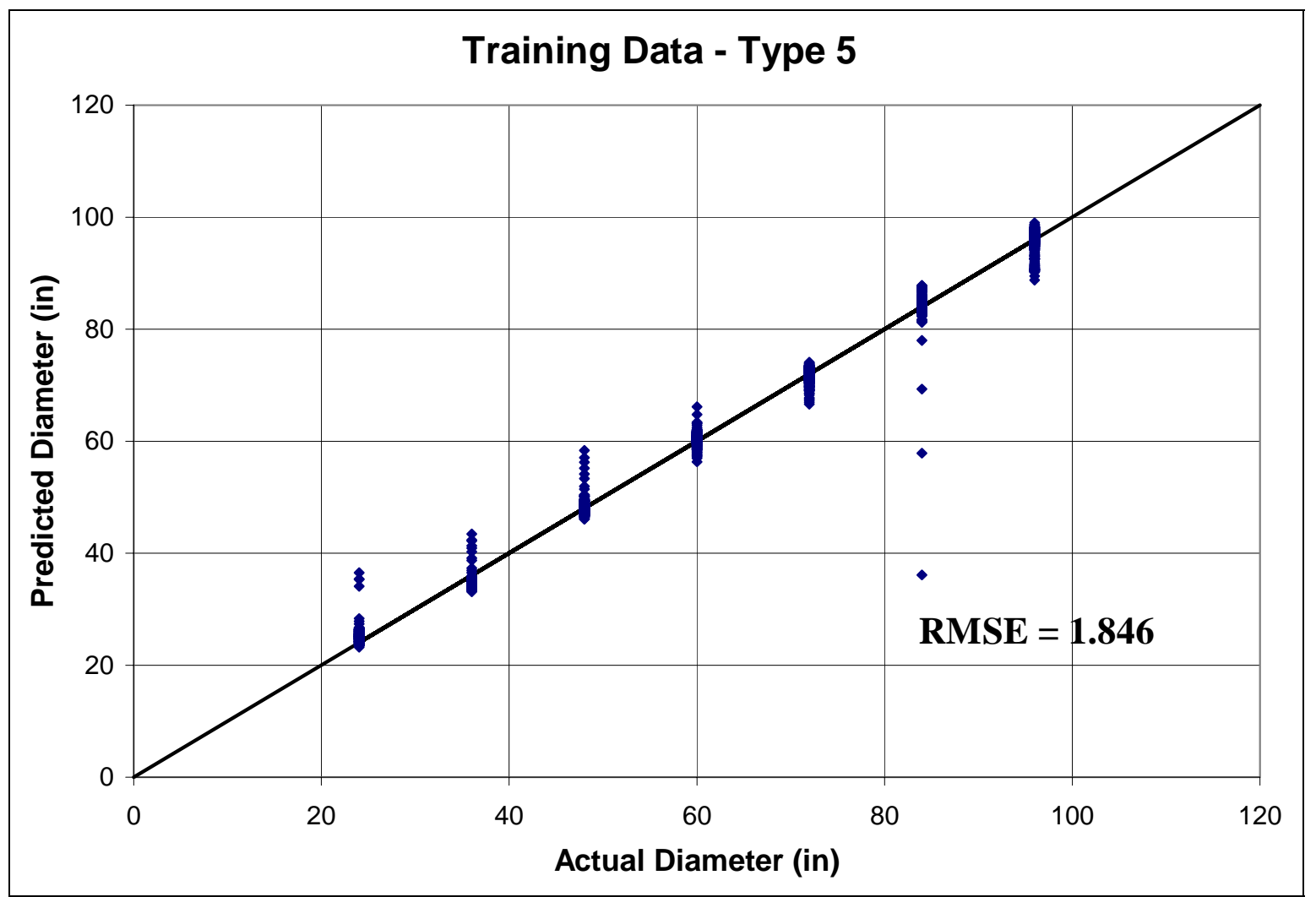

Figure 5.29. Training data set of Type 5 data.

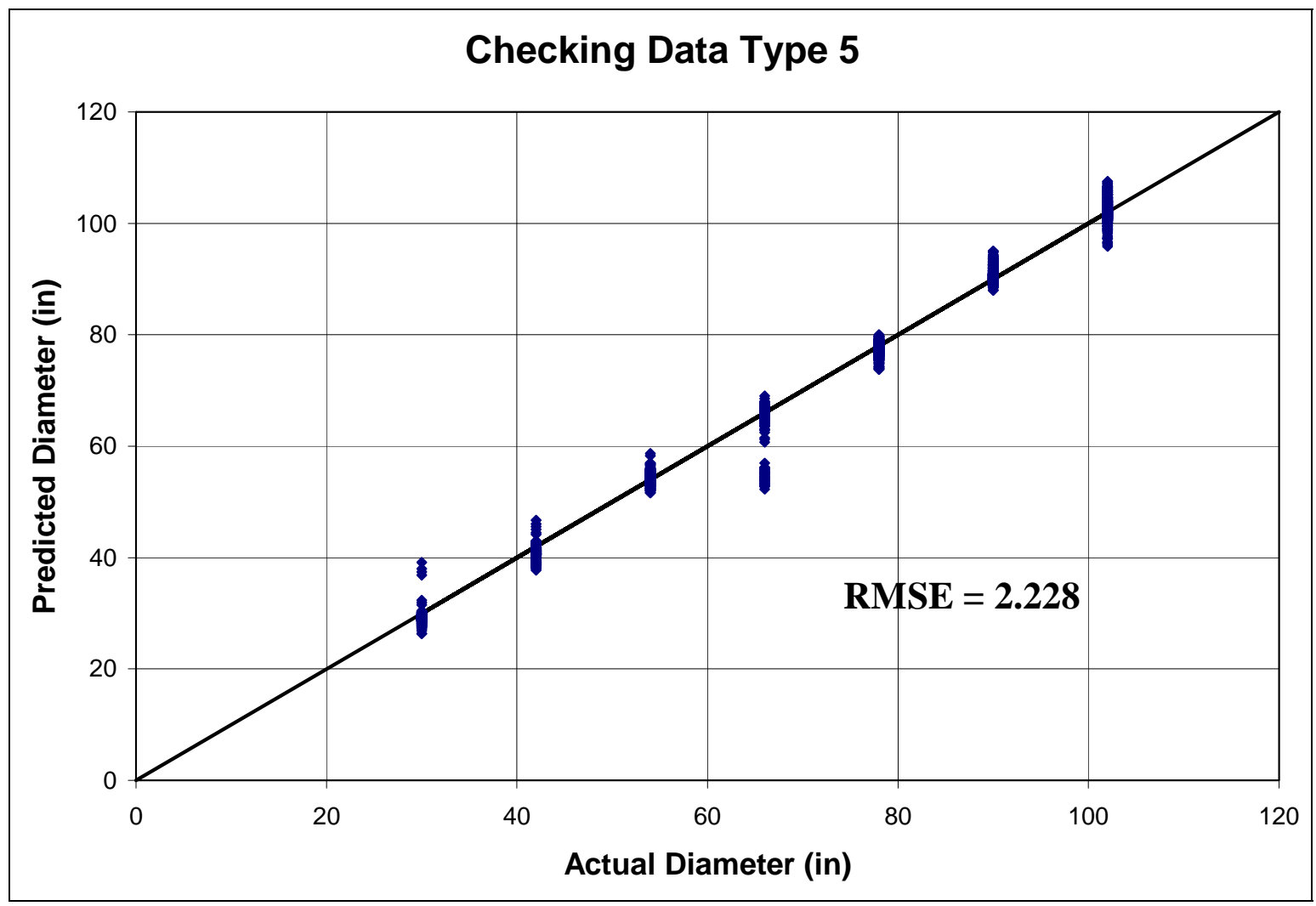

Figure 5.30. Checking data set of Type 5 data. 
The sixth, and final, type of culvert, Type 6 - Free Flow Free Outfall, was analyzed with all six columns as well. These data were also taken from the 11,550 line compilation of all data produced from Haestad Methods. The Type 6 data was also dissected out of the large 11,550 line data set by use of the two conditions presented in Figure 4.4. The difference between the first three types and Type 6 is that the culvert is flowing full. The two conditions are:

$$
\begin{array}{ll}
\text { First Condition, Type 6: } & \frac{H W}{D} \geq 1.5 \\
\text { Second Condition, Type 6: } & \frac{T W}{D} \leq 1.0
\end{array}
$$

These two conditions were checked against every row of the 11,550 lines of data. The ones that met both conditions were separated and saved as the data set for use in neural-fuzzy modeling. This data set has six columns and 4,840 rows. Those not meeting the conditions were separated and set aside. The training and checking root mean squared errors are presented as Figures 5.31 and 5.32. Type 6 data, like type 3, also produced impressive results. They were the best of all six types analyzed. 


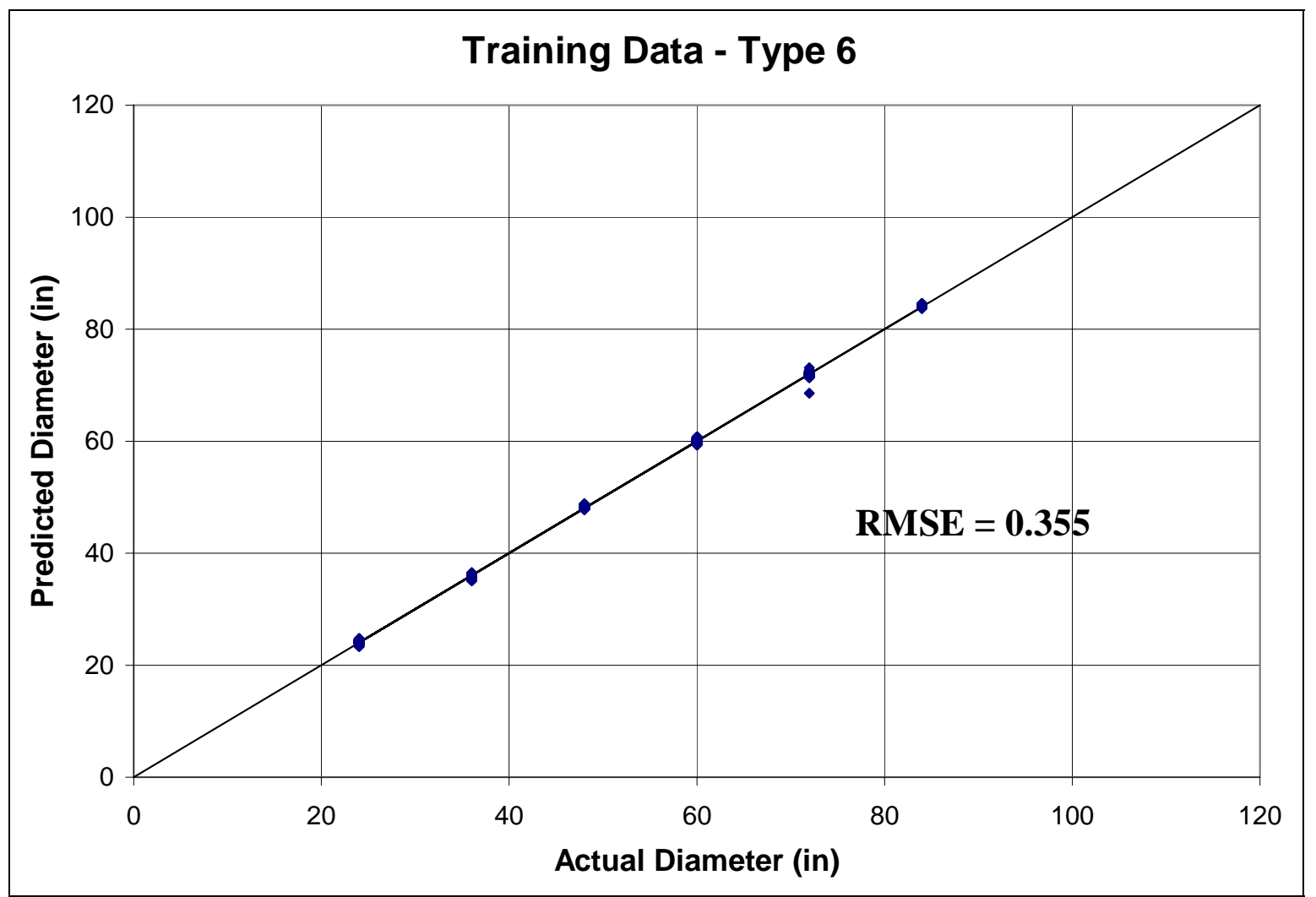

Figure 5.31. Training data set of Type 6 data.

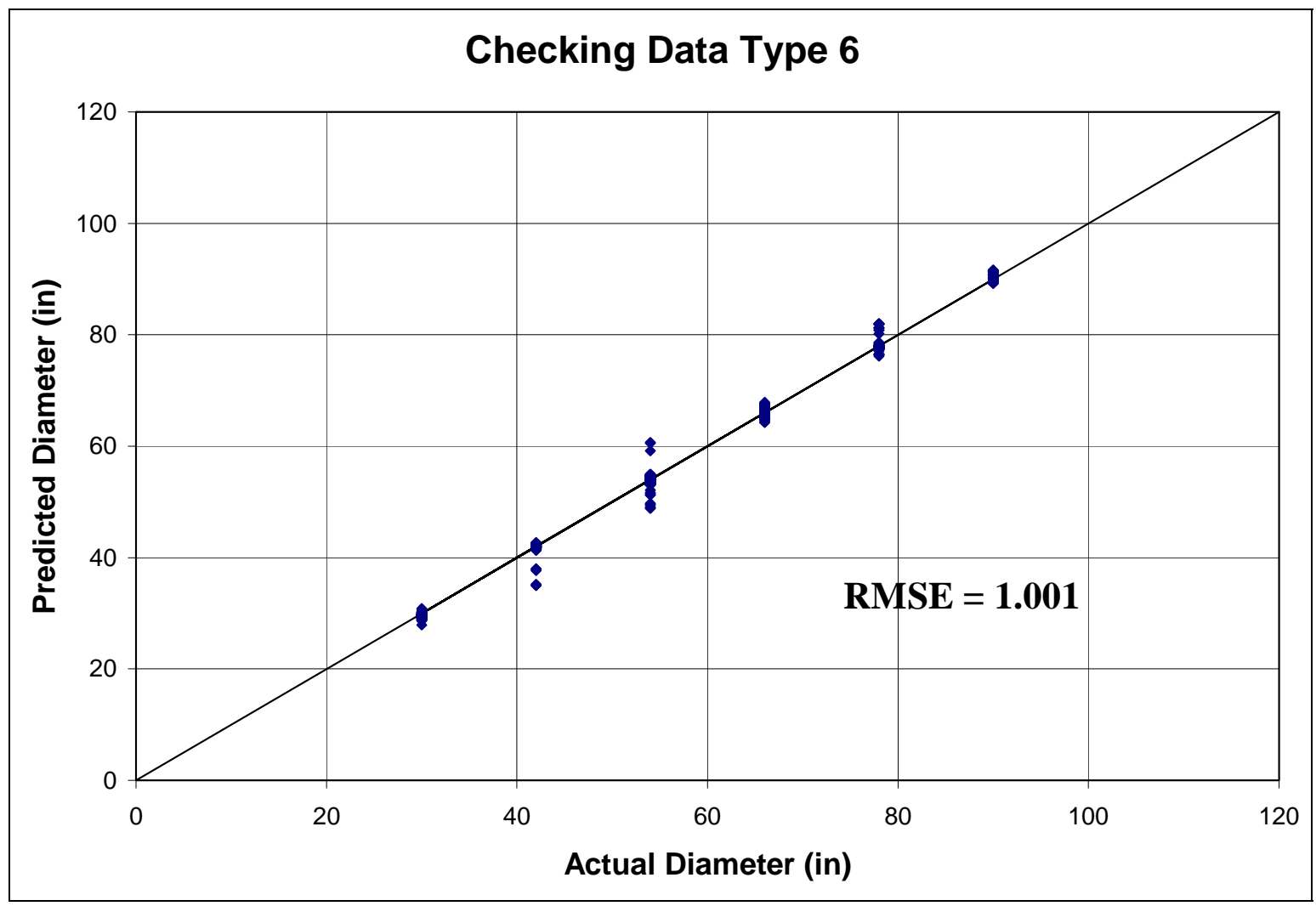

Figure 5.32. Checking data set of Type 6 data. 


\subsection{Quantifying the Results}

In order to quantify the error results, the fact that culvert designers are not looking for an exact numerical diameter, but the nearest approximate standard diameter for a specified geometry and flow rate combination, has been taken into consideration. With this in mind, the results were bracketed into six inches above the actual diameter and six inches below the actual diameter, which corresponds to the mid-point between standard pipe sizes. Therefore, if the data fell into this range of predicted diameters, they were rounded to the nearest standard pipe size. This process creates permissible error bounds for the data about each standard pipe diameter. In Figure 5.33 below there are several data points that are not within these error bounds. However, some of these results do fall into the range of six inches below and six inches above the actual diameter as depicted by the dotted line. In this particular example, 35 percent of the data points were not within the bracket range. These were the predicted data points that contributed to the large root mean squared error associated with this particular model run. This means that 65 percent of the data did fall within the range and were rounded to the nearest standard pipe size.

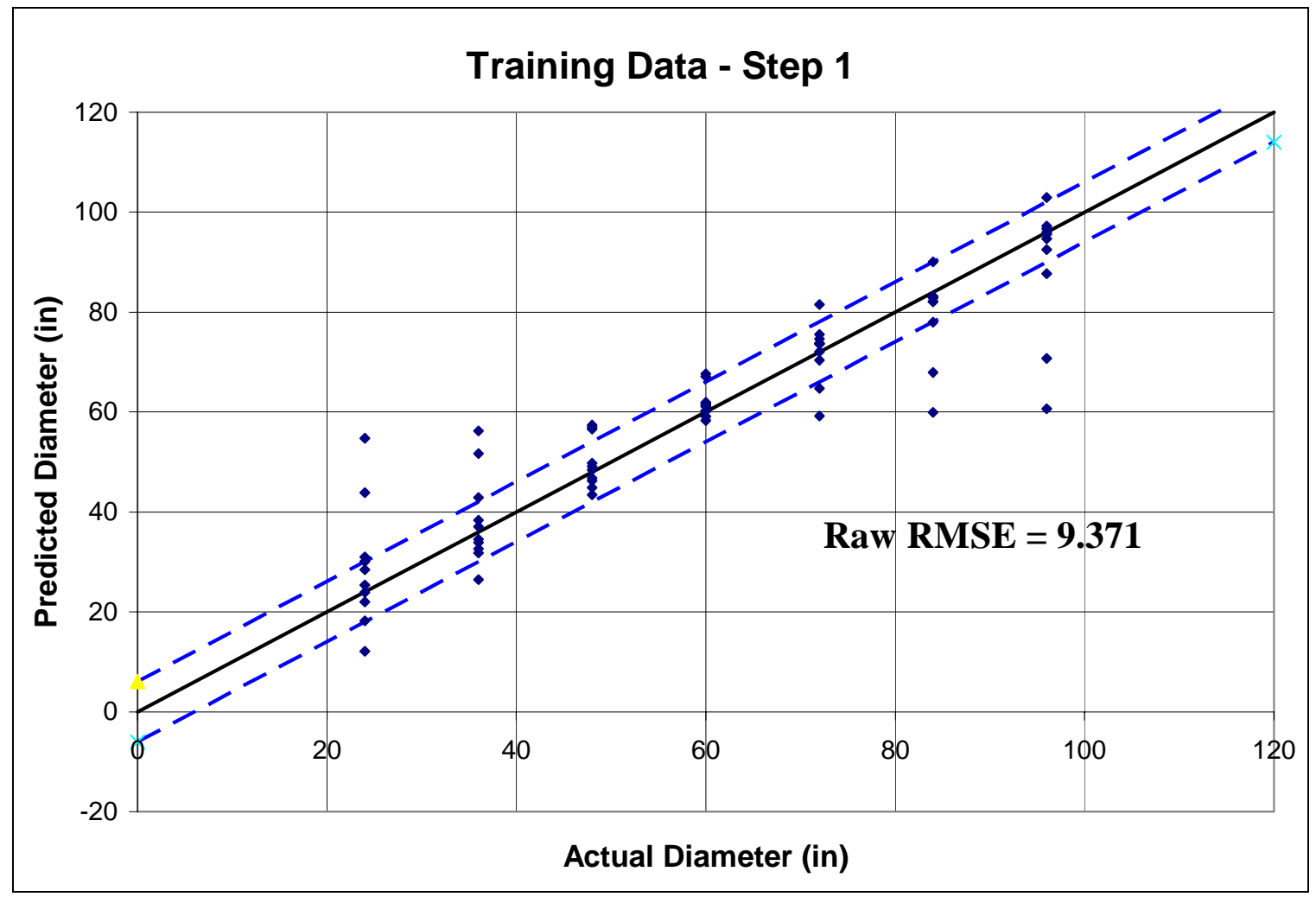

Figure 5.33. Example plot of training data with brackets above and below the expected result.

The results of all the data sets are presented in terms of what percent fell outside of the error bounds. The optimal result would be zero falling outside the error bounds. Table 5.2 
below shows the data sets and their respective percent falling outside of the error bounds, for step 1 through 4 data sets. These high percentages falling outside the error bounds correspond to the higher error results presented earlier in Table 5.1 and Figures 5.1 through 5.20.

\begin{tabular}{|c|c|c|}
\hline Nomenclature & Training, $\%$ outside & Checking, $\%$ outside \\
\hline Step 1 & 28.570 & 47.620 \\
\hline Step 2 & 18.570 & 17.500 \\
\hline Step 3 & 18.210 & 17.740 \\
\hline \multirow{5}{*}{ 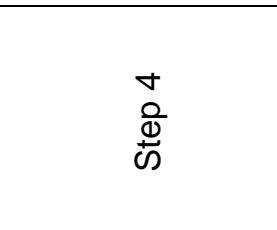 } & 47.79 & 53.56 \\
\hline & 38.25 & 41.89 \\
\hline & 33.90 & 38.54 \\
\hline & 26.56 & 27.05 \\
\hline & 17.96 & 18.35 \\
\hline
\end{tabular}

The results obtained with the six culvert type data sets were also analyzed to determine how well they fit the error bounds. Table 5.3 below lists the results of this error bound analysis. Additionally Figures 5.34 through 5.45 show how well these results fit into the error bounds.

\begin{tabular}{|c|c|c|}
\hline \multicolumn{3}{|c|}{ Table 5.3. Percent of data points falling outside error bounds for six } \\
culvert types. \\
\hline Nraining, \% outside & Checking, \% outside \\
\hline Nypen 1 & 0.00 & 2.89 \\
\hline Type 2 & 6.47 & 9.30 \\
\hline Type 3 & 0.00 & 0.24 \\
\hline Type 4 & 0.00 & 0.00 \\
\hline Type 5 & 0.74 & 2.34 \\
\hline Type 6 & 0.00 & 0.58 \\
\hline
\end{tabular}

Type 2 results were the worst, of all six types analyzed; however, more than 90 percent were within the error bounds, which is acceptable for culvert design. 


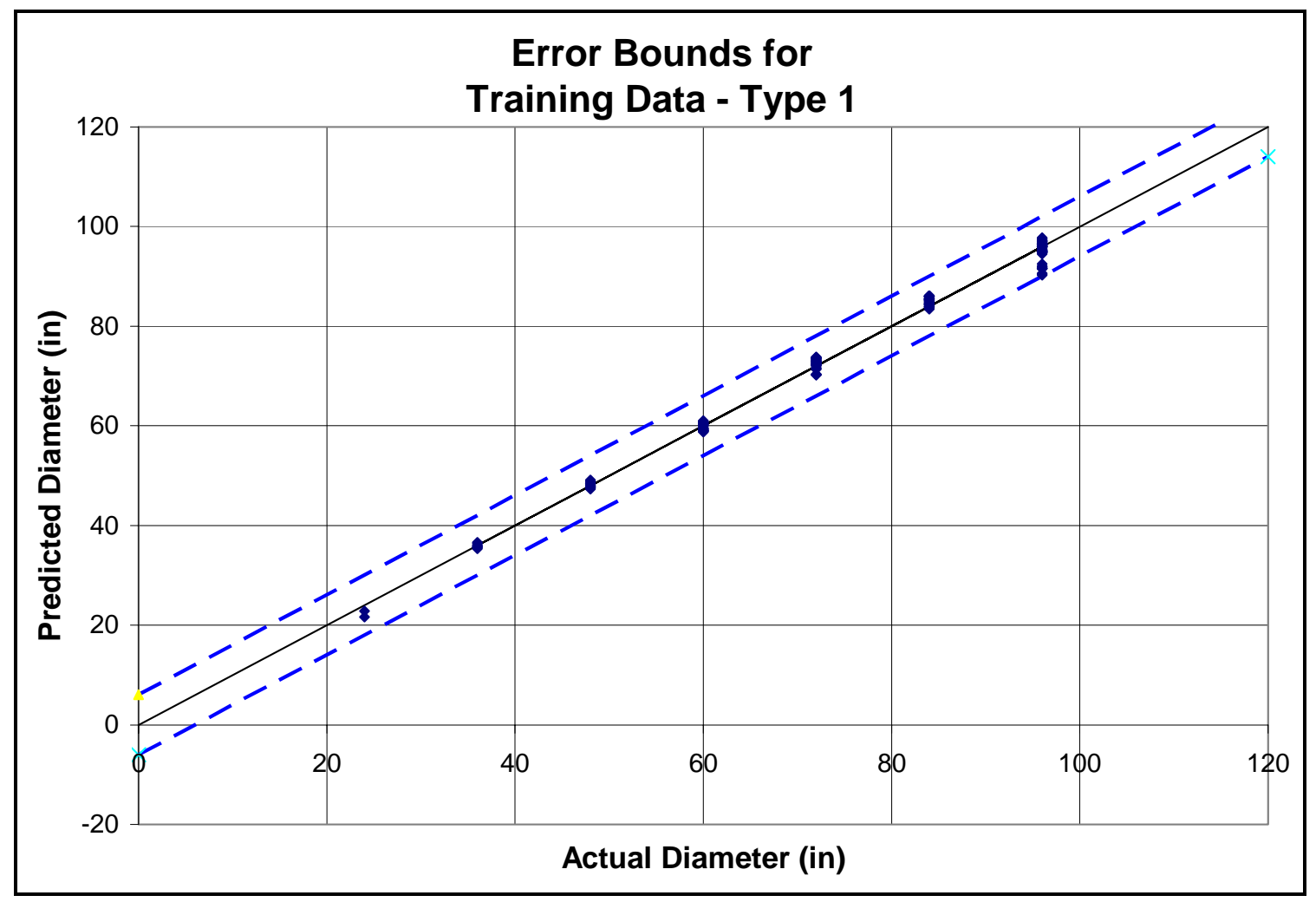

Figure 5.34. Type 1 training data with error bounds above and below the expected result.

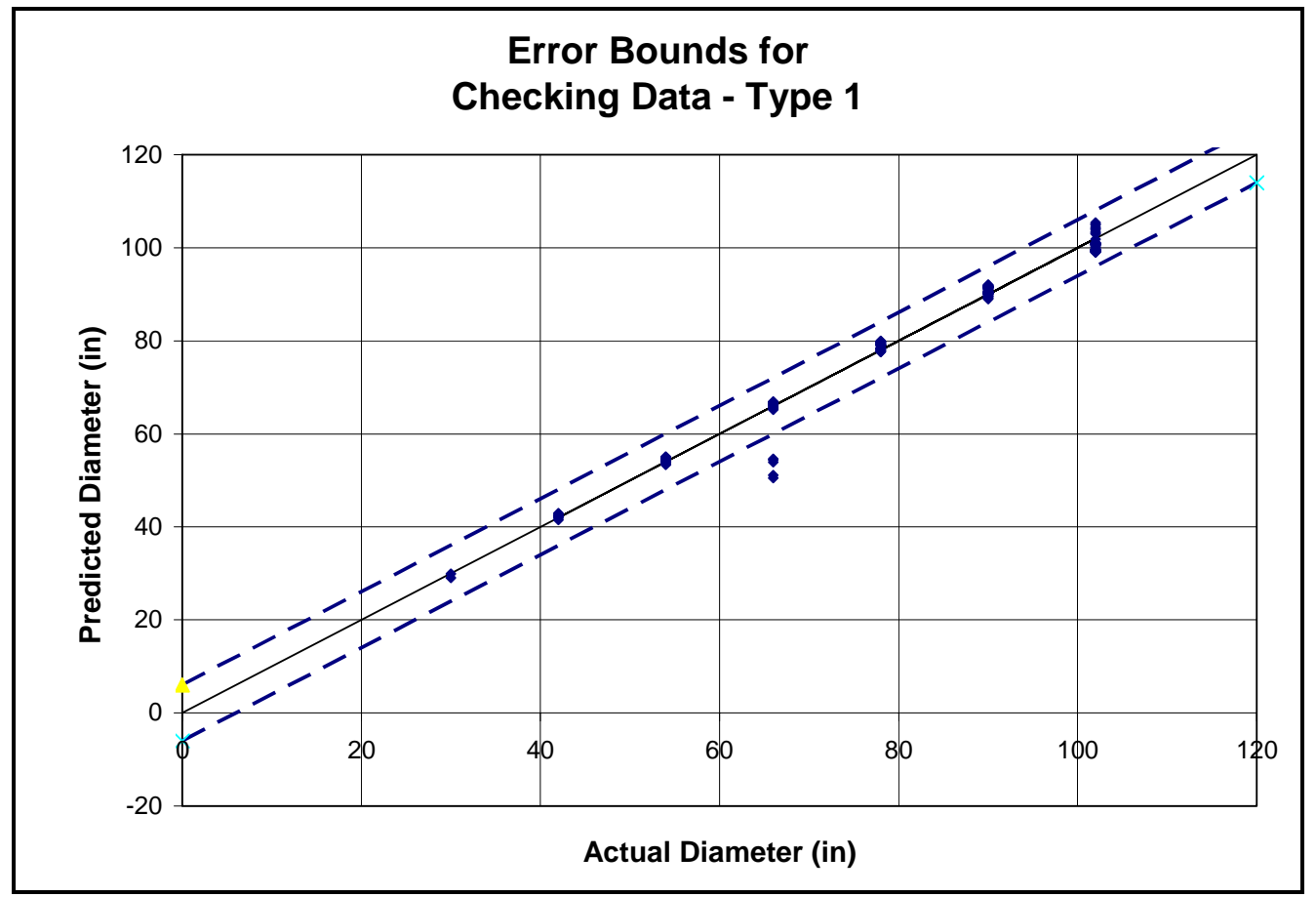

Figure 5.35. Type 1 checking data with error bounds above and below the expected result. 


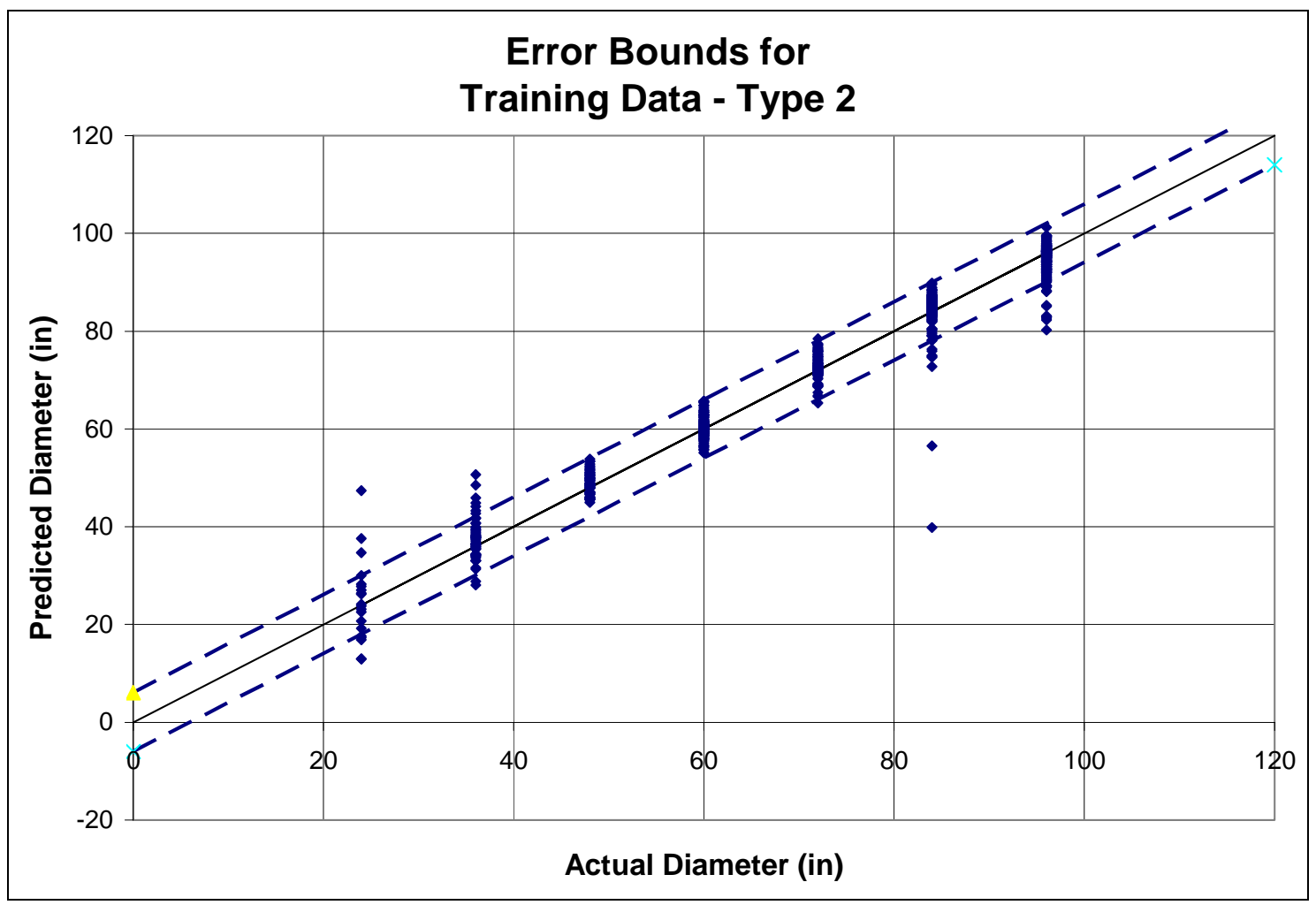

Figure 5.36. Type 2 training data with error bounds above and below the expected result.

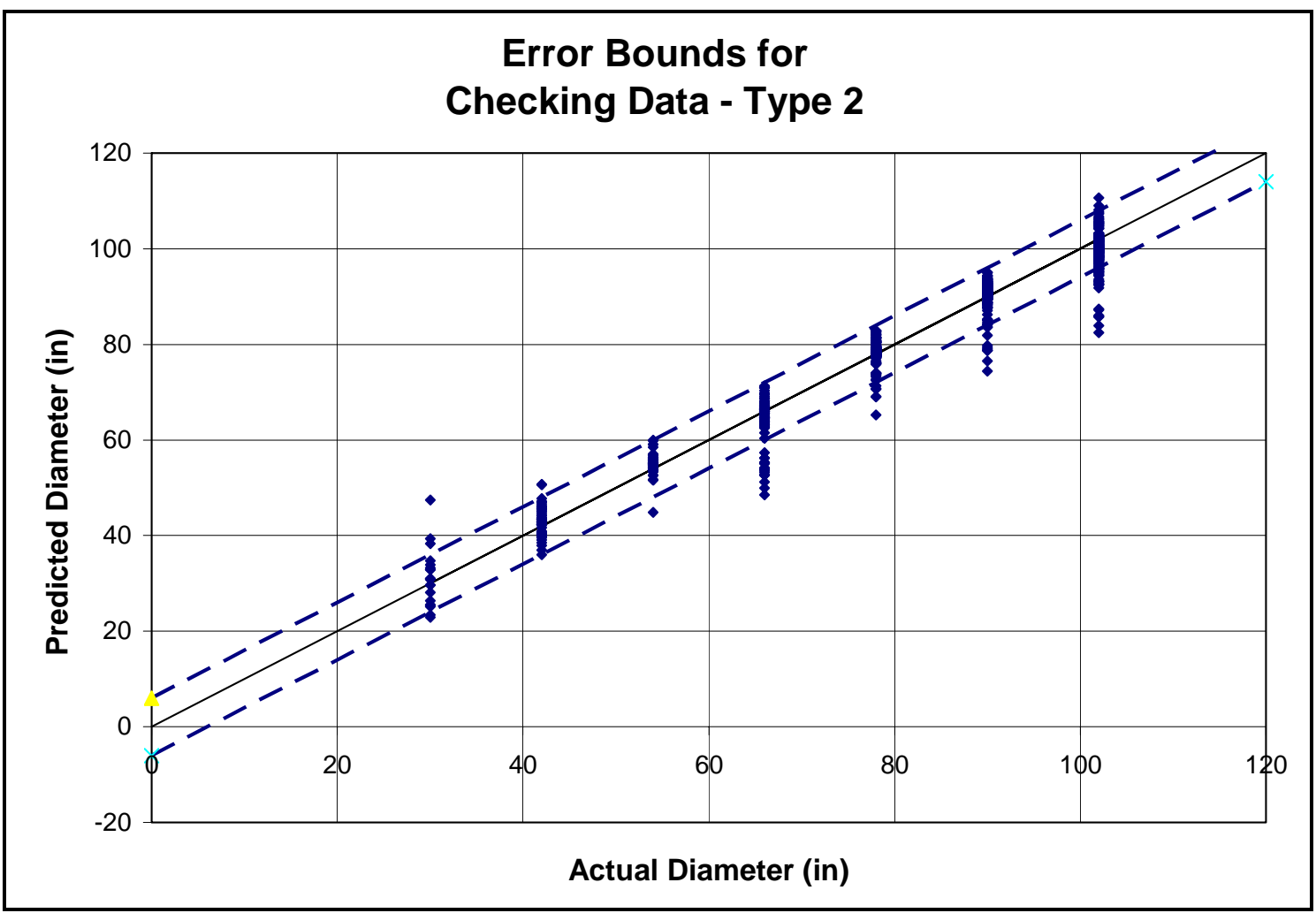

Figure 5.37. Type 2 checking data with error bounds above and below the expected result. 


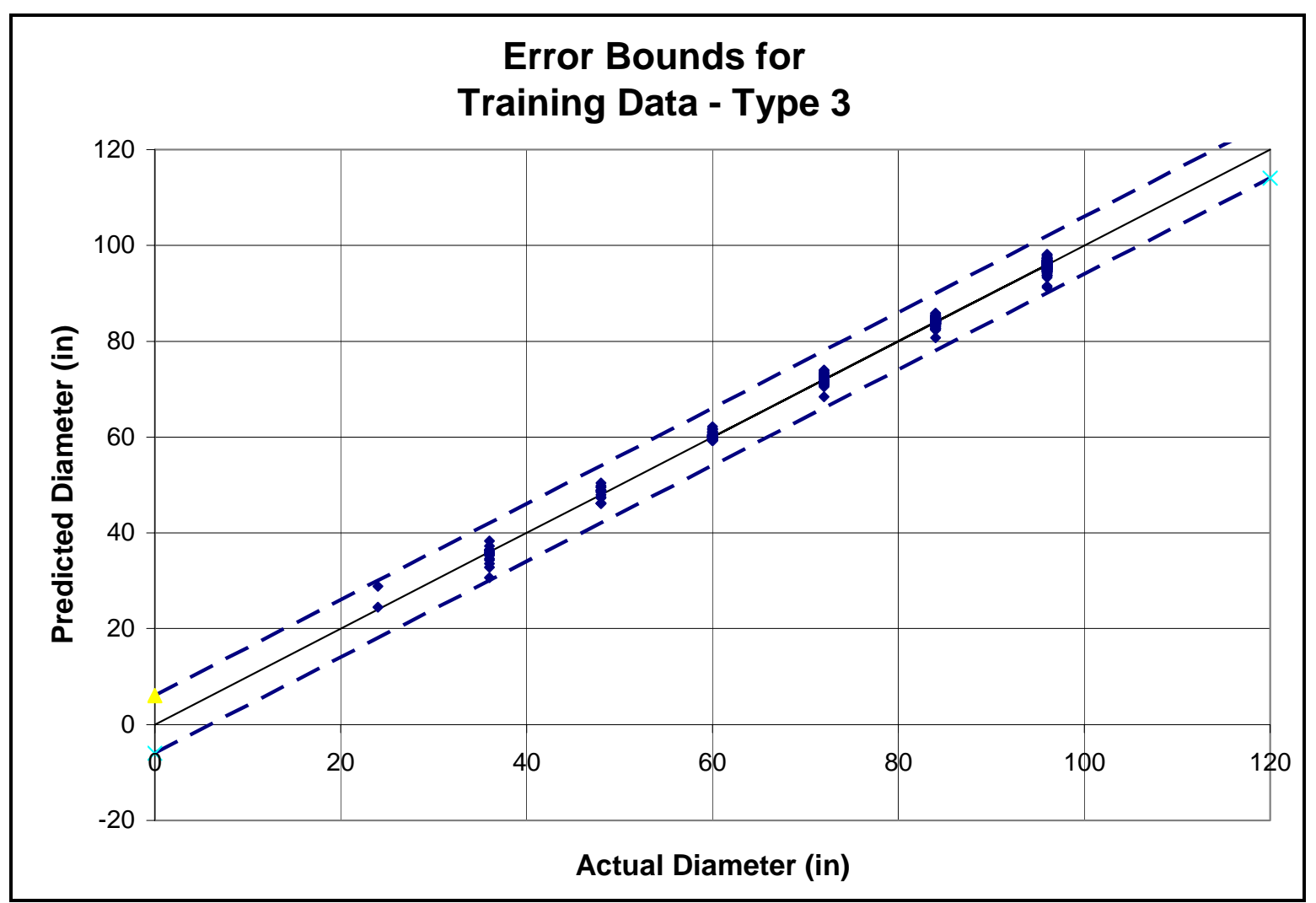

Figure 5.38. Type 3 training data with error bounds above and below the expected result.

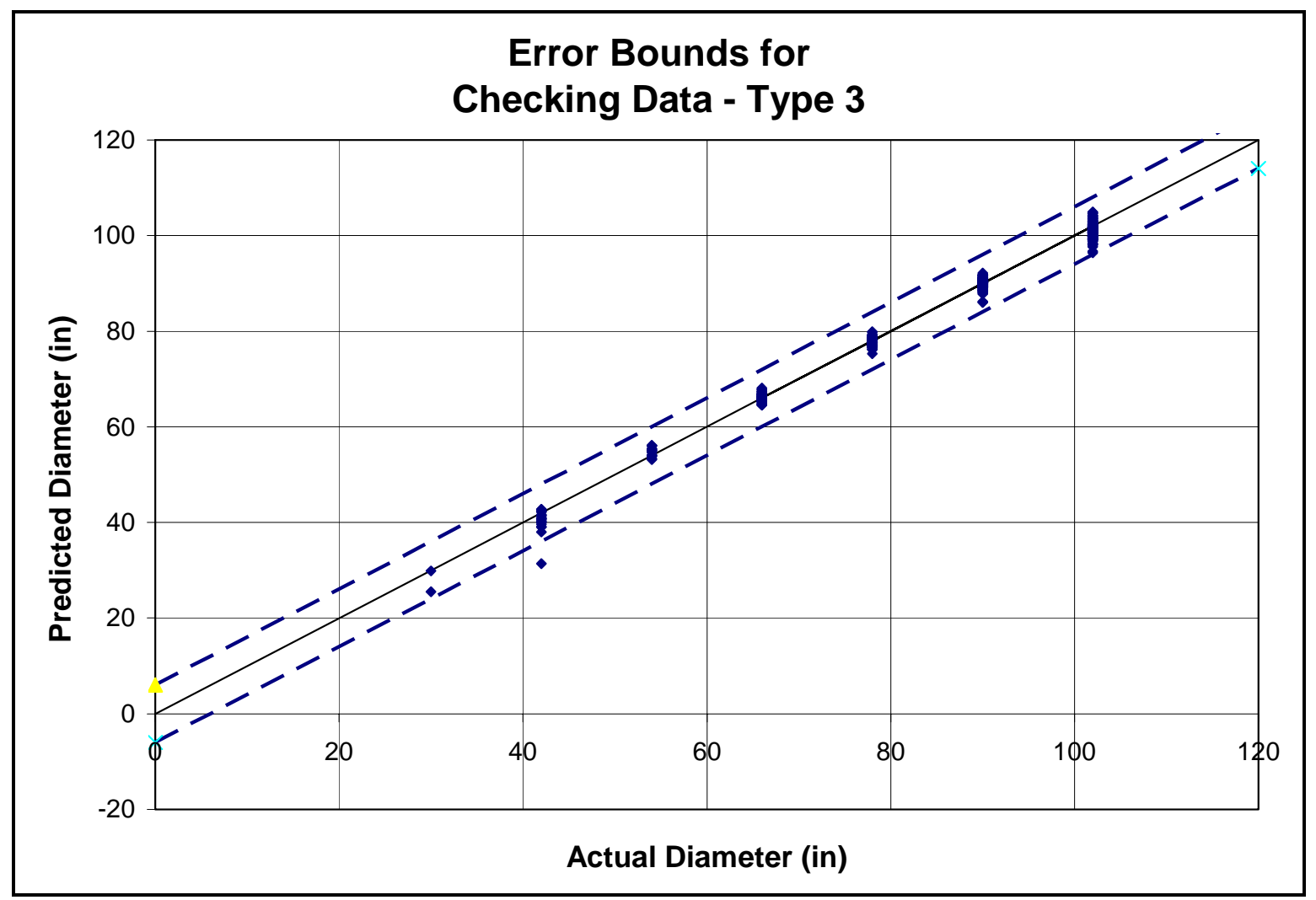

Figure 5.39. Type 3 checking data with error bounds above and below the expected result. 


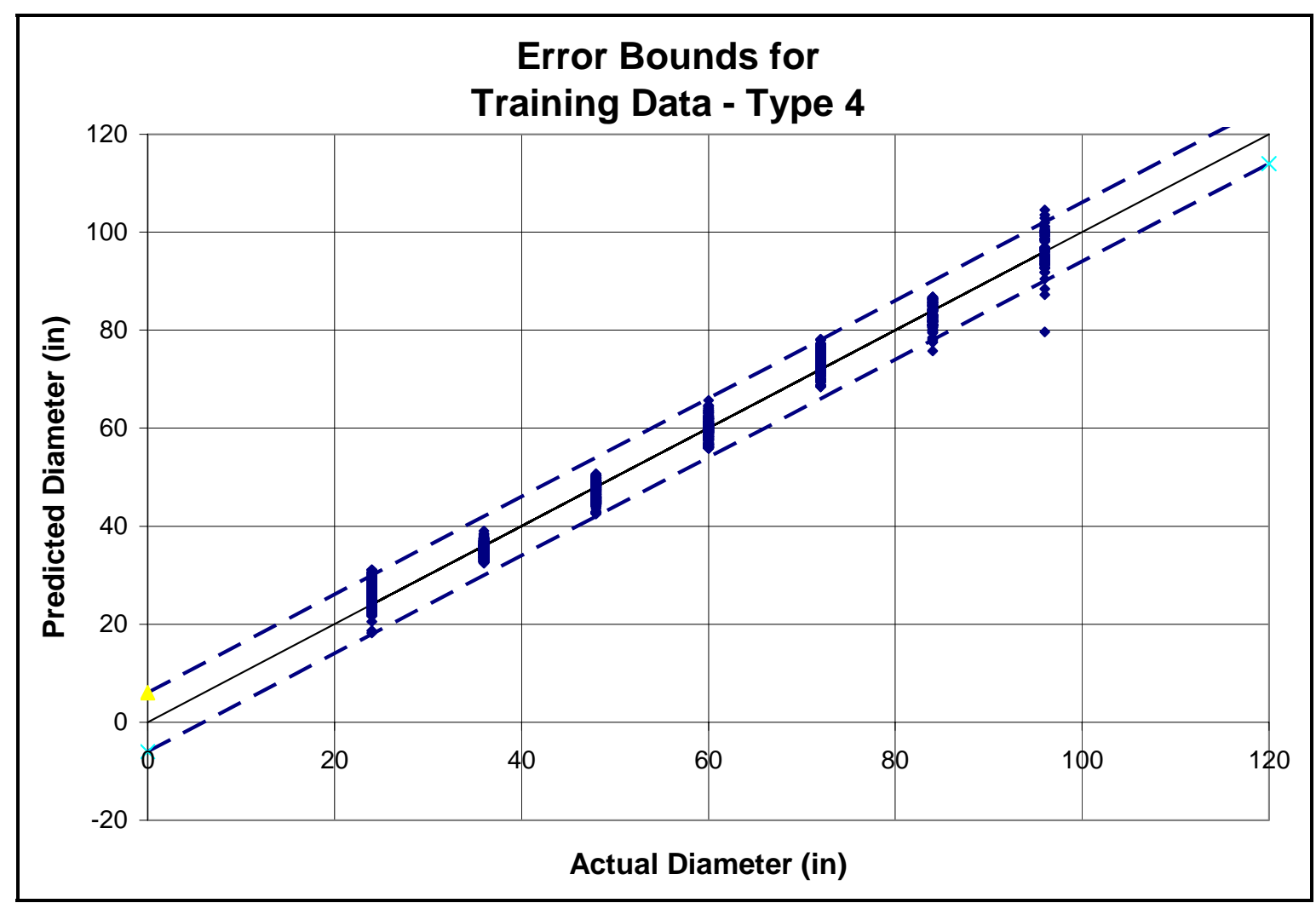

Figure 5.40. Type 4 training data with error bounds above and below the expected result.

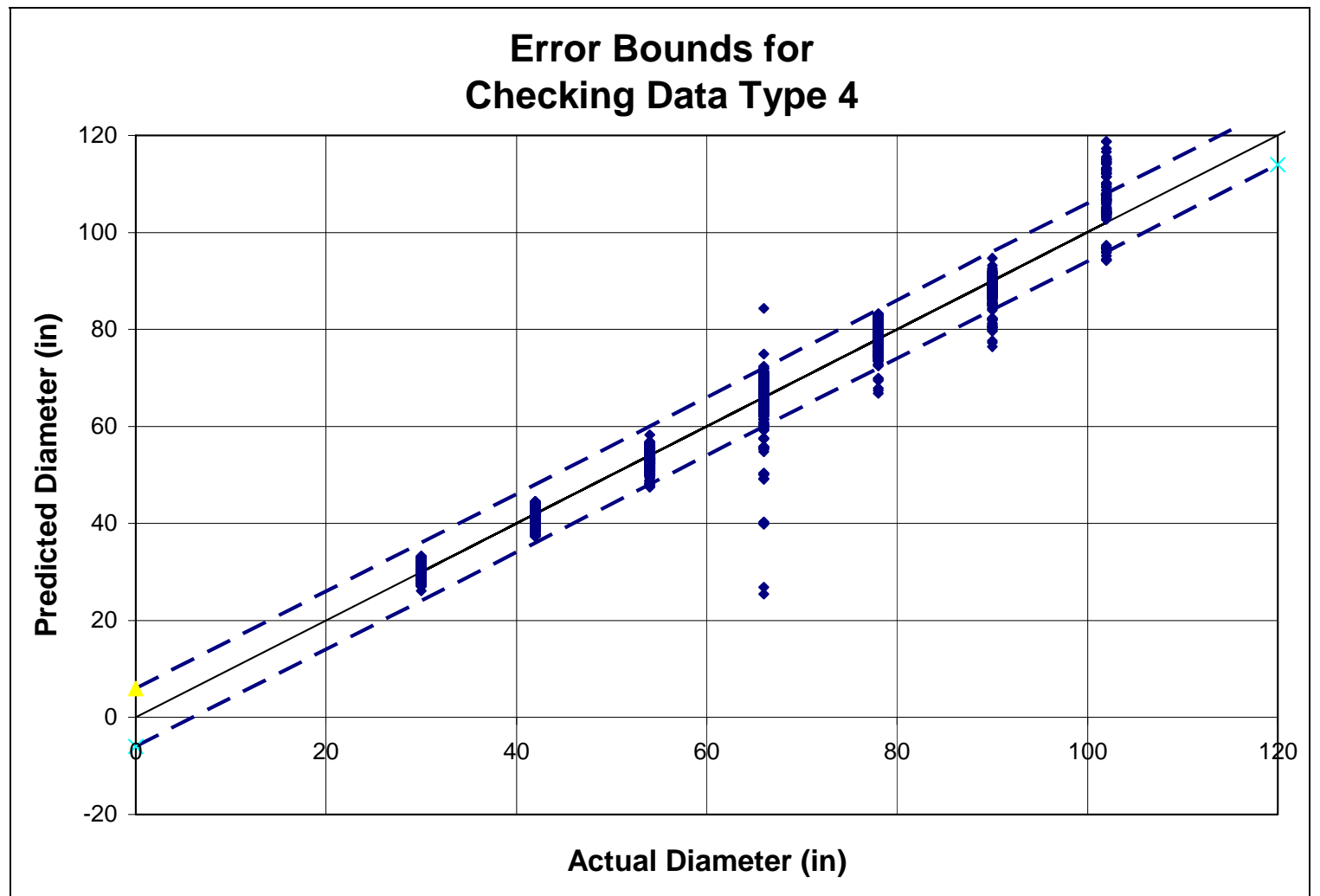

Figure 5.41. Type 4 checking data with error bounds above and below the expected result. 


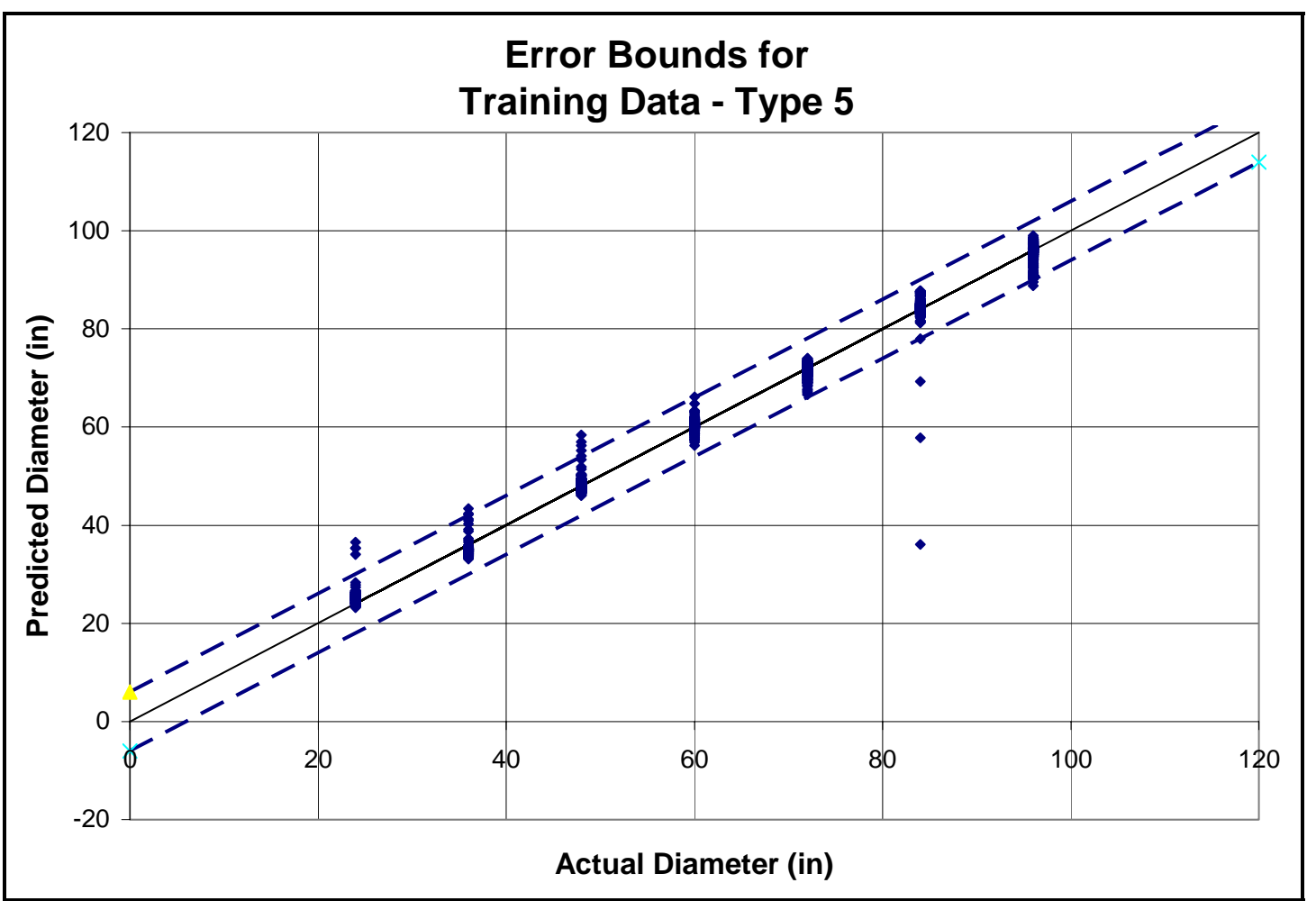

Figure 5.42. Type 5 training data with error bounds above and below the expected result.

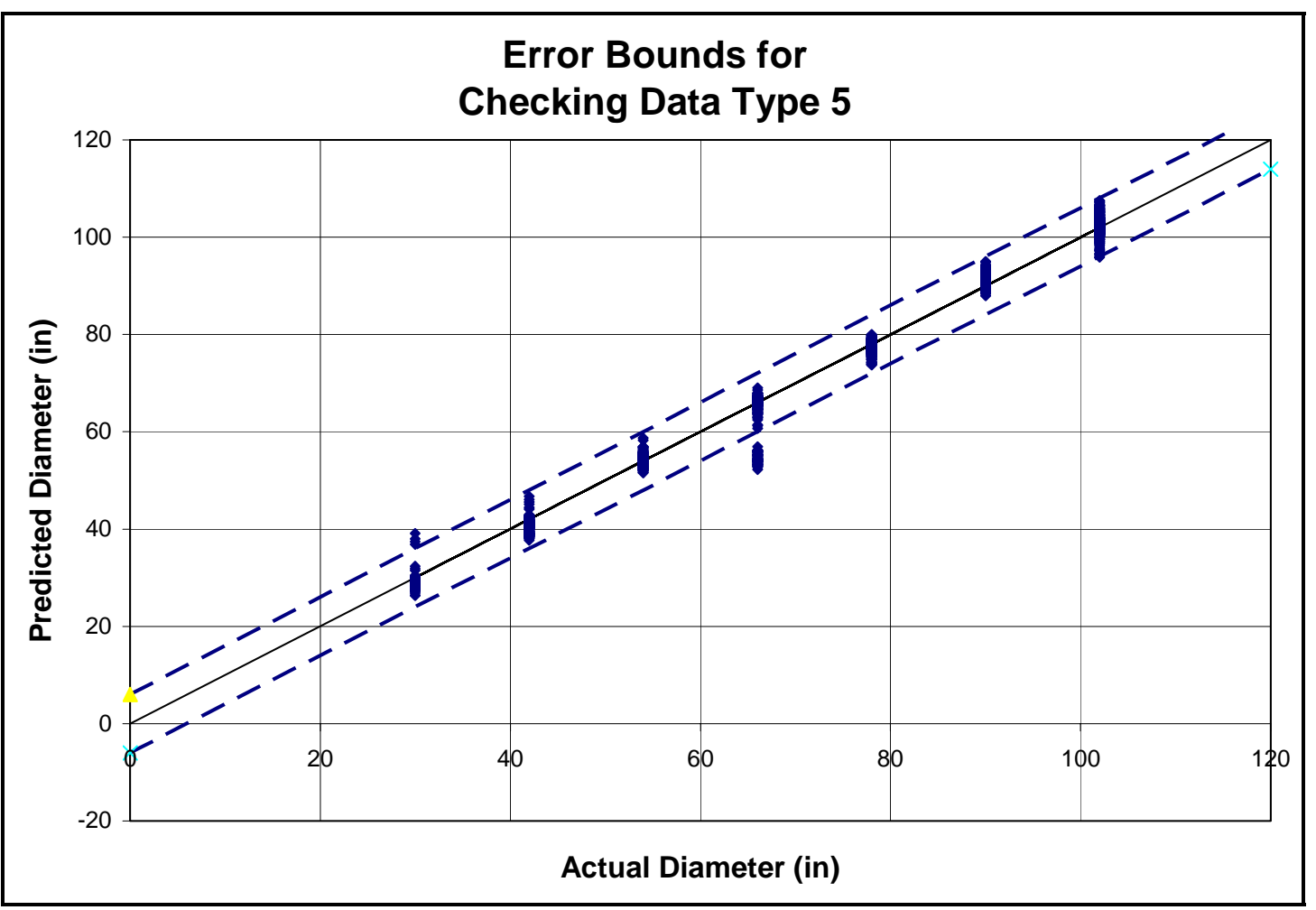

Figure 5.43. Type 5 checking data with error bounds above and below the expected result. 


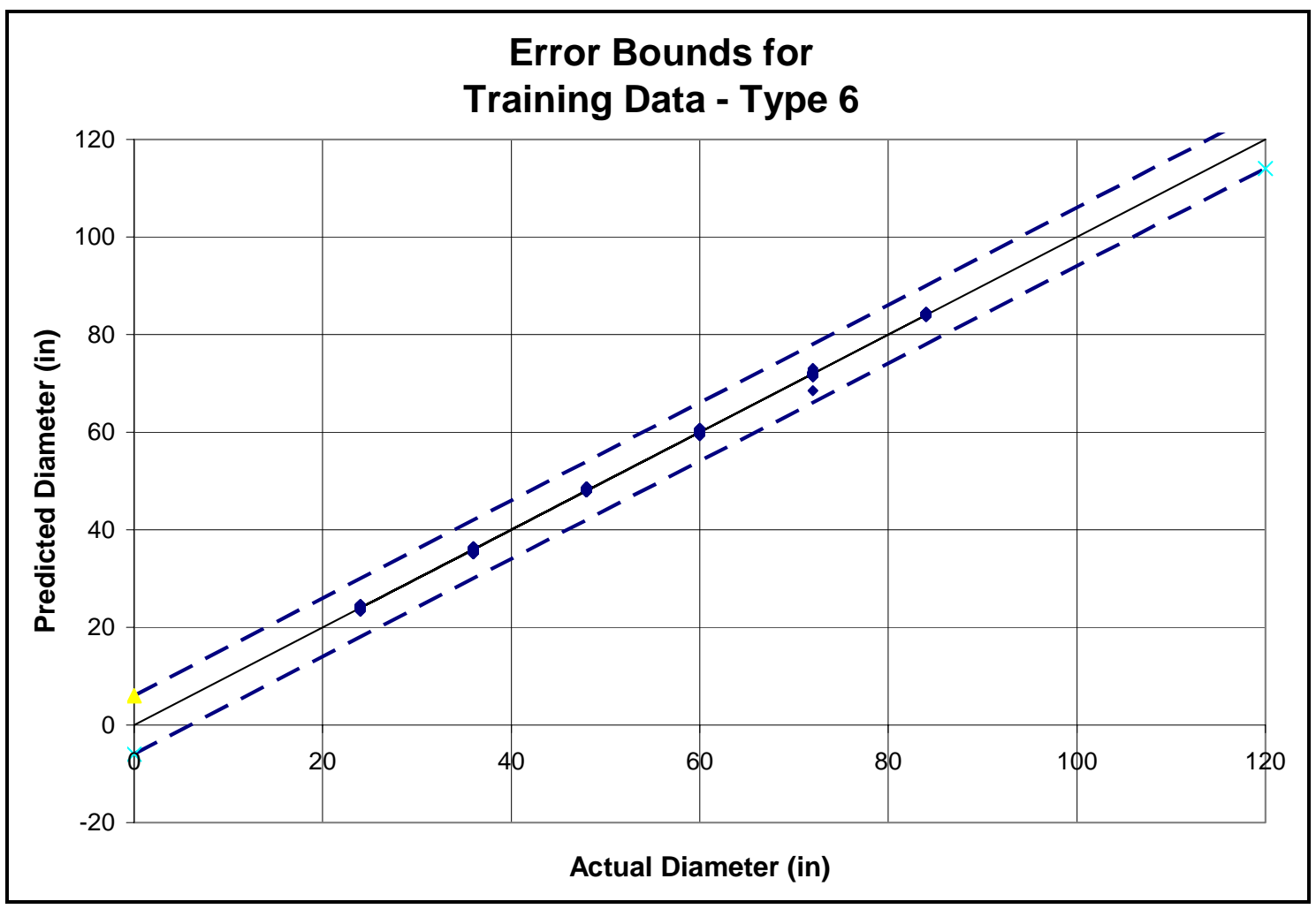

Figure 5.44. Type 6 training data with error bounds above and below the expected result.

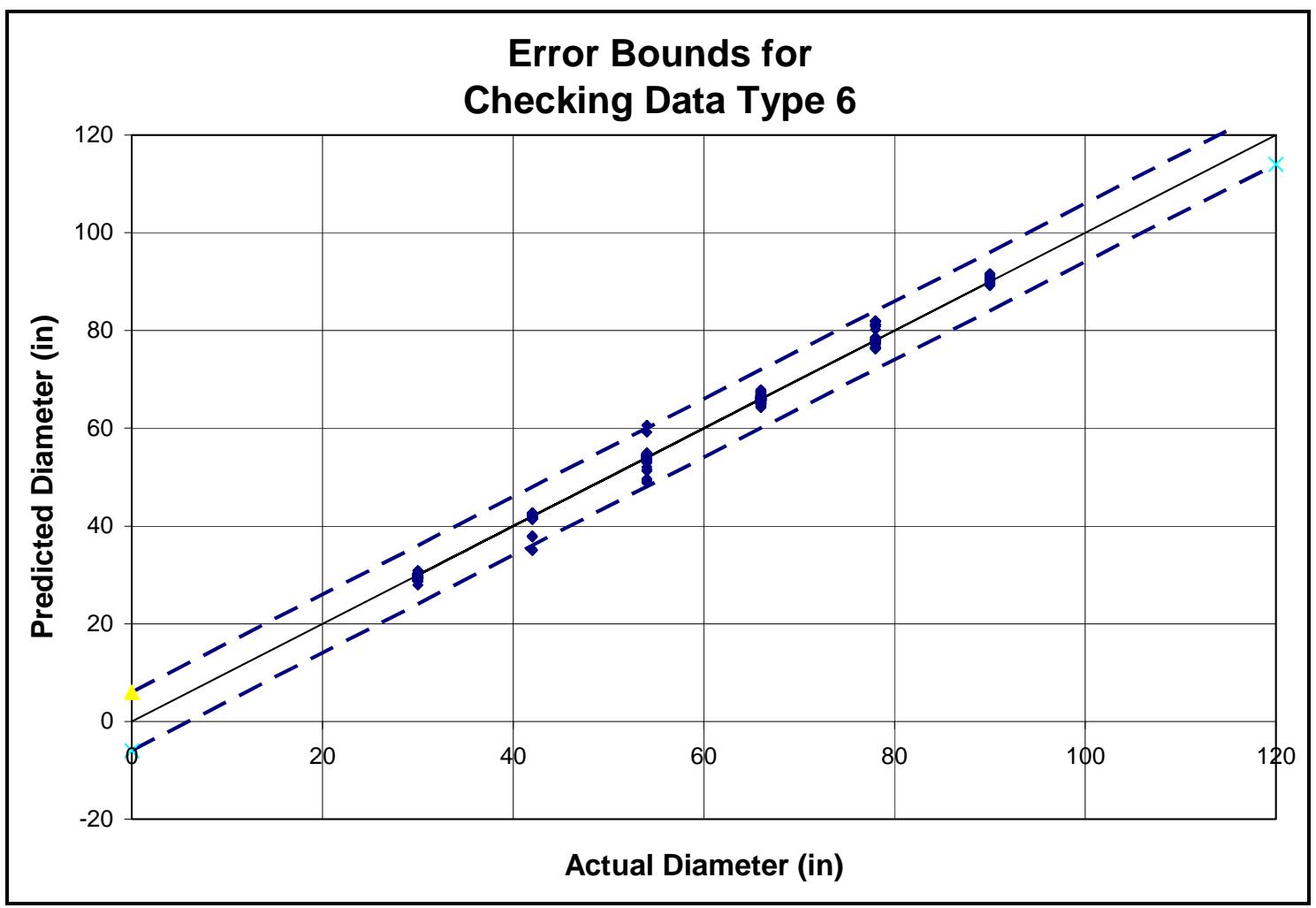

Figure 5.45. Type 6 checking data with error bounds above and below the expected result. 


\section{CHAPTER 6 -CONCLUSIONS AND RECOMMENDATIONS}

\subsection{Conclusions}

Since culvert designers utilize an approach that rounds to the next highest pipe size, it is believed that the use of a neural-fuzzy logic model is acceptable for predicting culvert diameters. These results were, however, based on concrete culvert pipe with a standard entrance loss coefficient.

\subsubsection{Explicit Solutions}

Initial results of ANFIS application to the formula generated Type 4 and 5 data sets revealed root mean square errors ranging between 1.5 and 3 inches. This fell into the acceptable design criteria for culverts. Using similar explicit solutions for the other four types proved too difficult, time consuming, and with questionable accuracy; therefore, an alternate method of calculating data to analyze was sought. The decision to use Haestad Methods - CulvertMaster software was made based on the capability with Hydraulic Design of Highway Culverts, (Normann, et al., 1985). This software produced results that were not classified according to the types, thus an intricate conditional if-then logic structure was employed to separate the large data set into the six different culvert types.

\subsubsection{Step Data Sets}

After creating the large data set, outlined above, the study to investigate the sensitivity of the ANFIS model to the number of input variables was conducted. This study involved the four data sets, listed in Table 4.2, which increase in degrees of complexity; however, results obtained from these four step data sets show that the predicted diameters deviate from seven and twelve inches about the actual diameter (see Table 5.1). It is not acceptable in culvert design for the predicted diameter to deviate by this amount.

\subsubsection{U.S.G.S. Culvert Types}

Given the less than acceptable results above, the six different culvert types (Figure 4.4), were analyzed to determine if the breakdown of data sets by culvert classification would produce better results. From the RMSE data from Chapter 5, listed in Table 5.1, it can be concluded that the error ranges from one inch to four inches. To put this error in perspective, if a 24" diameter culvert were predicted and the error was as much as four inches, this error would be seventeen percent. This is unacceptable by the standards used in culvert design. On the other end of the

spectrum, if a 96” diameter culvert was predicted and the error was as much as four inches, the 
error would be less than five percent. This latter error, by standards acceptable to most all culvert designers, would fall into the acceptable category.

\subsubsection{Relating Study Results to Design Practices}

When designing culverts, the purpose is to determine the diameter needed to pass the design flow-rate for the culvert geometry provided. This answer is then rounded up to the next available standard pipe size. In order to reduce manufacturing costs, standard pipe sizes have been adopted, thus reducing the higher cost of producing a uniquely sized pipe. With this approach in mind, the results were placed into a band of six inches above the actual diameter and six inches below the actual diameter, which is the half-way point between the standard diameters. This reduced the effective error, by placing more than 70 percent of the predicted diameters within the acceptable error band about each standard diameter.

\subsection{Recommendations}

This study explored the application of neural-fuzzy logic models to the culvert design problem for the first time. It was originally intended that the neural-fuzzy model be fitted to the culvert performance data without separation by flow regime classification; however, the predictive errors on diameter where too large to be acceptable for use as a design tool. It is possible that alternate approaches to the application of the neural-fuzzy model could result in more acceptable results with the combined data set. It is recommended that additional studies be conducted to explore the possibility of other optimal structures of number and type of membership functions used in the ANFIS model. It is possible that there are undiscovered model structures that will reduce the error to acceptable levels.

Additionally, it is recommended that the applicability of a neural network modeling approach be investigated, since this study shows that the neural network component of the neural-fuzzy logic model had some success in mapping the input to output data relationship. It is possible that a neural network, used alone, can perform better in mapping the input data to the output culvert diameter.

For a more thorough analysis of all culverts possible, the study should be broadened into different pipe material and entrance conditions, as well as a much broader range of bed slope values. 


\section{REFERENCES}

Abbott, M.B. \& Basco, D.R., 1989. Computational Fluid Dynamics, An Introduction for Engineers, Wiley \& Sons, New York.

American Association of State Highway and Transportation Officials, 1975. "Guidelines for the Hydraulic Design of Culverts." Task Force on Hydrology and Hydraulics AASHTO Operating Subcommittee on Design, , 341 National Press Bldg., Washington, D.C.

American Concrete Pipe Association, 1985. Concrete Pipe Design Manual, American Concrete Pipe Association, 8320 Old Courthouse Rd., Vienna, VA 22180.

American Iron and Steel Institute, 1983. Handbook of Steel Drainage and Highway

Construction Products, American Iron and Steel Institute, Washington, D.C., 20036.

American Iron and Steel Institute, 1990. Modern Sewer Design, American Iron and Steel Institute, 100016 th St, N.W., Washington, D.C., 20036.

Bishop, C., 1995. Neural Networks for Pattern Recognition. Oxford: University Press.

Braine, C.D.C., 1947. "Draw-down and other factors relating to the design of storm-water outflows on sewers," Journal of Institution of Civil Engineers, London, Vol. 28, No. 6, pp. 136163.

Brater, E.F., King, H.W., Lindell, J.E., and Wei, C.Y., 1996. Handbook of Hydraulics, $7^{\text {th }}$ Ed. McGraw-Hill, New York.

Carling, A., 1992. Introducing Neural Networks. Wilmslow, UK: Sigma Press.

Chaudhry, M. H., 1993. Open-Channel Flow, Prentice Hall, Englewood Cliffs, New Jersey.

Chow, V.T., 1955. "Integrating the Equation of Gradually Varied Flow," Journal of the Hydraulics Division, ASCE, Vol. 81, February, pp. 1-32.

Chow, V.T., 1959. Open Channel Hydraulics, McGraw-Hill, New York.

Coleman, G.S., 1932. "The Critical Depth of Flow in Open Channels," Journal of the Institution of Civil Engineers, London. Selected engineering papers, No. 124.

Dasika, B., 1995. "New Approach to Design of Culverts," Journal of Irrigation and Drainage Engineering, ASCE, Vol.121, No.3, May/June 1995, pp. 261-263.

Drainage Manual, 1984. Drainage Manual, West Virginia Department of Highways Roadway Design Division. 
Evett, J.B., and Liu, C., 1989. 2500 Solved Problems in Fluid Mechanics and Hydraulics, McGraw-Hill, New York.

Fausett, L., 1994. Fundamentals of Neural Networks. New York: Prentice Hall.

Franzini, J.B., and Finnemore, E.J., 1997. Fluid Mechanics with Engineering Applications, $9^{\text {th }}$ Ed., McGraw-Hill, New York.

French, L.J., 1957. "Hydraulics of Culverts, Third progress report, Effects of Approach Channel Characteristics on Model Pipe Culvert," NBS Report 5306, National Bureau of Standards, Washington, D.C., June 1957.

French, L.J. and Bossy (1967), "Hydraulics of Culverts, Seventh Progress Report, Tapered Box Culvert Inlets," NBS Report 9355, National Bureau of Standards, Washington, D.C., July 1967.

Giles, R.V., Evett, J.B., and Liu, C., 1994. Schaum's Outline of Fluid Mechanics and Hydraulics, $3^{\text {rd }}$ Ed. McGraw-Hill, New York.

Goodrich, R.D., 1960. “Tolkmitt's Backwater and Dropdown Curve Tables,” Journal of the Hydraulics Division, ASCE, Vol. 86 (HY5), pp.1-6.

Gray, D.D., 2000. A First Course In Fluid Mechanics for Civil Engineers, Water Resources Publications, LLC. Highlands Ranch, CO.

Hager, W.H., 1991. "Backwater Curves in Circular Channels," Journal of Irrigation and Drainage Engineering, Vol. 117, No. 2, pp. 173-182.

Hager, W.H., 1998. "Generalized Culvert Design Diagram," Journal of Irrigation and Drainage Engineering, Vol. 124, No. 5, pp. 271-273.

Hay, W.H., 1982. Railroad Engineering, $2^{\text {nd }}$ Ed., Wiley \& Sons, New York.

Haykin, S., 1994. Neural Networks: A Comprehensive Foundation. New York: Macmillan Publishing.

Henderson, F.M., 1966. Open Channel Flow, Macmillan, New York.

Hill, C.D., 1923. "Application of the Drop-Down Curve in Chicago Sewers," Engineering News and Record, Vol. 90, April, pp. 707-709.

Hoff-Clausen, N. E., Havno, K., and Kej, A., 1982. "System 11 sewer - A storm sewer model." In Urban Stormwater Hydraulics and Hydrology, (B.C. Yen, ed.) pp. 137 - 146. Water Resources Publ., Littleton, Colorado. 
Hwang, N.H.C., and Hita, C.E., 1987. Fundamentals of Hydraulic Engineering Systems, $2^{\text {nd }}$ Ed., Prentice-Hal, Englewood Cliffs, NJ 07632.

Jaeger, C., 1957. Engineering Fluid Mechanics, translated from German by P.O. Wolf, St. Martin's Press, Inc. New York.

Jang, J.S.R., 1993. “ANFIS: Adaptive-Network-Based Fuzzy Inference System,” IEEE Transactions on Systems, Man, and Cybernetics, Vol. 23, No. 3.

Jang, J.S.R. and Sun, C.T., 1995. “Neuro-fuzzy modeling and control,” Proceedings of the IEEE, Vol. 83, No.3.

Jensen, Mark, Hydraulic Engineering Center, Davis, California. Phone conversation May 2002

Joliffe, I. B., 1984a. "Free Surface and Pressurized Pipe Flow Computations." Proc. Int. Conf. Urban Strom Drainage, $3^{\text {rd }}$. (P.Balmer, P.A. Malmqvist, and A. Sjoberg, eds.) Vol. 1, pp. 397 405. Chalmers Univ. of Technology, Goteborg, Sweden.

Joliffe, I. B., 1984b. "Computation of Dynamic Waves in Channel Networks." Journal of Hydraulic Engineering, ASCE, Vol. 110, No. 10, pp. 1358 - 1370.

Mays, L.W., 1999. Hydraulic Design Handbook. McGraw-Hill, New York.

Meadows, M.E., and Walski, T.M., 1999. Computer Applications in Hydraulic Engineering, $3^{\text {rd }}$ Ed. Haestad Methods, Inc., Waterbury, CT.

Mathworks, 2001. “Fuzzy Logic Toolbox, for use with MatLab.” User’s Guide, Version 2.

Nalluri, C., and Tomlinson, J.H., 1978. "Varied Flow Functions for Circular Channels,” Journal of the Hydraulics Division, ASCE, Vol. 104, No. 7, pp. 983-1000.

Normann, J.M., Haughtalen, R.J., and W.J. Johnston, 1985. Hydraulic Design of Highway Culverts, Report No. FHWA-IP-85-15, Federal Highway Administration, McLean, VA.

Patterson, D., 1996. Artificial Neural Networks. Singapore: Prentice Hall.

Portland Cement Association, 1962. Culvert Design Aids: An Application of U.S. Bureau of

Public Roads Culvert Capacity Charts, Portland Cement Association, Chicago, IL.

Portland Cement Association, 1964. Handbook of Concrete Culvert Pipe Hydraulics, Portland Cement Association, Skokie, IL.

Portland Cement Association, 1975. Concrete Culverts and Conduits, Portland Cement Association, Skokie, IL. 
Rajaratnam, N. and Thiruvengadam, A., 1961. "Critical Depth in Open Channels." The Journal of the Institution of Engineers (India). Vol. 41, April 1961. pp. 287-290.

Rathore, S.S., 1993. "Computation of Critical Depth in Circular Channels." Journal of Indian Water Works Association, Vol. XXV, No. 4, Oct-Dec, 1993. pp. 293-296.

Rathore, S.S., 1998. “Computation of Critical Depth in Circular Channels - Part II.” Journal of Indian Water Works Association, Vol. 30, No. 2, Apr - June, 1998. pp. 121-128.

Ripley, B.D., 1996. Pattern Recognition and Neural Networks. Cambridge University Press.

Roberson, J.A. and Crowe, C.T., 1993. Engineering Fluid Mechanics, $5^{\text {th }}$ Ed., Wiley \& Sons, New York.

Roberson, J.A., Cassidy, J.J., Chaudhry, M.H., 1998. Hydraulic Engineering, $2^{\text {nd }}$ Ed., Wiley \& Sons, New York.

Straub, W.O., 1978. "A Quick and Easy Way to Calculate Critical and Conjugate Depths in Circular Open Channels." Civil Engineering, ASCE. Dec. 1978. pp. 70-71.

Subramanya, K., 1982. Flow in Open Channels. Vol. 1. Tata McGraw-Hill Publishing Co. Limited, New Delhi.

US Army Corps of Engineers - Hydraulic Engineering Center HEC - RAS River Analysis System. User’s Manual. Version 3.0, January 2001.

US Army Corps of Engineers - Hydraulic Engineering Center HEC - RAS River Analysis System. Hydraulic Reference Manual. Version 3.0, January 2001.

US Army Corps of Engineers - Hydraulic Engineering Center HEC - RAS River Analysis System. Applications Guide. Version 3.0, January 2001.

United States Geological Survey, 1973. Computation of Peak Discharge at Culverts, Circular No. 376.

United States Geological Survey, 1976. Measurement of Peak Discharge at Culverts by Indirect Methods, Book 3, Chapter A3.

Vennard, J.K., and Street, R.L., 1982. Elementary Fluid Mechanics, $6^{\text {th }}$ Ed., Wiley \& Sons, New York.

Yen, B.C., 1986. "Hydraulics of Sewers," Advances in Hydroscience. Vol.14. Academic Press Inc. Orlando, FL, pp. 1-115. 
Yen, B.C., and Gonzalez-Castro, J.A., 2000. "Open-Channel Capacity Determination Using Hydraulic Performance Graph." Journal of Hydraulic Engineering, ASCE, Vol. 126, No. 2, pp. $112-122$.

Young, G.K., J.S. Krolak, M. Mistichelli, and A.T. Atayee, 1993. Computational Methods for Hydraulic Analysis of Culverts, Draft Report for the Federal Highway Administration, McLean, VA.

Young, G. Kenneth and Joseph S. Krolak, 1993. HYDRAIN: Integrated Drainage Design Computer System Version 5.0: Volumes I to VII, Report No. FHWA-RD-92-061, Federal Highway Administration, McLean, VA.

Young, G, Childrey, M and Trent, R, 1974. "Optimal Design for Highway Drainage Culverts," Journal of the Hydraulics Division, Vol 100 No. HY-7 (Proc Paper 10676), American Society of Civil Engineers, 345 East 47 th Street, New York, NY 10017, 1974.

Zipparro, V.J., and Hasen, H., 1993. Davis' Handbook of Applied Hydraulics, $4^{\text {th }}$ Edition. McGraw-Hill, New York.

Zaghloul, N.A., 1992. "Gradually Varied Flow in Circular Channels with Variable Roughness," Advances in Engineering Software, Vol. 15, pp. 33-42.

Zoghi, M., 1993. "Short-Span Bridge Solutions," Civil Engineering, ASCE, Vol. 63, No. 7, July, pp. 53-55.

Zadeh, L.A., 1950. "Frequency analysis of variable networks," Proceedings of the IRE 3a8, pp.291-299.

Zadeh, L.A., Ragazzini, J.R., 1950. “An extension of Wiener's theory of prediction,” Journal of Applied Physics, pp. 645- 655.

Zadeh, L.A., Ragazzini, J.R., 1950. “The analysis of sampled-data systems,” Applications and Industry (AIEE), pp. 224-234.

Zadeh, L.A., Desoer, C. A., 1963. Linear System Theory-The State Space Approach, New York: McGraw-Hill Book Co.

http://www.emsl.pnl.gov:2080/proj/neuron/fuzzy/what.html

http://www.cs.berkeley.edu/ zadeh/

http://www.cis-ieee.org/eit2003/zadeh.asp

http://www.ieee-nns.org/ 


\section{APPENDIX A - MATLAB PROCEDURE}

\section{MUST HAVE THE MATLAB DOCUMENTATION CD INSERTED INTO THE}

\section{MACHINE!}

1. At the MatLab command window, type in: >>anfisedit This will bring up the Fuzzy logic editor

2. Load the data, both training and checking. Ensure that the proper format is selected in the lower left hand corner in the 'Load data' section.

3. Generate FIS using grid partition

a. Enter the MF and type

4. Select the number of epochs and hit the 'train now' button

5. View and record the epoch training error, the select the 'checking data' under the Test FIS box. This will give the resulting checking error.

6. From the top menu, select 'view' and then 'rules'

7. Save the file to the workspace. This will be a .fis file.

8. In order to view the results in tabulated columns, the following steps must be followed

a. Go to the Workspace editor (upper left hand portion of MatLab window) and select File > Import data, and then select either the training or checking .dat file from the directory. You will have to hit next and then finish after agreeing with the format for bringing this data into the workspace.

b. Go to the MatLab command window and type in the following command in order to tell it to negate the last column, which will be diameter.

i. In = filename(:,1:3)

1. Make sure that the exact file name is typed with either trn or chk

2. If there are 4 columns, you would ask for the input to select $1: 3$, as shown above. If there are more, you tell it to select one less than the total number of columns.

c. After the file has been imported, you can extract the last column, which is diameter with the following command:

i. $\quad \mathrm{D}=$ evalfis(in,name you saved to workspace)

d. Now simply take this column of data and copy it into Excel to compare with the actual diameters that were used to generate the model.

e. If the data set is large, the data will need to be saved as a text file in the following manner:

Save outputfile.txt D -ASCII 


\section{APPENDIX B - INVESTIGATION OF ALL MEMBERSHIP FUNCTION TYPES IN MATLAB}

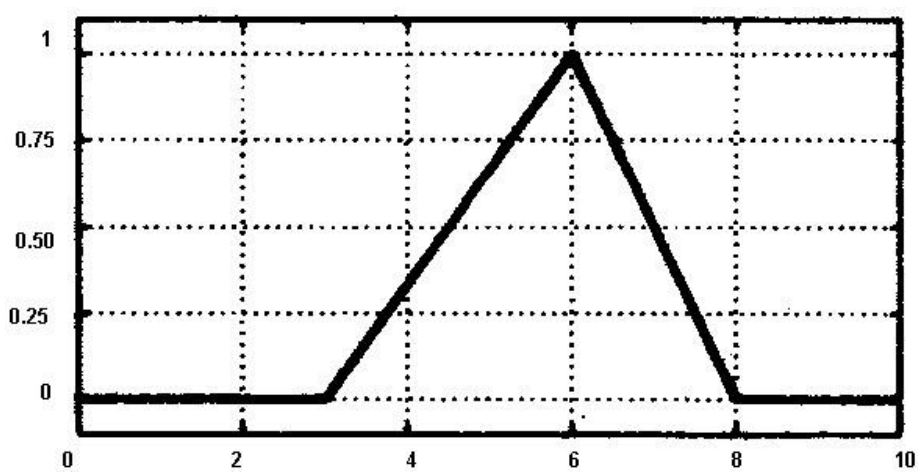

Figure B.1. Triangular membership function - trimf.

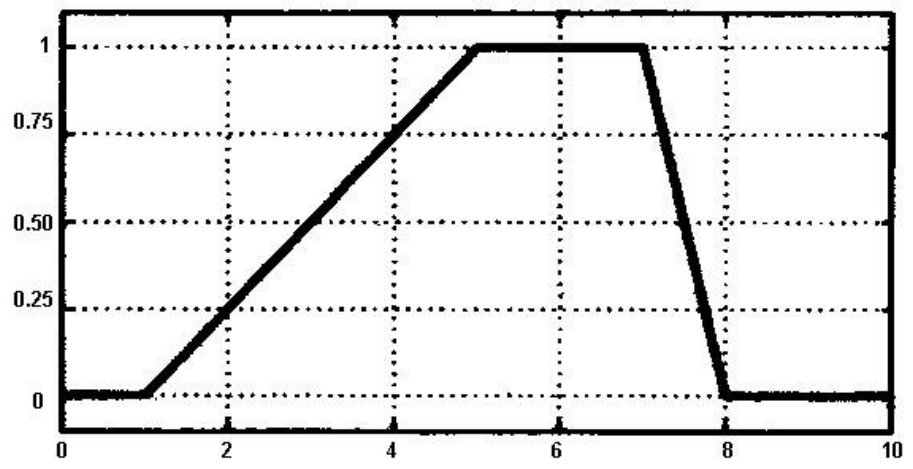

Figure B.2. Trapezoidal membership function - trapmf.

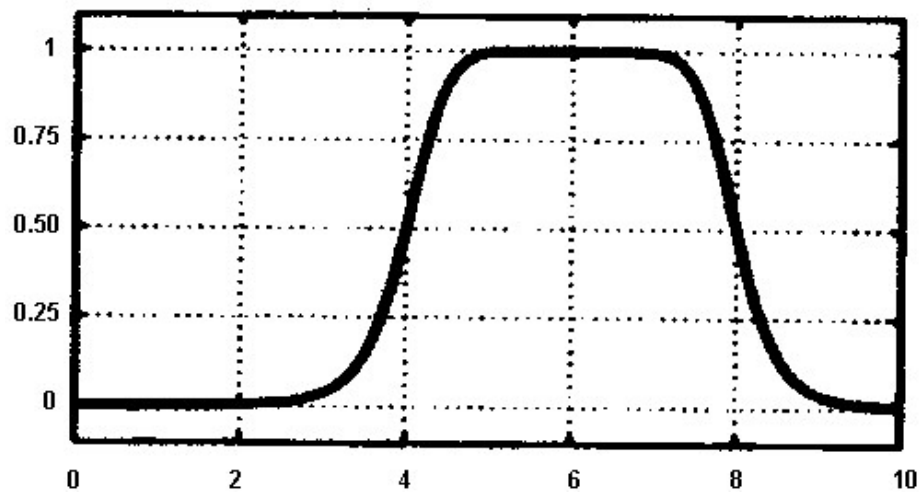

Figure B.3. Generalized bell membership function - gbellmf. 


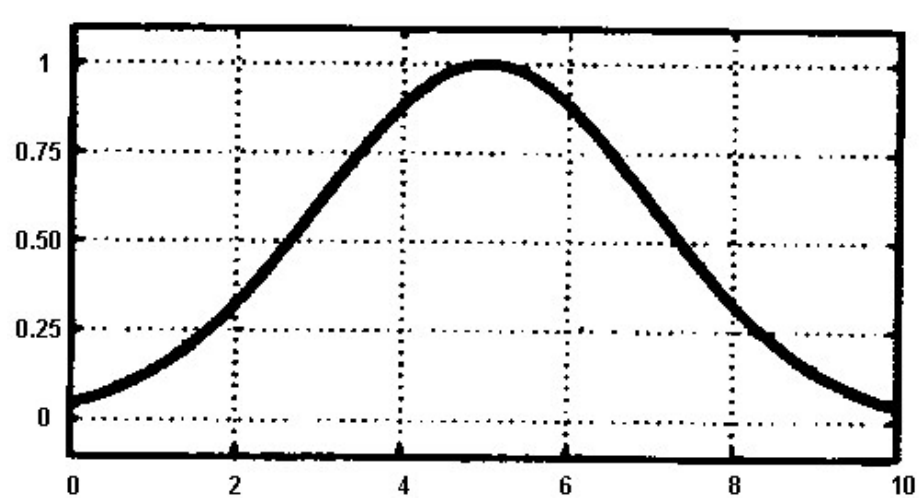

Figure B.4. Gaussian membership function - gaussmf.

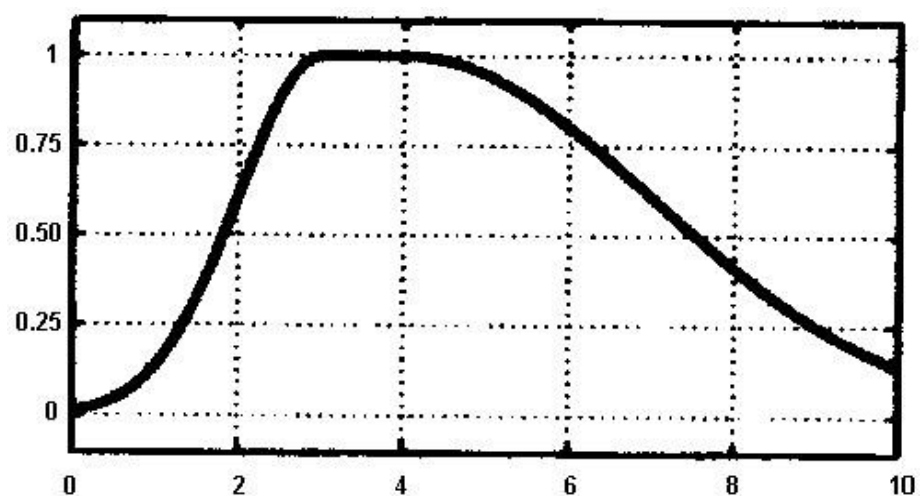

Figure B.5. Two-sided composite of two different Gaussian curves - gauss2mf.

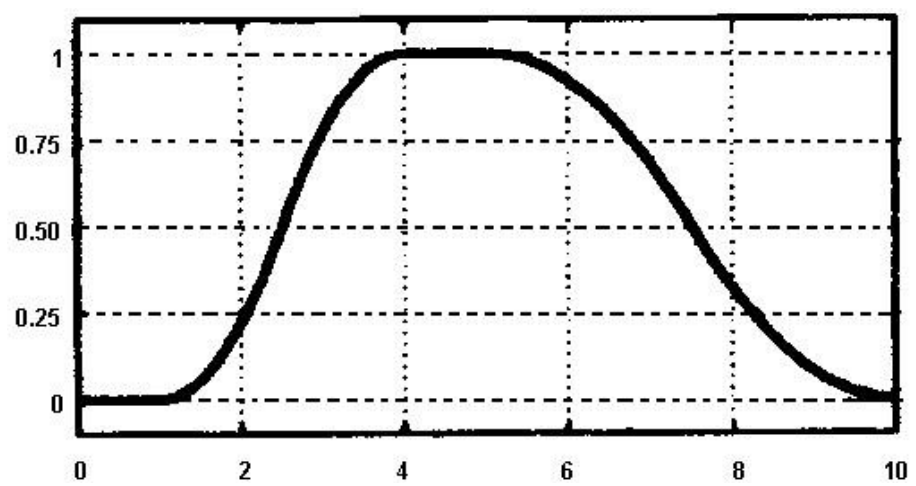

Figure B.6. Pi membership function - pimf.

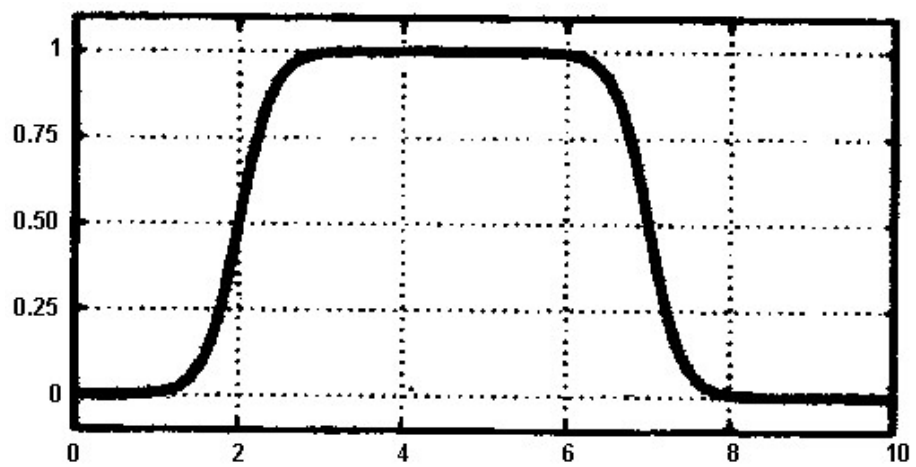

Figure B.7. The difference between two sigmodial functions - dsigmf. 


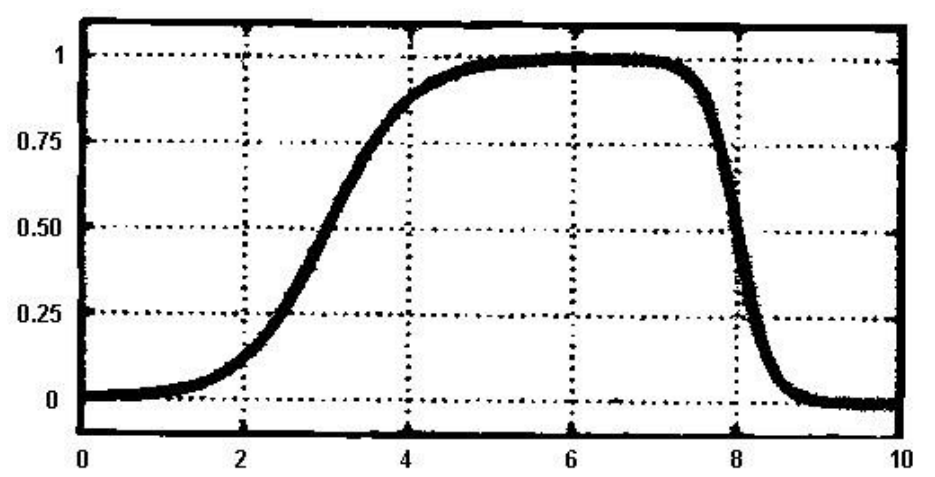

Figure B.8. The product of two sigmodial functions - psigmf.

The following figures are from a type 4 culverts training on Diameter

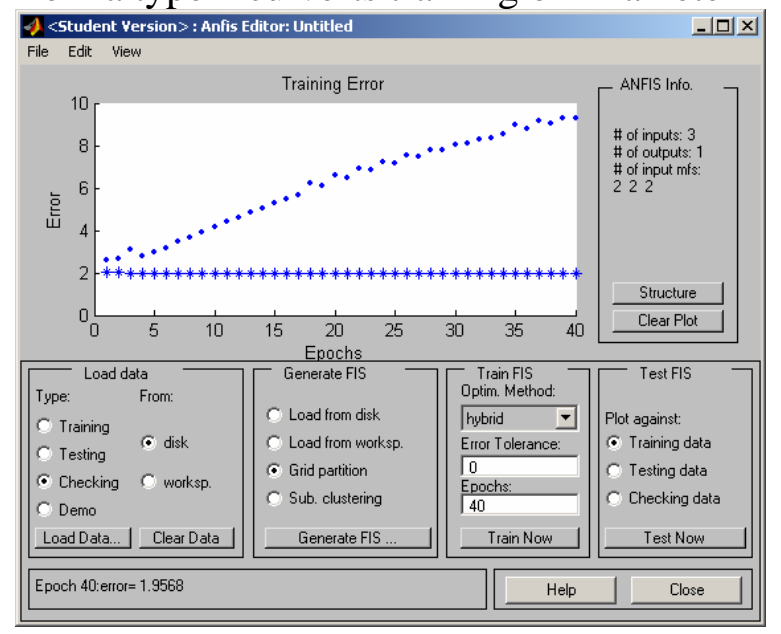

Figure B.9. Type 4 culvert, training on Diameter. Triangular membership function - trimf.

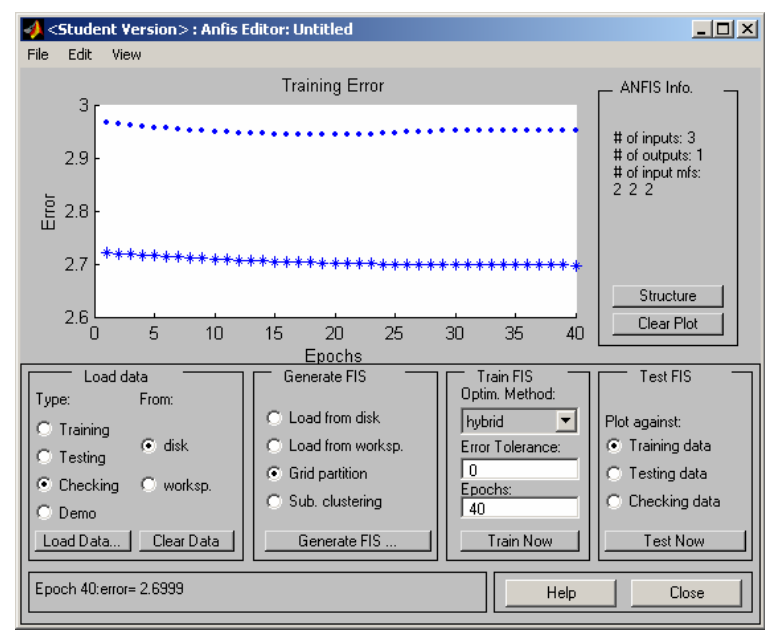

Figure B.10. Type 4 culvert, training on Diameter. Trapezoidal membership function - trapmf. 


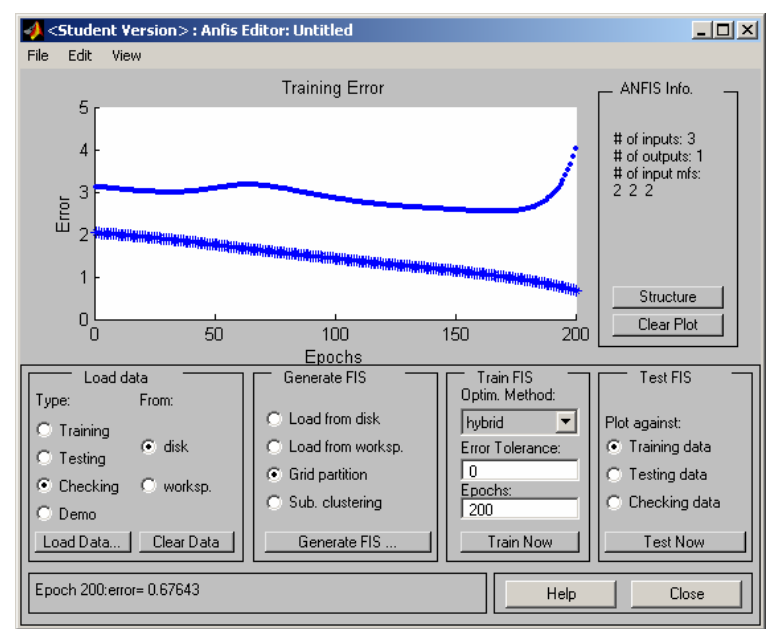

Figure B.11. Type 4 culvert, training on Diameter. Generalized bell membership function gbellmf.

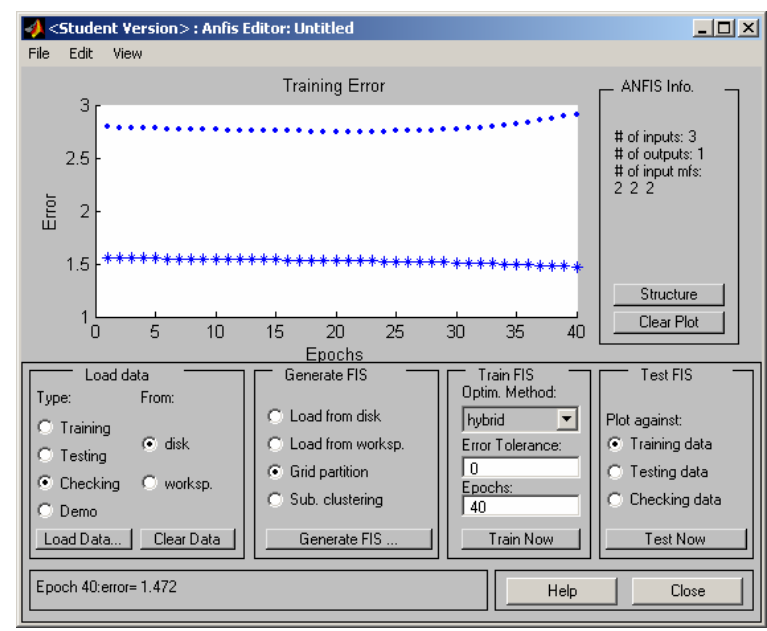

Figure B.12. Type 4 culvert, training on Diameter. Gaussian membership function - gaussmf.

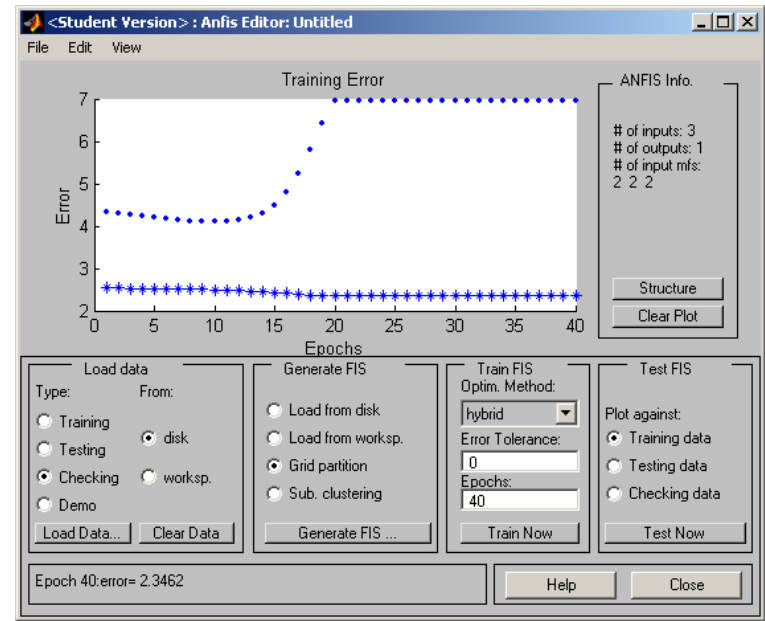

Figure B.13. Type 4 culvert, training on Diameter. Two-sided composite of two different Gaussian curves - gauss2mf. 


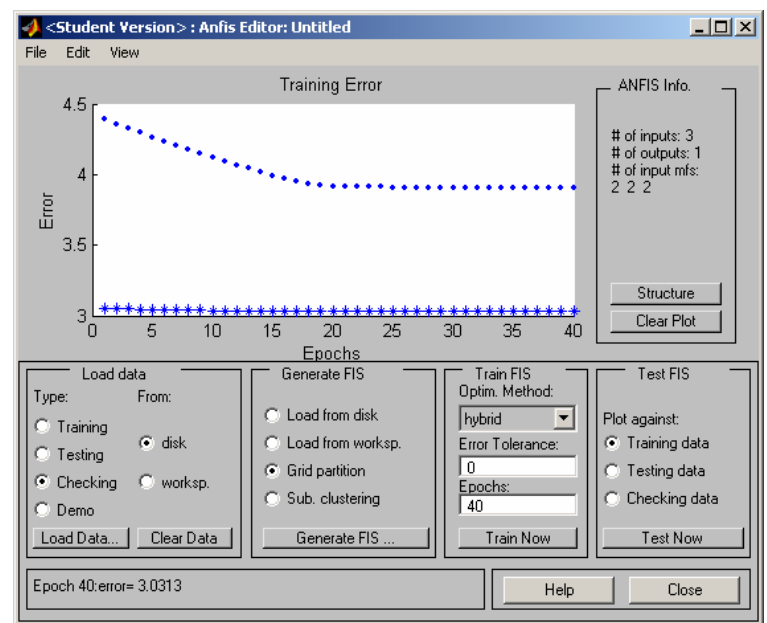

Figure B.14. Type 4 culvert, training on Diameter. Pi membership function - pimf.

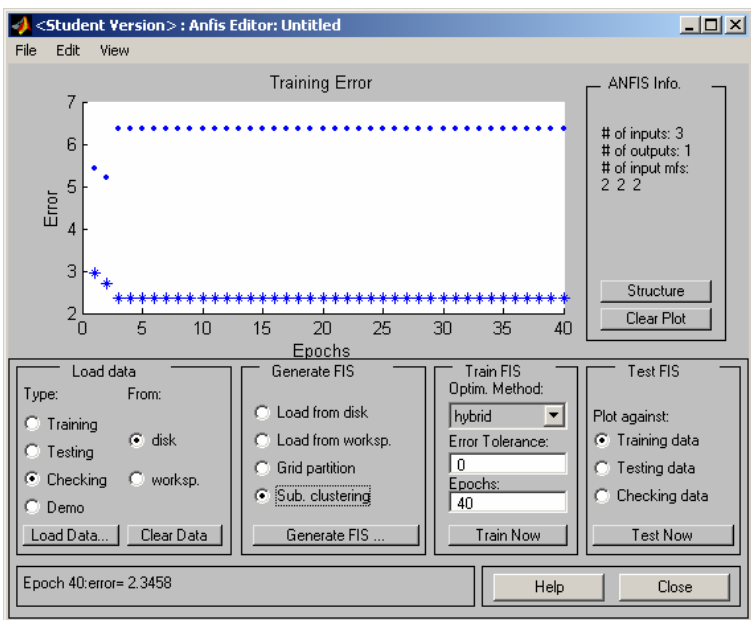

Figure B.15. Type 4 culvert, training on Diameter. The difference between two sigmodial functions - dsigmf.

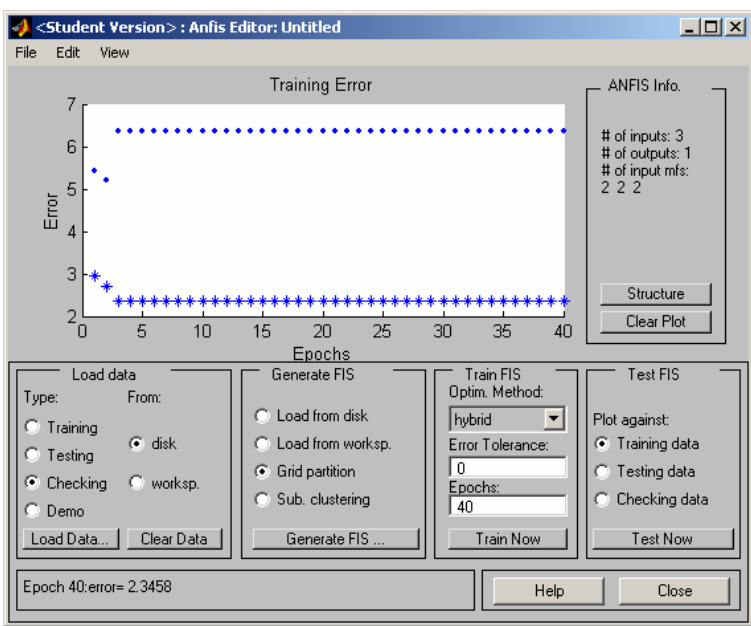

Figure B.16. Type 4 culvert, training on Diameter. Product of two sigmodial functions-psigmf. 
The figures below are a type 4 culvert training on flow rate:

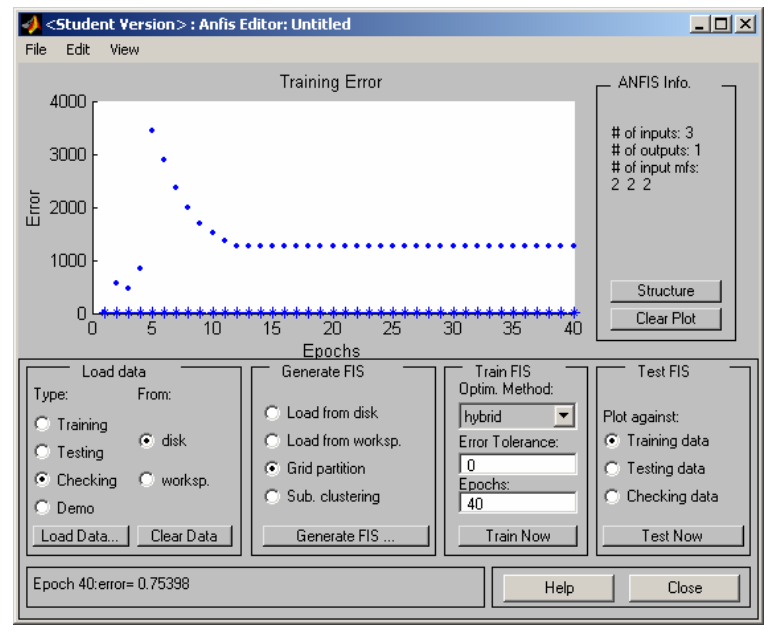

Figure B.17. Type 4 culvert, training on flow rate. Triangular membership function - trimf.

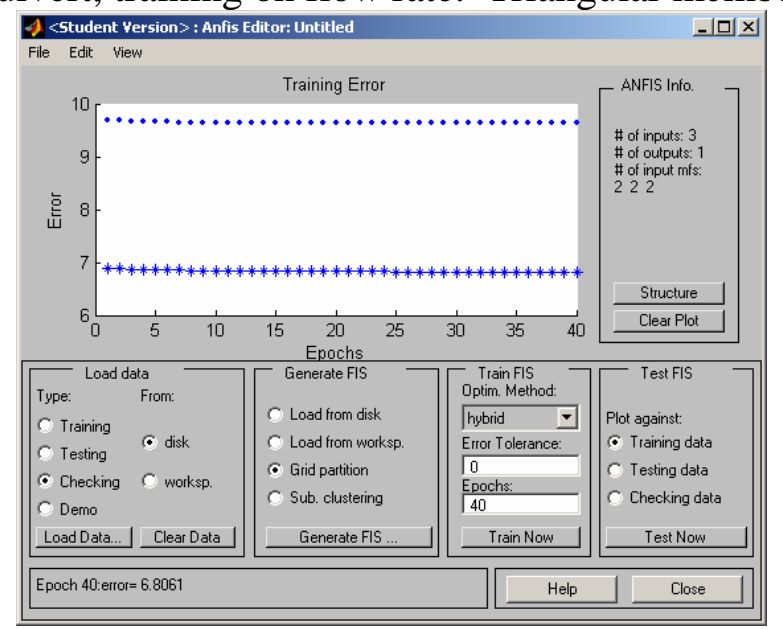

Figure B.18. Type 4 culvert, training on flow rate. Trapezoidal membership function - trapmf.

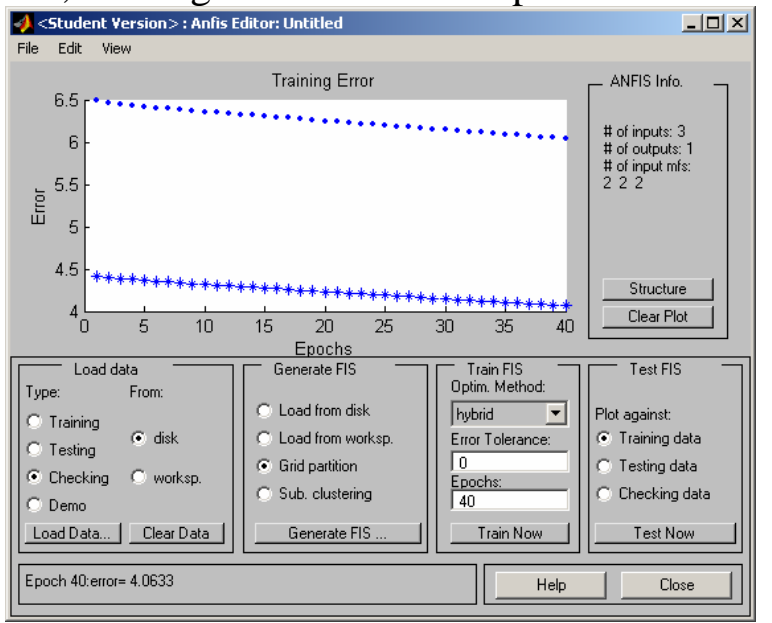

Figure B.19. Type 4 culvert, training on flow rate. Generalized bell membership function gbellmf. 


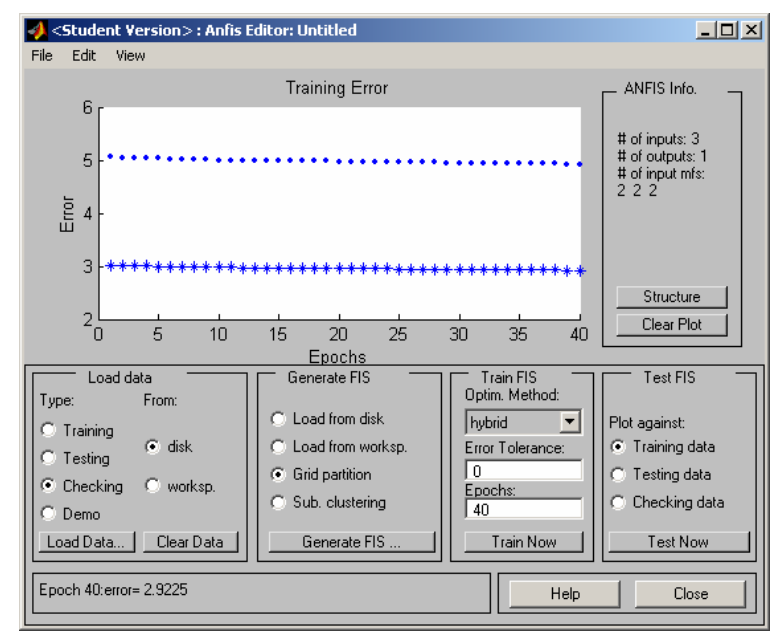

Figure B.20. Type 4 culvert, training on flow rate. Gaussian membership function - gaussmf.

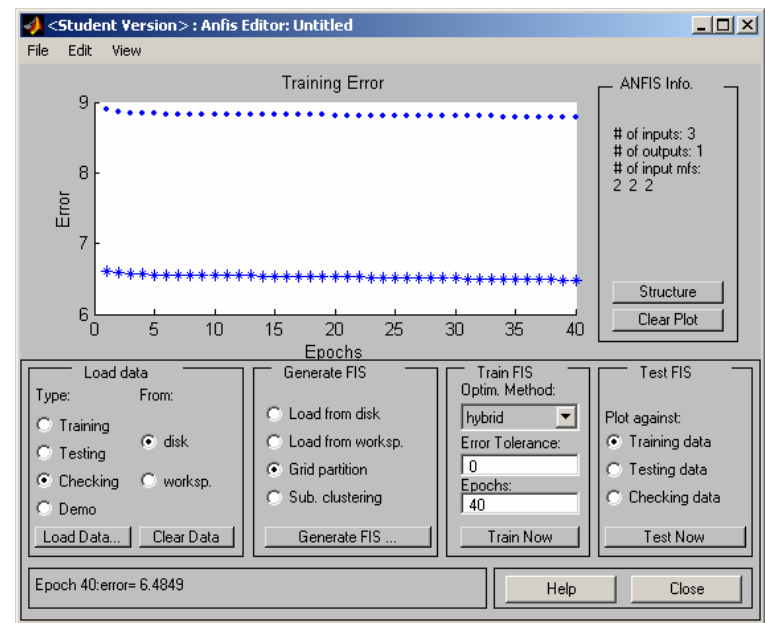

Figure B.21. Type 4 culvert, training on flow rate. Two-sided composite of two different Gaussian curves - gauss2mf.

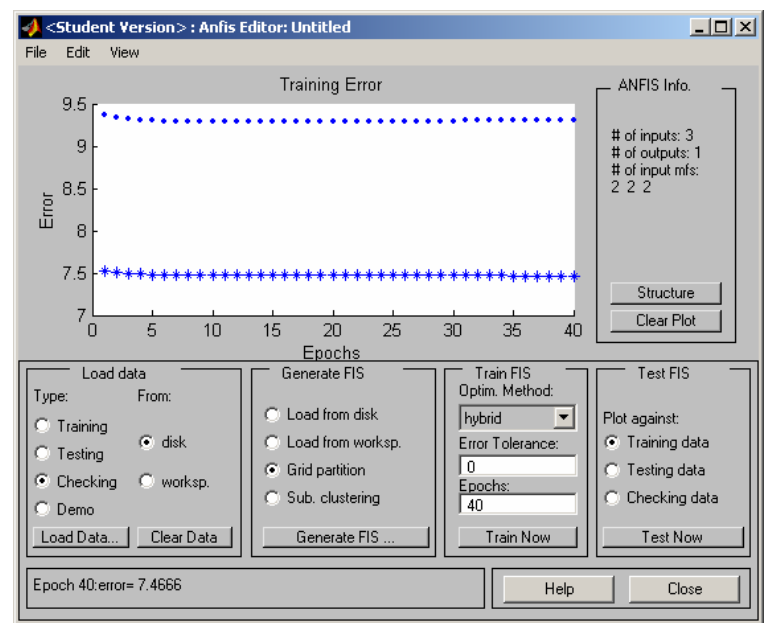

Figure B.22. Type 4 culvert, training on flow rate. Pi membership function - pimf. 


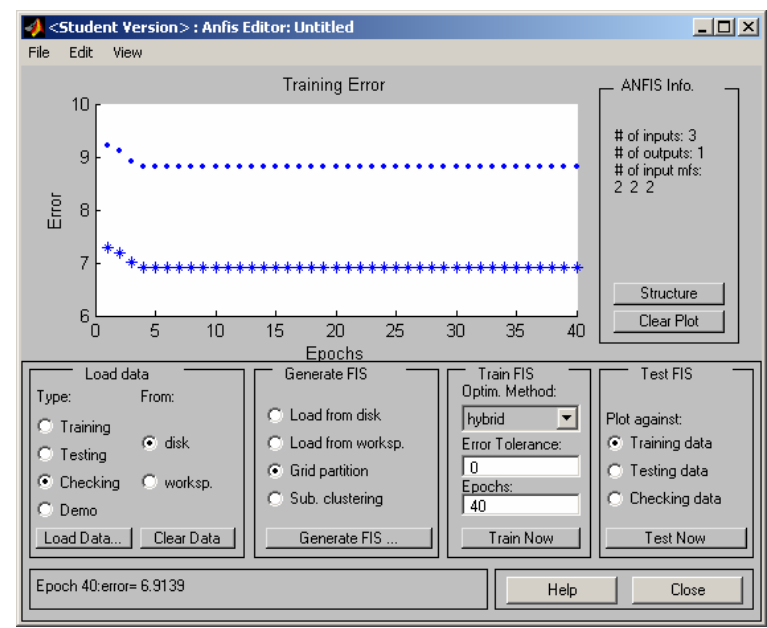

Figure B.23. Type 4 culvert, training on flow rate. Difference between two sigmodial functions - dsigmf.

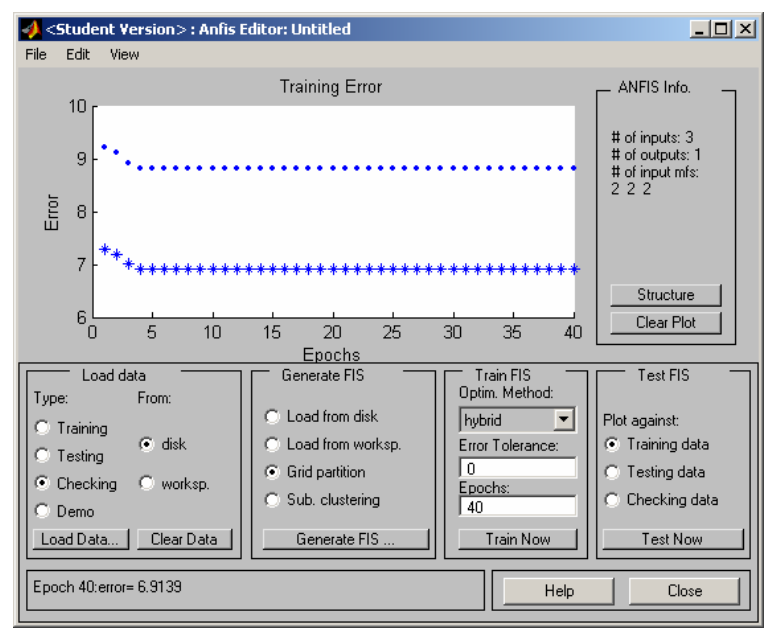

Figure B.24. Type 4 culvert, training on flow rate. Product of two sigmodial functions - psigmf. 
The following figures are from a type 5 culverts training on Diameter

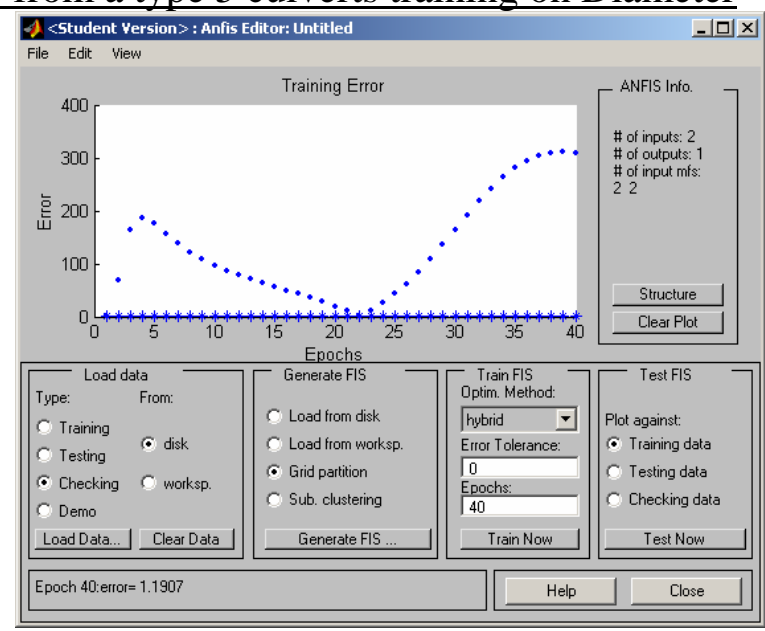

Figure B.25. Type 5 culvert, training on Diameter. Triangular membership function - trimf.
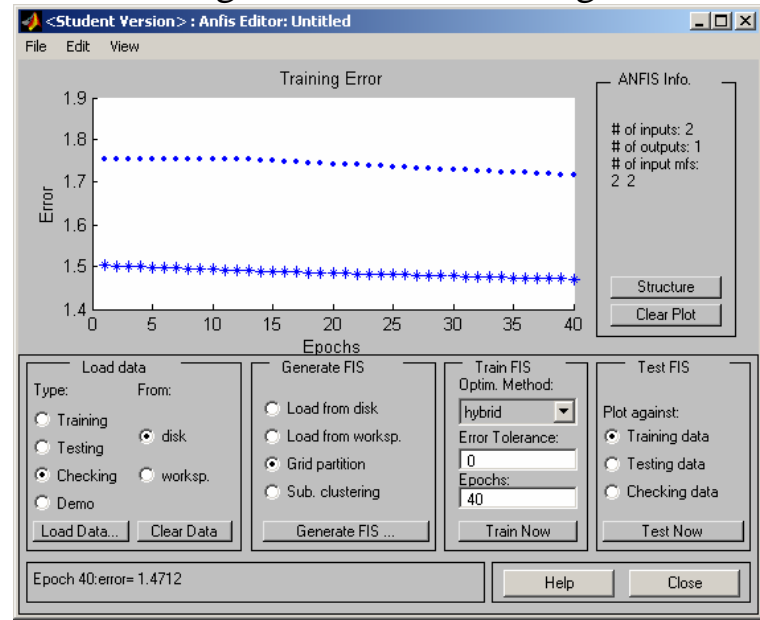

Figure B.26. Type 5 culvert, training on Diameter. Trapezoidal membership function - trapmf.

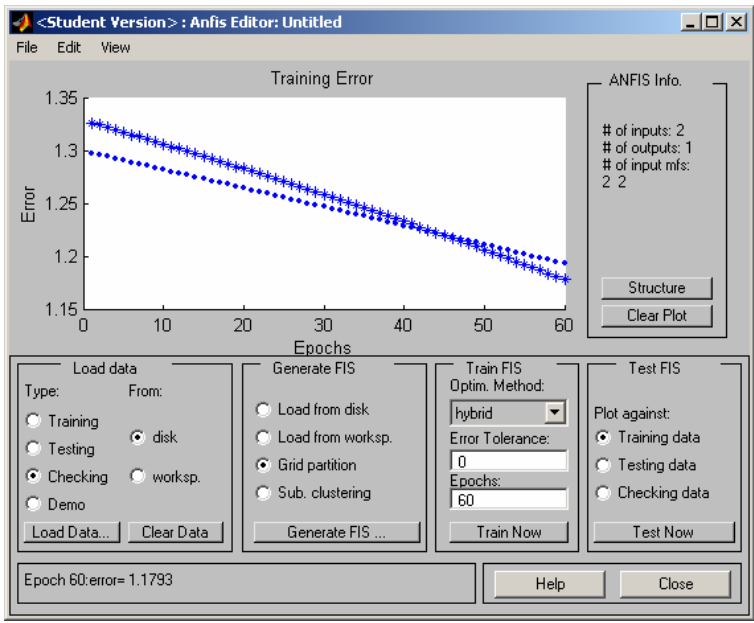

Figure B.27. Type 5 culvert, training on Diameter. Generalized bell membership function gbellmf. 


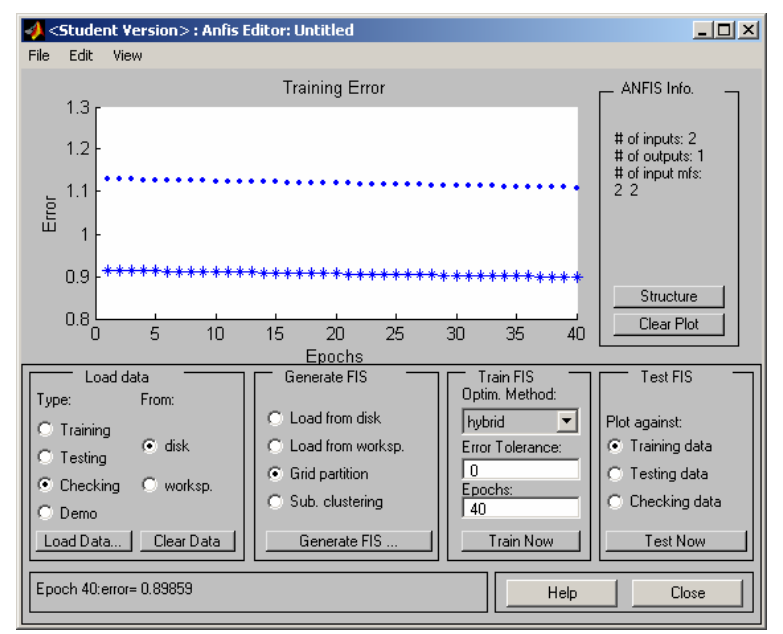

Figure B.28. Type 5 culvert, training on Diameter. Gaussian membership function - gaussmf.

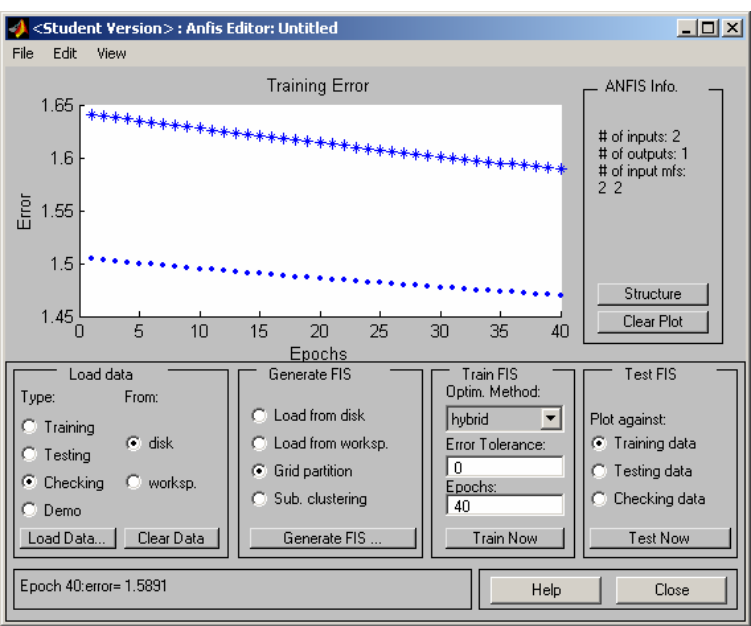

Figure B.29. Type 5 culvert, training on Diameter. Two-sided composite of two different Gaussian curves - gauss2mf.

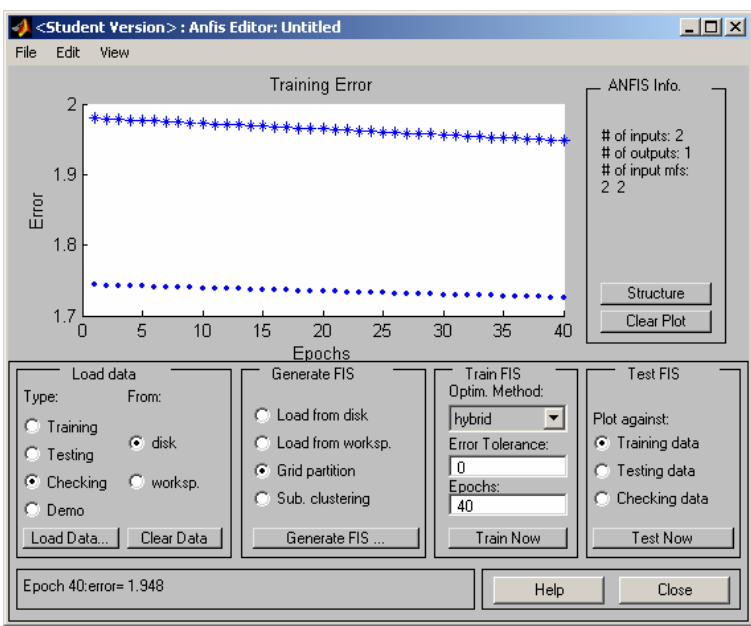

Figure B.30. Type 5 culvert, training on Diameter. Pi membership function - pimf. 


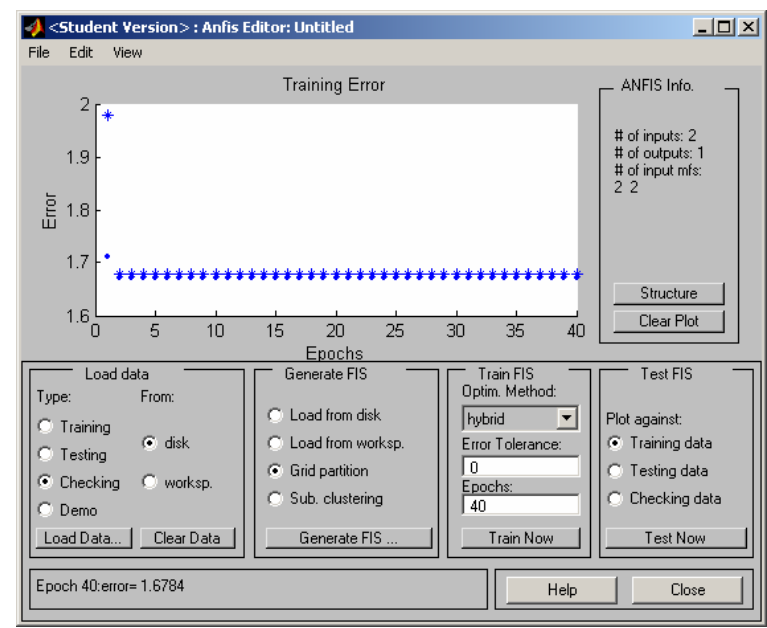

Figure B.31. Type 5 culvert, training on Diameter. Difference between two sigmodial functions - dsigmf.

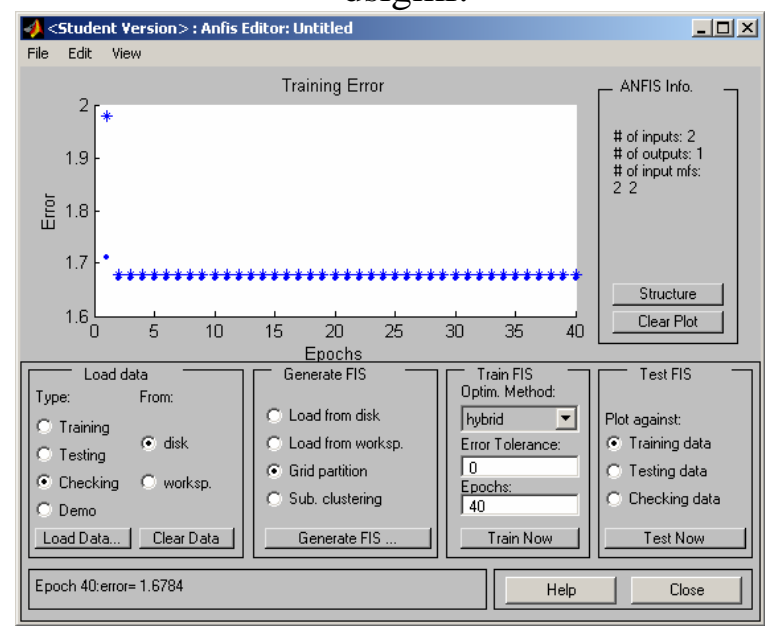

Figure B.32. Type 5 culvert, training on Diameter. Product of two sigmodial functions psigmf. 
The figures below are a type 5 culvert training on flow rate:

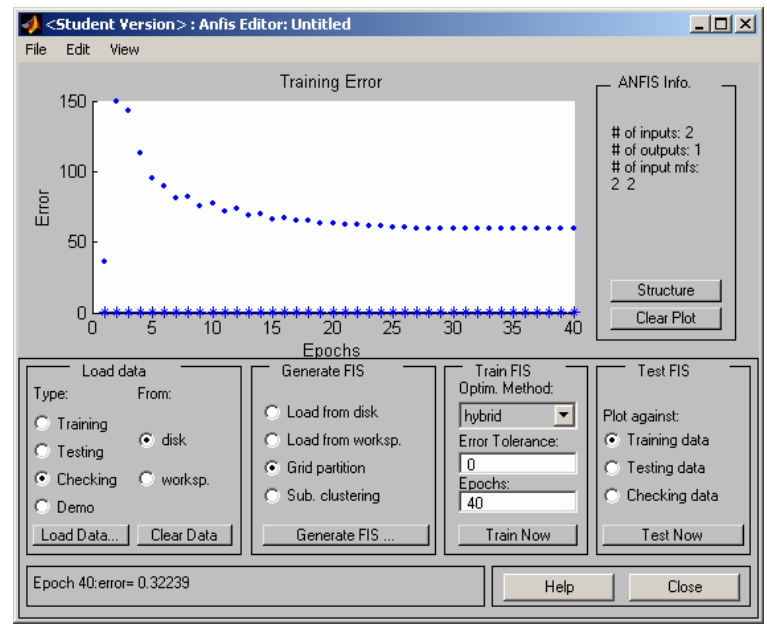

Figure B.33. Type 5 culvert, training on flow rate. Triangular membership function - trimf.

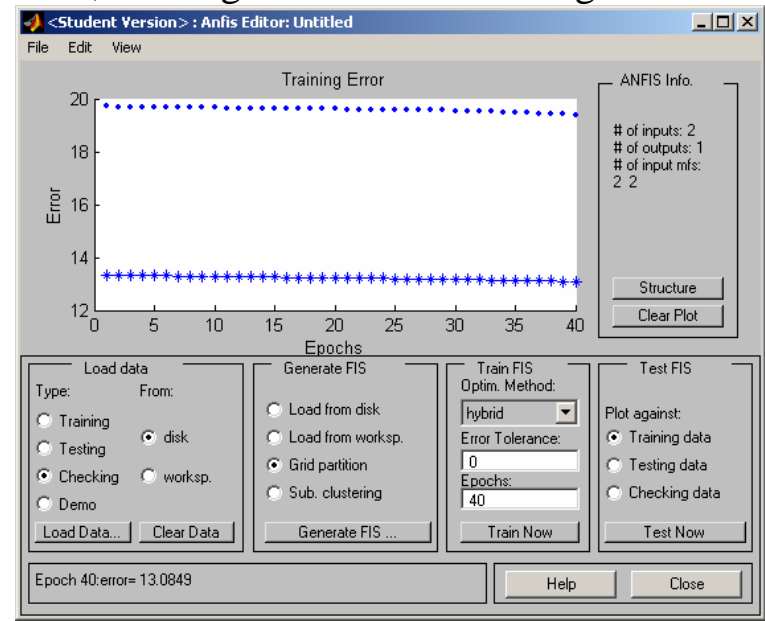

Figure B.34. Type 5 culvert, training on flow rate. Trapezoidal membership function - trapmf.

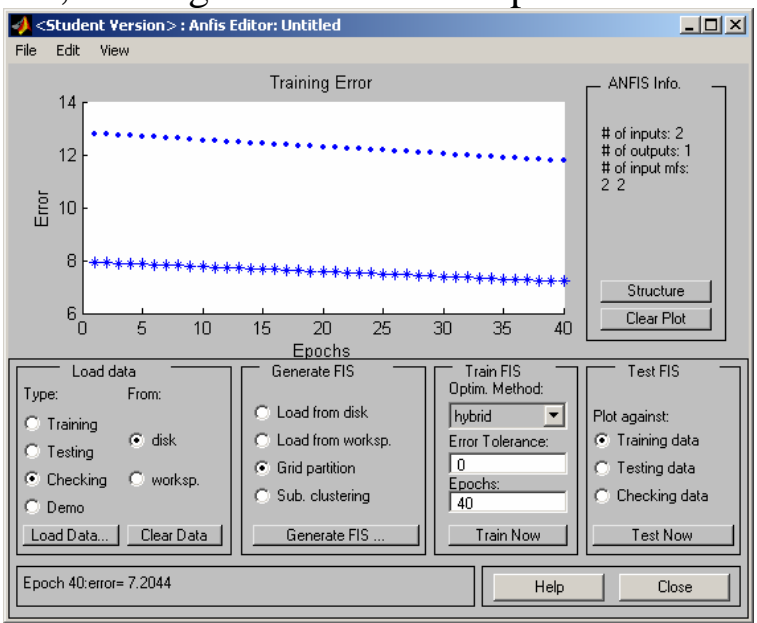

Figure B.35. Type 5 culvert, training on flow rate. Generalized bell membership function gbellmf. 


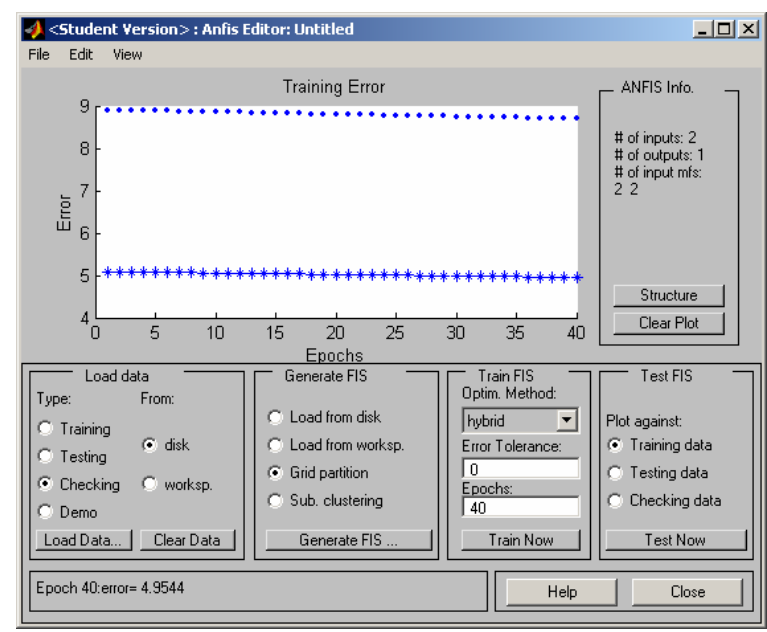

Figure B.36. Type 5 culvert, training on flow rate. Gaussian membership function - gaussmf.

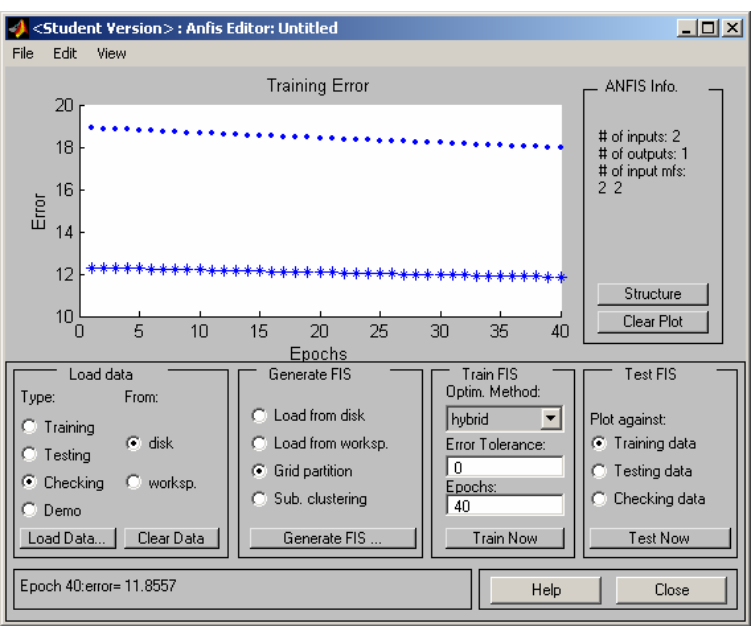

Figure B.37. Type 5 culvert, training on flow rate. Two-sided composite of two different Gaussian curves - gauss2mf.

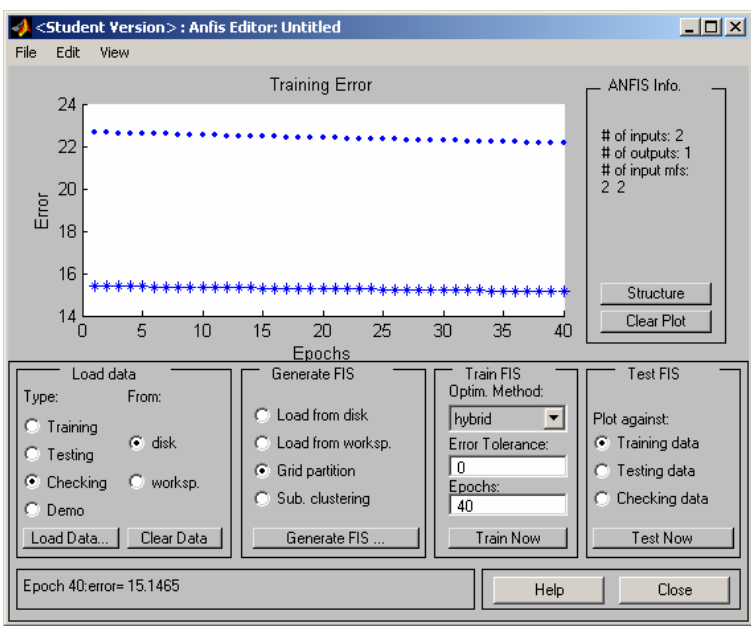

Figure B.38. Type 5 culvert, training on flow rate. Pi membership function - pimf. 


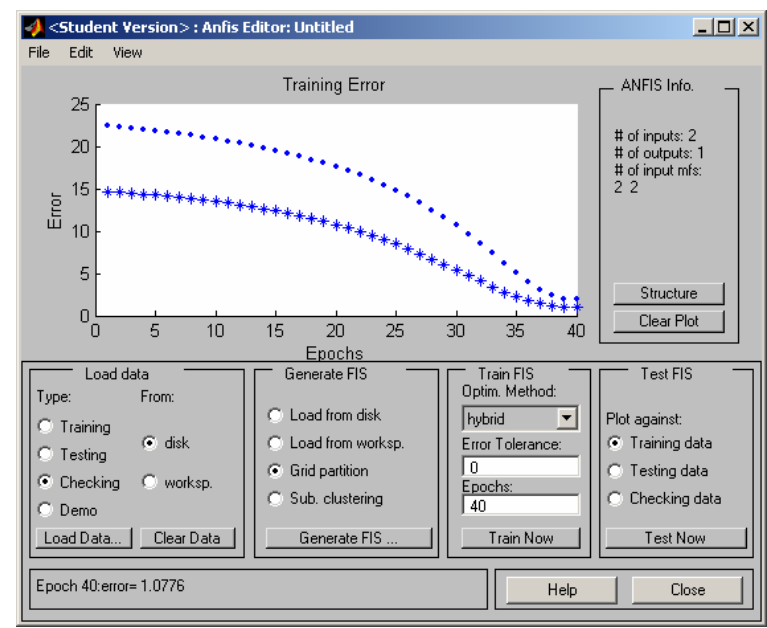

Figure B.39. Type 5 culvert, training on flow rate. Difference between two sigmodial functions - dsigmf.

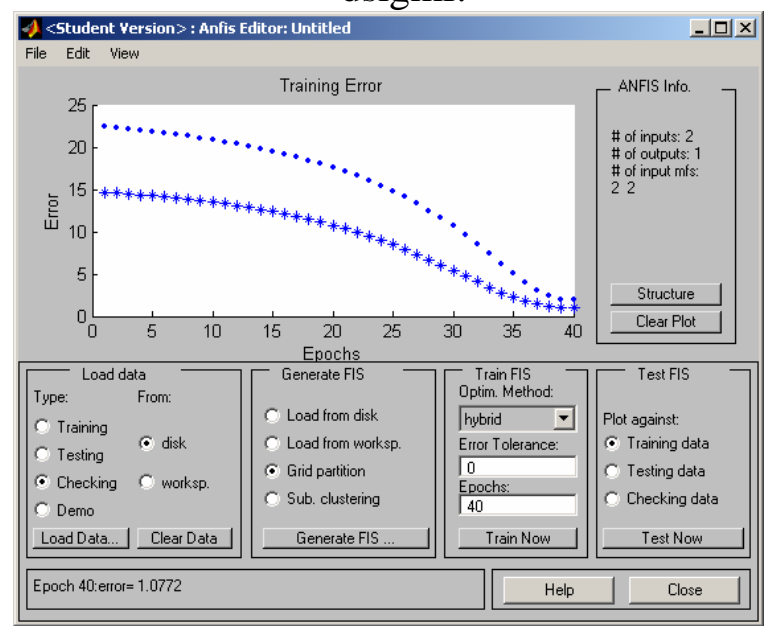

Figure B.40. Type 5 culvert, training on flow rate. Product of two sigmodial functions - psigmf. 


\section{VITAE}

Jonathan Mark Lester was born in Wytheville, Virginia on 8 February 1970. He was raised in nearby Rural Retreat, attended Rural Retreat School and graduated in May of 1988. He then matriculated into the Virginia Military Institute (Lexington, Virginia) on 16 August 1988. In May, 1992 he graduated with a Bachelor of Science Degree in Civil Engineering. After a four year tour of active duty as an Infantry Officer in the United States Marine Corps, he began Graduate School at West Virginia University in Morgantown, West Virginia. He received his Master of Science in Civil Engineering in December, 1997. While finishing his doctoral program, he worked on a part time basis for Parsons Birnckerhoff in Fairmont, WV as an intern Civil Engineer. He accepted a teaching position at Virginia Military Institute and began teaching there in August, 2001. He is a candidate for the degree of Ph.D. 